\title{
WestVirginiaUniversity
}

THE RESEARCH REPOSITORY @ WVU

Graduate Theses, Dissertations, and Problem Reports

2014

\section{Effects of the popcorn flavorings, diacetyl and 2,3-pentanedione, in the airways}

Eric J. Zaccone

Follow this and additional works at: https://researchrepository.wvu.edu/etd

\section{Recommended Citation}

Zaccone, Eric J., "Effects of the popcorn flavorings, diacetyl and 2,3-pentanedione, in the airways" (2014). Graduate Theses, Dissertations, and Problem Reports. 7359.

https://researchrepository.wvu.edu/etd/7359

This Dissertation is protected by copyright and/or related rights. It has been brought to you by the The Research Repository @ WVU with permission from the rights-holder(s). You are free to use this Dissertation in any way that is permitted by the copyright and related rights legislation that applies to your use. For other uses you must obtain permission from the rights-holder(s) directly, unless additional rights are indicated by a Creative Commons license in the record and/ or on the work itself. This Dissertation has been accepted for inclusion in WVU Graduate Theses, Dissertations, and Problem Reports collection by an authorized administrator of The Research Repository @ WVU.

For more information, please contact researchrepository@mail.wvu.edu. 


\title{
Effects of the popcorn flavorings, diacetyl and 2,3-pentanedione, in the airways
}

\author{
Eric J. Zaccone
}

Dissertation submitted to the School of Pharmacy at West Virginia University in partial fulfillment of the requirements for the degree of

Doctor of Philosophy

In

Pharmaceutical and Pharmacological Sciences

\author{
Jeffrey S. Fedan, Ph.D., Chair \\ James M. Antonini, Ph.D. \\ Richard D. Dey, Ph.D. \\ Ann F. Hubbs, Ph.D. \\ S. Jamal Mustafa, Ph.D. \\ Department of Basic Pharmaceutical Sciences \\ Morgantown, West Virginia \\ 2014
}

Key words: Diacetyl; Epithelium; Airway Reactivity; 2,3-Pentanedione; Popcorn Flavorings. 
UMI Number: 3618975

All rights reserved

INFORMATION TO ALL USERS

The quality of this reproduction is dependent upon the quality of the copy submitted.

In the unlikely event that the author did not send a complete manuscript and there are missing pages, these will be noted. Also, if material had to be removed, a note will indicate the deletion.

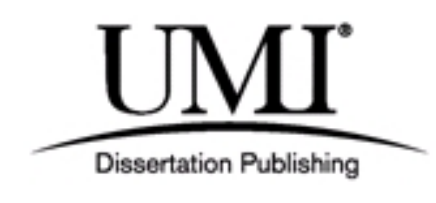

UMI 3618975

Published by ProQuest LLC (2014). Copyright in the Dissertation held by the Author.

Microform Edition () ProQuest LLC.

All rights reserved. This work is protected against unauthorized copying under Title 17, United States Code

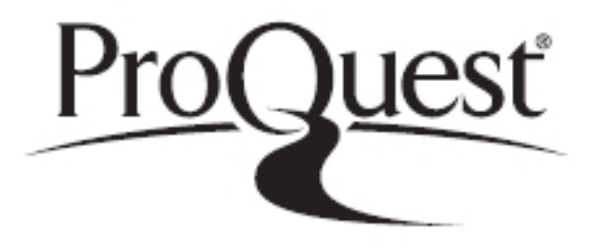

ProQuest LLC.

789 East Eisenhower Parkway

P.O. Box 1346

Ann Arbor, MI 48106 - 1346 


\title{
Abstract \\ Effects of the popcorn flavorings, diacetyl and 2,3- pentanedione, in the airways
}

\author{
Eric J. Zaccone
}

"Popcorn workers' lung" (PWL) is a bronchiolitis obliterans-like obstructive disease caused by inhalation of butter flavoring vapor during the manufacture of microwave popcorn. Lung function tests of employees at several microwave popcorn plants revealed that the severity of abnormal lung function correlated with increasing cumulative exposure to the butter flavorant, diacetyl. Recently, the diacetyl substitute, 2,3-pentanedione, has also been identified as a respiratory hazard. The National Institute for Occupational Safety and Health (NIOSH) demonstrated in rats that inhalation of occupationally-relevant concentrations of diacetyl and 2,3-pentanedione vapor for $6 \mathrm{~h}$ resulted in airway epithelial necrosis and apoptosis in the nasal passages $18 \mathrm{~h}$ after exposure. Anatomical differences in the airways exist between animals and humans, which, in turn, give rise to different sites of lung injury after flavoring exposure. However, a consistent feature from these studies is the demonstration that the airway epithelium is a major target of injury after flavoring exposure.

Our hypothesis was, diacetyl and 2,3-pentanedione damage airway epithelium by altering epithelial ion transport and tight junction integrity, and modifying airway smooth muscle (ASM), contributing to initial pathophysiological events leading to flavoringinduced lung disease. The focus of the first specific aim was to investigate concentrationresponse relationships for flavoring induced toxicity in rats, assessing changes in respiratory mechanics and reactivity to methacholine (MCh). There was negligible change in vivo in basal 
lung resistance $\left(R_{L}\right)$ and basal dynamic compliance $\left(C_{d y n}\right) 18 \mathrm{~h}$ after a $6-\mathrm{h}$ inhalation exposure to diacetyl or 2,3-pentanedione (100 - 360 ppm). Despite evidence of substantial epithelial damage in upper airways of the rat, reactivity to MCh was not increased after flavoring exposure but was slightly decreased. Other flavorings, such as acetic acid and acetoin, are often present in abundant amounts in butter flavoring vapor (Boylstein et al., 2006; van Rooy et al., 2007, 2009). Reactivity to MCh was also slightly decreased in mixed flavoring exposures diacetyl (250 ppm $)+$ acetoin $(150 \mathrm{ppm})+$ acetic acid $(27 \mathrm{ppm})$. In order to evaluate epithelium function and integrity as well as effects on ASM, the rat isolated, perfused trachea preparation (IPT) was employed. Diacetyl exposure caused essentially no effect on reactivity to mucosally-applied MCh $18 \mathrm{~h}$ after $6 \mathrm{~h}$ exposure; in contrast, 2,3-pentanedione (320 and 360 ppm) increased reactivity to MCh. To further investigate the effects of flavoring on ASM, we assessed diacetyl and 2,3-pentanedione ( $\geq 3 \mathrm{mM}$ ) applied to the serosal and mucosal surfaces of intact and denuded tracheas in IPT, which resulted in ASM relaxation independent of the presence of epithelium. The purpose of the second specific aim was to investigate the potential mechanisms of this flavoring-induced relaxation. Using precontracted rat tracheal strips (MCh; $3 \times 10^{-5} \mathrm{M}$ ), we investigated the potential involvement of bitter taste receptors (TAS2Rs) in denatonium (1 $\mathrm{mM}$ ) and flavoring-induced relaxant responses of ASM and bioelectric responses of tracheal epithelial cells. For the first time, it was demonstrated that the TAS2R agonist, denatonium, induces ASM relaxation in rat tracheal strips via an iberiotoxin-dependant pathway. Flavoring-induced relaxation and reduced short-circuit current $\left(I_{\mathrm{sc}}\right)$ were not mediated by TAS2R. The purpose of the third specific aim was to understand better the bioelectric responses caused by diacetyl and 2,3-pentanedione vapor on the airway epithelium and to determine toxic flavoring concentrations. Malfunctions of pulmonary epithelial ion transport processes and, therefore, impairment of the liquid balance in the airways is associated with severe respiratory diseases, such as cystic fibrosis and pulmonary edema. Normal human bronchial/tracheal epithelial cells (NHBEs) were exposed to flavoring vapor using a custom-made apparatus and 
then assessed for changes in ion transport. Concentrations at $60 \mathrm{ppm}$ and above resulted in cell death. Ussing chamber studies indicated that $6 \mathrm{~h}$ of flavoring exposure at $25 \mathrm{ppm}$ significantly reduced amiloride $\left(3.5 \times 10^{-5} \mathrm{M}\right)$-sensitive $\mathrm{Na}^{+}$transport but not NPPB $\left(10^{-4} \mathrm{M}\right)$-sensitive $\mathrm{Cl}^{-}$ transport at a $0 \mathrm{~h}$ post-exposure time point. Thus, our results indicated that flavoring-induced loss of apical $\mathrm{Na}^{+}$conductance. These studies helped to clarify the direct effects of the flavorings on the epithelium as well as potentially identifying their initial pathophysiological effects. In addition, we demonstrated that NHBEs metabolize diacetyl and 2,3-pentanedione vapors during exposure.

This investigation provides critical information regarding the relationship between flavoring vapor concentration and toxicity to airway epithelium. In addition, key new information was obtained regarding the mechanisms of toxicity of a-dicarbonyl flavorings in the lungs.

This dissertation begins with an overall literature review in Chapter 1, with the primary focus on inhalation exposure to diacetyl and 2,3-pentanedione vapor, resulting in PWL. Chapters 2, 3, and 4, focus on each Specific Aim, our results, and the comparison of diacetyl and 2,3-pentanedione as well as possible underlying mechanisms of toxicity. Chapter $\mathbf{5}$ is an extension of Chapter 4 and describes an emerging study of diacetyl and 2,3-pentanedione metabolism by epithelial cells. Finally, the general discussion is found in Chapter 6 . 


\section{Dedication}

I dedicate this dissertation to my family, especially...

to my father, Lou Zaccone, who taught me and exemplified the importance of persistence and

hard work;

to Alexa, for her patience, understanding and full support;

to my mother, Ginny Zaccone, for her encouragement;

to all those who played an important role in motivating

and encouraging me to reach my desired goals. 


\section{Acknowledgments}

My graduate school career here at West Virginia University (WVU) has been a great privilege and positive research experience. Working at $\mathrm{NIOSH}$ has been a very encouraging experience and a positive step in pursuing my career interest in the field of respiratory disease. My advisor, Dr. Jeffrey S. Fedan, is an excellent role model both as a scientist and as a person. Dr. Fedan is admirable in his dedication to research, teaching students, as well as contributing time to charities and organizations outside of work. Dr. Fedan is overall highly involved in student and faculty activities and always made time to assist when needed, putting students before his own personal schedule. The commitment to studying respiratory disease by $\mathrm{Dr}$. Fedan and others at the NIOSH facility has greatly inspired my ambition to advance my career in lung toxicity.

My dissertation committee, Drs. Fedan, Antonini, Dey, Hubbs, and Mustafa has been a crucial source of information and support for me during my time as a graduate student. Thank you for your dedication, suggestions, encouragement and pushing me towards success. The guidance I have received from my committee has influenced my research direction and assisted in my accomplishments.

There are many faculty and staff at WVU and $\mathrm{NIOSH}$ that I am grateful to for their support in my years as a graduate student. Deepest appreciation goes to Janet Thompson and Mike Shimko for all their support, assistance and scientific discussions.

My family, friends and Alexa, if not for you, this dissertation would not be possible. Thank you for all the inspiration.

I would like to acknowledge the support and guidance of the Pharmaceutical and Pharmacological Sciences Program as well as funding from the NIH Cardiovascular and

Pulmonary Disease Training Grant 5T32HL090610-05 and the National Institute for Occupational Safety and Health. 


\section{Table of Contents}

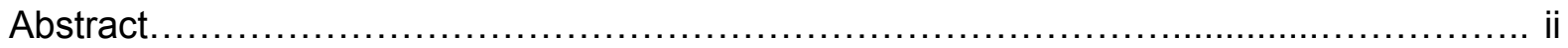

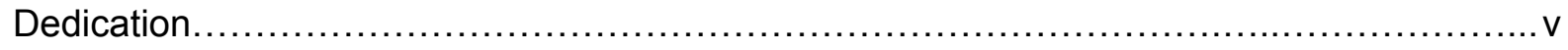

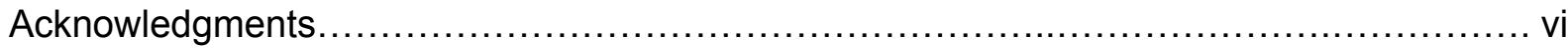

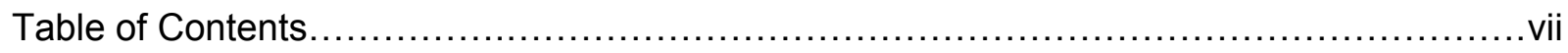

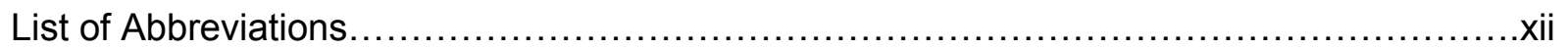

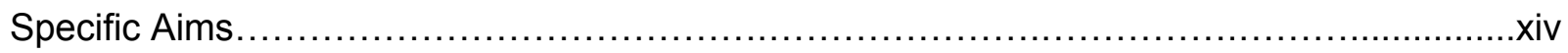

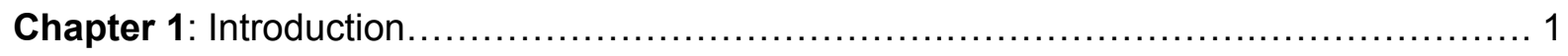

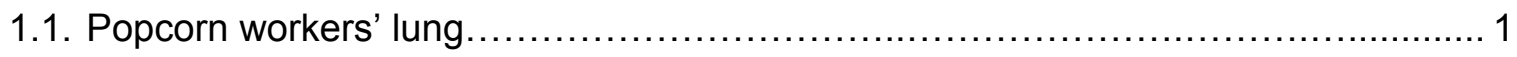

1.1.1. Flavoring-induced toxicity

1.1.2. Pathogenesis and symptoms

1.1.3. Preventative measures for PWL

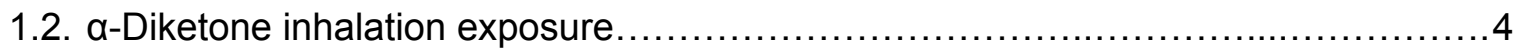

1.2.1. Diacetyl and 2,3-pentanedione

1.2.2. Animal models of flavoring inhalation exposure

1.2.3. Relevance of our investigation

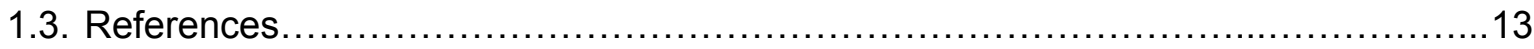

Chapter 2: Popcorn flavoring effects on reactivity of rat airways in vivo and in vitro......... 20 Zaccone, E. J., Thompson, J. A., Ponnoth, D. S., Cumpston, A. M., Goldsmith, W. T., Jackson, M. C., Frazer, D. G., Hubbs, A. F., Shimko, M., and Fedan, J. S. 2013. J. Toxicol. Env. Heal. A, 76: 669-689.

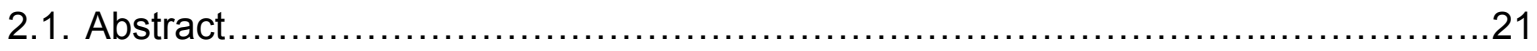

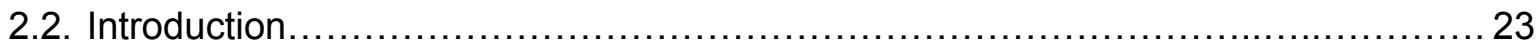

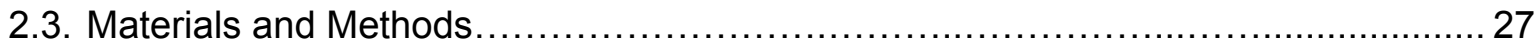




\subsubsection{Animals}

2.3.2. Exposure of rats to diacetyl, 2,3-pentanedione, acetoin and acetic acid vapors

2.3.3. Effects of flavoring exposure on respiratory mechanics and reactivity to MCh in vivo

2.3.4. Effects of diacetyl and 2,3-pentanedione inhalation on reactivity to MCh in the IPT preparations

2.3.5. Reactivity to diacetyl and 2,3-pentanedione in the IPT; influence of the epithelium

2.3.6. Solutions and reagents

2.3.7. Statistical analysis

2.4. Results.

2.4.1. Effect of diacetyl and 2,3-pentanedione inhalation on basal pulmonary function and reactivity to inhaled MCh

2.4.2. Effects of diacetyl and 2,3-pentanedione inhalation on reactivity in vitro of rat trachea to $\mathrm{MCh}$

2.4.3. Effects of diacetyl and 2,3-pentanedione in the IPT

2.4.4. Effects of mixed inhalation exposure to diacetyl, acetic acid and acetoin on reactivity to $\mathrm{MCh}$ in vivo

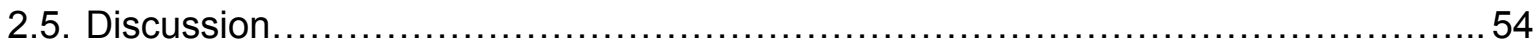

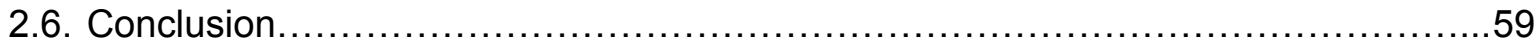

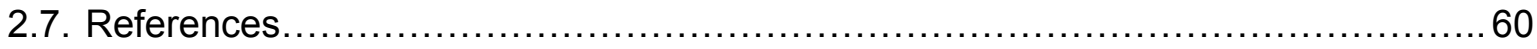


Chapter 3: Butter flavoring-elicited relaxation of airway smooth muscle and bioelectric responses of epithelium in rat airways are independent of TAS2R.

Zaccone, E. J., Shimko, M., Thompson, J. A., and Fedan, J. S. 2014.

Submitted to Eur. J. Pharmacol.

3.1. Abstract. 68

3.2. Introduction. 69

3.3. Materials and methods 71

\subsubsection{Animals}

3.3.2. Preparation of rat tracheal strips for tension studies

3.3.3. Preparation of rat tracheal segments for bioelectric studies

3.3.4. Solutions and reagents

3.3.5. Statistical analysis

3.4. Results

3.4.1. Effects of denatonium and butter flavorings on tracheal strips

3.4.2. Bioelectric effects of denatonium and butter flavorings on airway epithelium

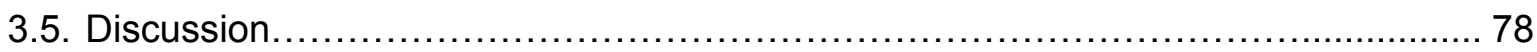

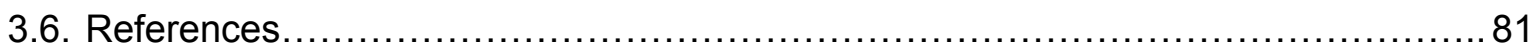

Chapter 4: Effects of butter flavoring vapor exposure on human cultured bronchial/tracheal

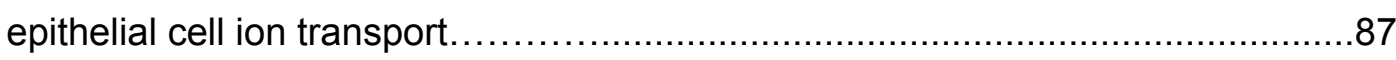

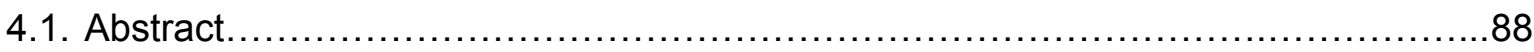

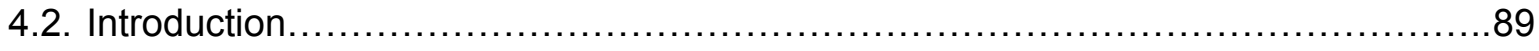

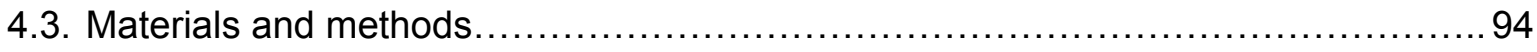

4.3.1. Cell culture

4.3.2. Cell imaging 


\subsubsection{Exposure of NHBEs to flavorings}

4.3.4. Investigation of alterations in NHBE on ion transport after flavoring exposure

\subsubsection{Solutions and reagents}

\subsubsection{Statistical analysis}

4.4. Results

4.5. Discussion

4.6. Conclusion

4.7. References

Chapter 5: Dicarbonyl/L-xylulose reductase (DCXR) metabolizes diacetyl and

5.1. DCXR.

5.2. Role of DCXR in flavoring-induced toxicity.... 122

5.3. Materials and methods

5.4. Results.

5.5. Discussion

5.6. References

Chapter 6: General Discussion.

6.1. Specific Aim 1: Establish the concentration-response relationships for

butter flavor vapor toxicity in vivo and in vitro

6.2. Specific Aim 2: Investigate the possible involvement of the bitter taste receptor, TAS2R, in relaxant responses of ASM and bioelectric responses of tracheal epithelial cells in response to flavoring.

6.3. Specific Aim 3: With the use of human cultured airway epithelial cells, to determine whether flavoring exposure affects ion transport and/or epithelial tight junctions 
6.4.1. Flavoring vapor exposure via IPT

6.4.2. Bioelectric effects of NHBEs exposed to flavoring vapor

6.4.3. Role of DCXR in ion transport

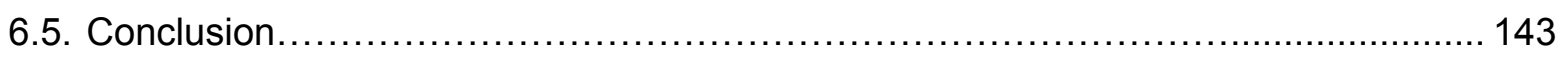

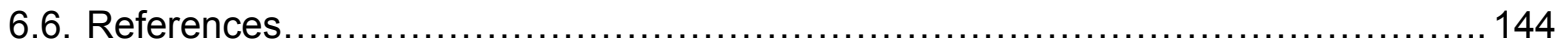




\section{List of Abbreviations}

AGE

ALI

ASL

ASM

BFV

$\mathrm{BK}_{\mathrm{Ca}}$

$\mathrm{C}_{\mathrm{dyn}}$

$\mathrm{C}_{\text {dynmin }}$

CFD-PBPK

$\mathrm{Cl}$

DCXR

$\mathrm{EC}_{50}$

ECC

EL

EpDRF

$\mathrm{FEV}_{1}$

FVC

5-HT

IbTx

IL

IL-6

$\mathrm{IP}_{3}$

IPT

$I_{\mathrm{sc}}$
Advanced glycation end products

Air-liquid interface

Airway surface liquid

Airway smooth muscle

Butter flavoring vapor

Large-conductance $\mathrm{Ca}^{2+}$-activated $\mathrm{K}^{+}$channels

Dynamic compliance

Minimum $\mathrm{C}_{\text {dyn }}$

Computational fluid dynamic-physiologically-based pharmacokinetic

Confidence interval

Dicarbonyl/L-xylulose reductase

Concentration producing $50 \%$ of the maximal effect

Exposure chamber control cells

Extraluminal

Epithelial-derived relaxant factor

Forced expired volume in $1 \mathrm{sec}$

Forced vital capacity

5-hydroxytryptamine (serotonin)

Iberiotoxin

Intraluminal

Interleukin-6

Inositol 1,4,5-triphosphate

Isolated, perfused trachea

Transepithelial short-circuit current 
MCh

MKHS

NHBE

NPPB

$\mathrm{O}_{3}$

$\triangle P$

PID

PLC

9,10-PQ

PWL

$R_{L}$

$\mathrm{R}_{\mathrm{Lmax}}$

ROS

SCC

SE

SEM

TAS2R

TEM

$\mathrm{V}_{\mathrm{t}}$
Methacholine

Modified Krebs-Henseleit solution

Normal human bronchial/tracheal epithelial cell

5-Nitro-2-(3-phenylpropylamino)benzoic acid

Ozone

Inlet minus outlet perfusion pressure difference

Photoionization detector

Phospholipase C

9,10-Phenanthrenequinone

Popcorn workers' lung

Lung resistance

Maximum $\mathrm{R}_{\mathrm{L}}$

Reactive oxygen species

Solitary chemosensory cells

Standard error

Scanning electron microscopy

Bitter taste receptor

Transmission electron microscopy

Transepithelial potential difference 


\section{Specific Aims}

Employees at microwave popcorn factories are at risk of developing an irreversible and potentially deadly lung disease resembling bronchiolitis obliterans, in which the airway epithelium appears to be the initial target of injury (King, 1989; Schachter, 2002). The $\alpha$ diketones, diacetyl and 2,3-pentanedione, are volatile organic compounds in popcorn flavoring mixtures and thought to be the primary contributing factor to PWL (Akpinar-Elci et al., 2004; Boylstein et al., 2006; Day et al., 2011; Fedan et al., 2006; Hubbs et al., 2002; Kreiss et al., 2002; Lockey et al., 2009; Morgan et al., 2008, 2012; Morris, 2009, 2012; Palmer et al., 2011; van Rooy et al., 2007, 2009). Although histological investigation has demonstrated that inhalation exposure to flavorings results in airway epithelial damage in animal models, there are critical gaps in knowledge of the functional consequences and underlying-mechanisms of flavoring-induced epithelial damage. The central hypothesis of the project is: The pathophysiological events leading to PWL results from adverse effects of diacetyl and 2,3pentanedione on airway epithelial ion transport, tight junction integrity, and ASM contractility. To achieve this long-term goal, my project had three specific aims:

Specific Aim 1: To establish the concentration-response relationships for butter flavor vapor toxicity in vivo and in vitro.

Specific Aim 2: To investigate the possible involvement of the bitter taste receptor, TAS2R, in relaxant responses $\mathrm{ASM}$ and bioelectric responses of tracheal epithelial cells in response to flavorings.

Specific Aim 3: With the use of human cultured airway epithelial cells, to determine whether flavoring exposure affects ion transport and/or epithelial tight junctions. 


\section{Chapter 1}

\section{Introduction}

\subsection{Popcorn workers' lung}

\subsubsection{Flavoring-induced toxicity}

Bronchiolitis obliterans is a small airway fibrotic respiratory disease that may develop from inhalation of toxic chemicals, viral infections, or a lung transplant (Palmer et al., 2011; Vilchez et al., 2003). Although understanding this life-threatening lung disease is clinically important, there is still little known regarding the underlying disease mechanisms (Palmer et al., 2011; Vilchez et al., 2003).

Occupational or environmental exposures to irritant gases such as nitrogen oxides, sulfur dioxide, chlorine, and ammonia, are recognized as potential respiratory hazards for developing bronchiolitis obliterans (Akpinar-Elci et al., 2004; King, 1989). As a result of the inhalation of artificial butter flavoring vapor (BFV), employees at popcorn manufacturing factories have developed an irreversible lung disease known as PWL, which resembles bronchiolitis obliterans (Kreiss et al., 2002; Lockey et al., 2009; Schachter, 2002; van Rooy et al., 2009). The hazard of inhaling BFV became public health knowledge due to the presence of PWL in employees of a small microwave popcorn plant in Missouri (Kreiss et al., 2002). Based on lung function tests, it was determined that several workers at this plant developed PWL characterized by fixed airways obstruction (Akpinar-Elci et al., 2004; Kreiss et al., 2002). The airways of these workers contained excess fibrous connective tissue beneath the epithelial layer, constricting the airway lumen in the bronchioles (Akpinar-Elci et al., 2004). Studies at NIOSH revealed an association between exposure to BFV and decreased lung function (Kreiss et al., 2002). PWL is not limited to microwave popcorn factory employees but has also occurred in 
workers at other flavoring manufacturing facilities that involve the use of diacetyl (Cavalcanti Zdo et al., 2012; Day et al. 2011; Harber et al. 2006; Martyny et al. 2008; Lockey et al., 2002).

\subsubsection{Pathogenesis and symptoms}

Initially, flavoring-exposed employees with fibrotic respiratory disease were misdiagnosed with various respiratory diseases such as asthma and chronic bronchitis (OSHA, 2010). Although such diseases may develop due to flavoring exposure, lung biopsies and pulmonary function testing were consistent with bronchiolitis obliterans (Akpinar-Elci and Elci, 2004; Kreiss et al., 2002).

Constrictive bronchiolitis is a fibrotic process that develops externally to the airway lumen. The inflammation and fibrosis eventually causes the small airways (bronchioles) to become narrowed, impeding airflow resulting in lung hyperinflation (Cosio Piqueras and Cosio, 2001; Epler, 2007, 2010; Mauad et al., 2002). Pulmonary function testing, such as spirometry, determines airflow obstruction as measured by a decrease in the forced expired volume in $1 \mathrm{sec}$ $\left(\mathrm{FEV}_{1}\right)$ or the $\mathrm{FEV}_{1} / \mathrm{FVC}$ (forced vital capacity) ratio (Epler, 2010; Estenne and Hertz, 2002; Kanwal et al., 2006; Lockey et al., 2009). Measuring these parameters, workers in microwave popcorn factories were observed to have symptoms consistent with bronchiolitis obliterans, such as significantly decreased $\mathrm{FEV}_{1}$ (Kanwal et al., 2006). Thus, in patients who have developed PWL, spirometry reveals increased airway resistance, contributed by airway wall thickening and dynamic compression of the lungs caused by air-trapping (Kanwal et al., 2006; Lockey et al., 2009).

In addition to being a physical protective barrier, the airway epithelium can modulate airway smooth muscle function and airway reactivity through the release of inflammatory and excitatory/inhibitory mediators (Fedan et al., 2000; Hay et al., 1986; Raeburn et al., 1986; Spina, 1998). Many studies have demonstrated increased responsiveness of ASM in vitro to contractile 
agonists such as acetylcholine, MCh and 5-hydroxytryptamine (5-HT), following removal of the epithelium (Aarrhus et al., 1984; Spina, 1998). Therefore, there is an expected increase in reactivity to contractile agonists in vivo and in vitro following damage to or removal of the epithelium, especially after contractile agonists are applied to the mucosal surface. Therefore, inhaled toxicants known to damage epithelium induce airway hyperresponsiveness, posing a risk to normal pulmonary function and an even greater risk to employees with pre-existing conditions such as asthma (Roux et al., 2002). BFV exposure may even result in asthma symptoms and diagnosis (Kanwal et al. 2006; Sahakian et al., 2008; van Rooy et al., 2009). An employee in a microwave popcorn factory was initially diagnosed with reactive airways disease with a positive methacholine challenge test (Zlotolow et al., 2007). Years later, this same employee was diagnosed with bronchiolitis obliterans with no response to a bronchodilator. Another employee exposed to BFV had a positive methacholine test and her condition eventually deteriorated to bronchiolitis obliterans (Zlotolow et al., 2007). Therefore, inhalation of butter flavoring chemicals may result in asthma diagnosis and exacerbated asthma symptoms in popcorn factory workers (Sahakian et al., 2008).

\subsubsection{Preventative measures for PWL}

Once the occupational hazard of inhaling flavoring vapor was identified, $\mathrm{NIOSH}$ used a hierarchy of controls as a means of determining how to prevent the inhalation exposure, such engineering control efforts, or removal of the exposed workers from the workplace (OSHA, 2007).

Typically, factory workers who were exposed to BFV do not experience a relief of symptoms upon leaving the workplace (Kreiss et al., 2002). Most clinical cases have demonstrated little response to medical treatment. Antifibrotic agents may be a successful 
treatment in the future (Epler, 2007). Overall, the most successful option for those with severe PWL may be a lung transplant (Epler, 2007).

In rare cases, flavoring inhalation may pose a respiratory risk to consumers. Consumer practices such as cooling the popcorn bag could potentially eliminate the risk of severe lung disease (Egilman and Schilling, 2011).

\section{2. $\alpha$-Diketone inhalation exposure}

\subsubsection{Diacetyl and 2,3-pentanedione}

This section will introduce the properties and production of flavoring compounds selected for our study, as well as similar compounds used in industry. Butter flavoring usually contains many chemicals composed of various natural and artificial substances (Kreiss et al., 2002; Martyny et al., 2008). There are over 1,300 flavoring ingredients considered by the flavorings industry as potential inhalation hazards due to their volatility and irritant properties (i.e., $\alpha, \beta$-unsaturated aldehydes and ketones, aliphatic aldehydes, and aliphatic carboxylic acids) that may result in lung injury (Hallagan and Hall, 2009). The ketones found in butter flavoring may include acetoin, acetoin dimers, and 2-nonanones. Organic acids that may potentially be found in butter flavoring vapor include acetic and butyric acid. These compounds can potentially contribute to the epithelial damage associated with flavoring-induced toxicity (Boylstein et al., 2006; Hubbs et al., 2002; Kullman et al., 2005; Morris and Hubbs, 2009).

$\mathrm{NIOSH}$ studies in which rats were exposed by inhalation to BFV for $6 \mathrm{~h}$ revealed vaporconcentration-dependent damage to the epithelium (Hubbs et al., 2002). The a-diketone butter flavoring, diacetyl, is the predominant volatile organic compound in popcorn flavoring mixtures and is the primary contributing factor to PWL (Akpinar-Elci et al., 2004; Boylstein et al., 2006; Hubbs et al., 2002; Kreiss et al., 2002; Lockey et al., 2009; Mathews et al., 2010; van Rooy et al., 2007). Produced both naturally and artificially, this low molecular weight a-diketone can be easily vaporized and inhaled upon heating (Harber et al., 2006; Hubbs et al., 2008; Martyny et 
al., 2008). The decline in pulmonary function of workers correlated with increasing cumulative diacetyl exposure (Lockey et al., 2009). Because of the hazard of inhaling diacetyl, some manufacturers have substituted for diacetyl other $\alpha$-diketones that are likely to pose a similar risk (Egilman et al., 2011). The a-diketone, 2,3-pentanedione, is one such substitute currently being used in the flavoring industry (Day et al., 2011; Hubbs et al., 2012; Morgan et al., 2012). As with diacetyl, 2,3-pentanedione targets the epithelium of the upper airways resulting in ulceration, inflammation and necrosis (Day et al., 2011; Hubbs et al., 2012; Morgan et al., 2012).

To understand the potential hazards of inhaling diacetyl and 2,3-pentanedione, it is important to understand the properties of these compounds and potential causes of their underlying harmful effects. Diacetyl and 2,3-pentanedione are compounds that consist of two carbon groups double bonded to oxygen as seen in Figure 1.<smiles>CCC(=O)C(C)=O</smiles>

2,3-Pentanedione

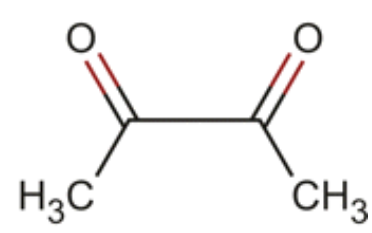

2,3-Butanedione

FIGURE 1. Structurally related a-diketones, 2,3pentanedione (acetyl propionyl; $\mathrm{C}_{5} \mathrm{H}_{8} \mathrm{O}_{2}$ ) and diacetyl (2,3butanedione; $\mathrm{C}_{4} \mathrm{H}_{6} \mathrm{O}_{2}$ ). (Image used with permission from Morgan et al., 2012).

These vicinal diketones are highly reactive due to the electron sharing between the adjacent carbonyl groups and can react at the site of contact (Morgan et al., 2012; Wondrak et al., 2002). Necrosis and apoptosis of bronchial epithelium and disruption of the underlying basement membrane may occur upon direct contact with these $\alpha$-diketone flavorings. This in turn, exposes the connective tissue of the lamina propria and eventually results in a fibroblastic response (Morgan et al., 2012). Diacetyl is also known to cause DNA damage, binding 
covalently to guanyl nucleotides, resulting in plasmid DNA unwinding and cellular apoptosis (More et al., 2012). Diacetyl and similar a-diketones are known to selectively bind with the guanidine function of the side chain of arginine containing proteins and enzymes (Borders and Riordan, 1975; Epperly and Dekker, 1989; Mueller et al., 1995). Therefore, a-diketones can alter protein structure and function (Mathews et al., 2010; More et al., 2012) as well as disrupt normal electron transfer processes, generating reactive oxygen species (Kovacic and Cooksy, 2010). Recently, it was demonstrated that inhaling 2,3-pentanedione (270 ppm) for roughly $6 \mathrm{~h}$ resulted in increased expression of interleukin-6 (IL-6) and nitric oxide synthase-2 and decreased expression of vascular endothelial growth factor A in the olfactory bulb, striatum, hippocampus, and cerebellum (Hubbs et al., 2012). Diacetyl and 2,3-pentanedione exposure also results in neuroinflammation and ubiquitination of proteins (Hubbs et al., 2012, 2013).

High risk environments within a popcorn factory can increase chances of hazardous exposure levels to these a-diketones. Risks of high exposures to diacetyl or 2,3-pentanedione may occur during typical work activities including mixing, weighing, pouring, transferring, and other handlings of butter flavorings (Martyny et al., 2008; Morgan et al., 2008). Upon opening butter flavoring mixing tanks to manually add flavoring to heated oil, workers may be exposed to peak exposures of diacetyl as high as 1232 ppm (Kreiss et al., 2002). Diacetyl substitutes may also readily enter the vapor phase upon heating. 2,3-Pentanedione vapor pressure $(21.4 \mathrm{~mm}$ $\mathrm{Hg}$ at $\left.20^{\circ} \mathrm{C}\right)$ is lower compared to diacetyl $\left(52.2 \mathrm{~mm} \mathrm{Hg}\right.$ at $\left.20^{\circ} \mathrm{C}\right)$, but 2,3-pentanedione is still considered a volatile organic compound based on its $108^{\circ} \mathrm{C}$ boiling point (EPA, 2013). The form flavorings may come in, such as powder vs. liquid, can also influence exposure level (Martyny et al., 2008). Overall, the greatest risk to employees comes from those who experience long exposure durations near production areas.

\subsubsection{Animal models of flavoring inhalation exposure}


Mimicking occupationally-relevant exposures, rats exposed to diacetyl (294.6 ppm) for 6 h developed concentration-dependent damage to airway epithelial cells, including changes in the surface morphology of the trachea as demonstrated by Figure 2 (Hubbs et al., 2008).
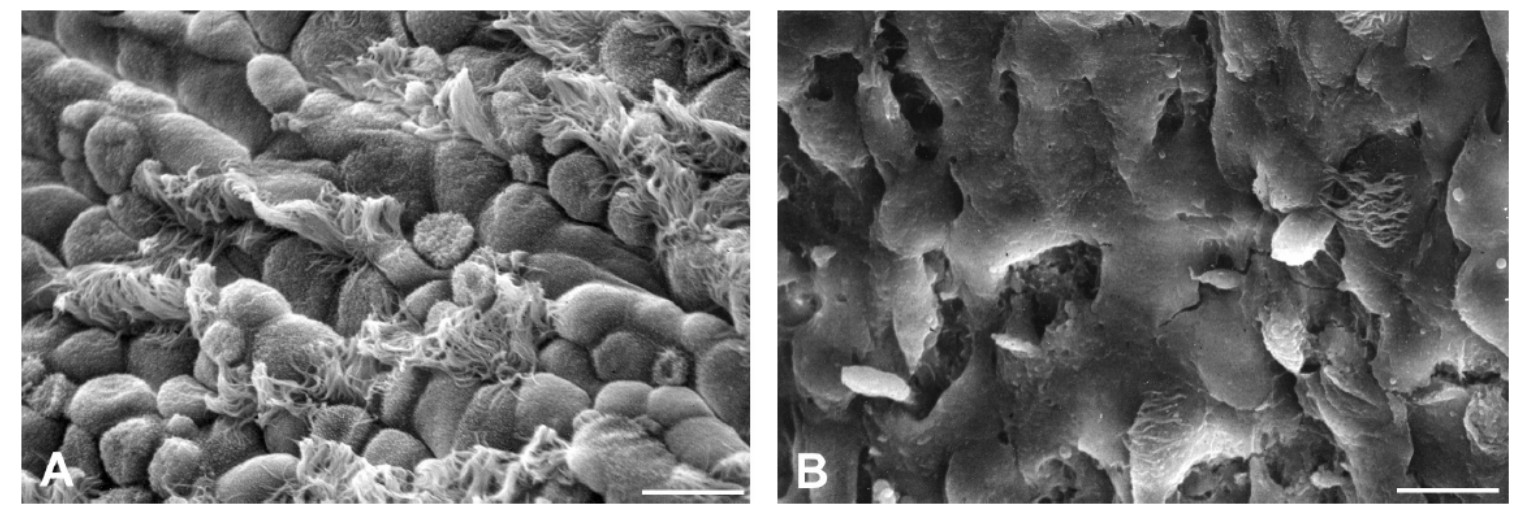

FIGURE 2. Scanning electron microscopy image of the surface morphology of the tracheal bifurcation of rats exposed for $6 \mathrm{~h}$ to (A) air (control) or (B) diacetyl (294.6 ppm). The diacetyl-exposed epithelium demonstrates fissure formation, loss of microvilli and cilia, and flattening of the epithelial cells. Bar $=10 \mu \mathrm{m}$. (Image used with permission from Hubbs et al., 2008).

Acute exposures of diacetyl or 2,3-pentanedione in rats resulted in necrotizing rhinitis, tracheitis, and bronchitis in rats (Hubbs et al., 2012). Mice exposed to high exposures of diacetyl (1200 ppm) for $15 \mathrm{~min}$, twice a d, for 2 weeks developed peribronchiolar lymphocytic inflammation and damage to airway epithelium (Morgan et al., 2008). Subchronic exposures of $25 \mathrm{ppm}$ for up to 12 weeks caused nasal cavity inflammation and necrotizing rhinitis in mice (Morgan et al., 2008). Cellular regeneration will likely occur to resolve the regions of injury in cases of mild epithelial damage without injury to the basement membrane and severe inflammation (Morgan et al., 2012). However, in repeated or high exposures to diacetyl or 2,3pentanedione, epithelial regeneration may not occur, resulting in squamous epithelial cells less susceptible to injury. These a-diketones may eventually disrupt the underlying basement 
membrane, which in turn is thought to activate myofibroblasts to repair epithelial injury. This results in the development of bronchial fibrosis (Siddiqui et al., 1996; Morgan et al., 2012). In animal models most fibrotic lesions tend to occur in the larger airways. However, fibrotic lesions have been observed in the preterminal bronchioles, as demonstrated after 2,3-pentanedione (200 ppm) exposure (Morgan et al., 2012; Figure 3). Although alveoli are relatively spared, inhalation studies of diacetyl and 2,3-pentanedione indicate that the entire respiratory system is a target organ (Hubbs et al. 2008, 2012; Morgan et al., 2008, 2012).

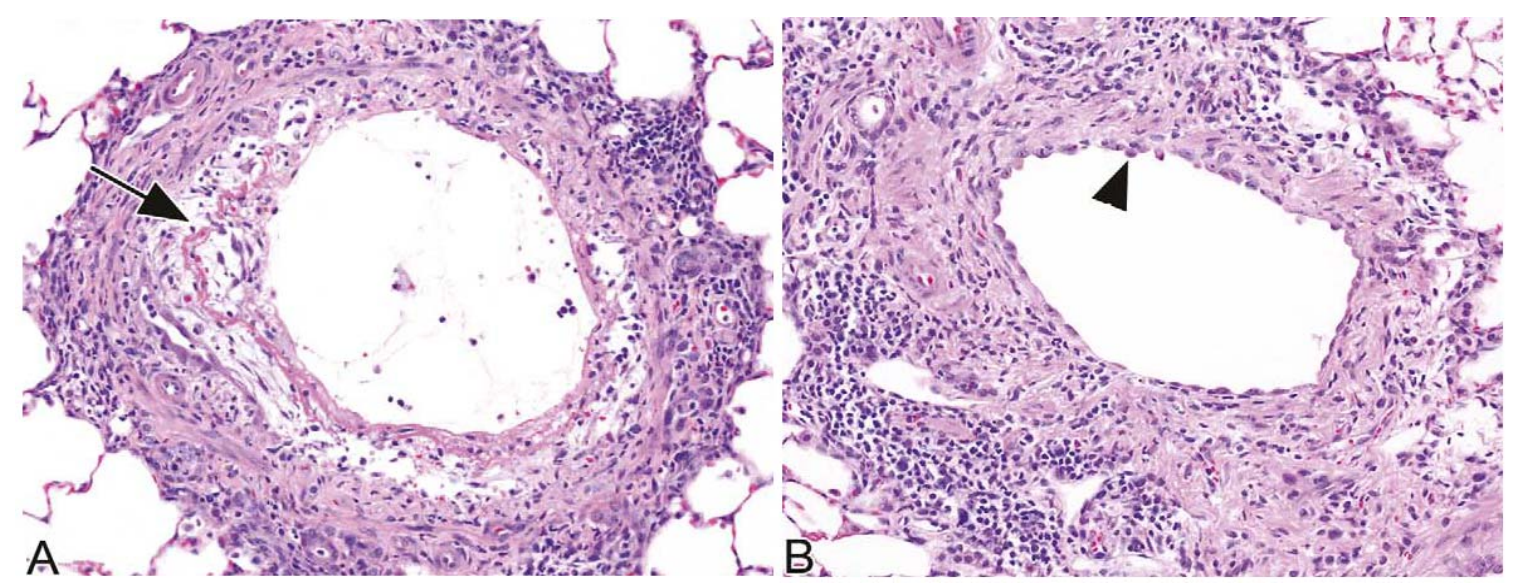

FIGURE 3. Bronchiolar fibrosis in rat airways exposed to 2,3-pentanedione (200 ppm). (A) Complete erosion of the mucosal epithelium, with a thin layer of fibrin deposition located on the eroded surface (arrow). The lamina propria and the adventitia exhibit a mature fibrocollagenous appearance. Bronchiole luminal diameter $=240 \mu \mathrm{m}(\mathrm{H} \& \mathrm{E}$, original objective magnification $=10 x)$. (B) Mucosal epithelium was eroded and replaced by regenerating epithelial cells (arrowhead). Apparent fibrosis of all layers of the airway and replacement of the smooth muscle layer occurs in some regions. Bronchiole luminal diameter $=180 \mu \mathrm{m}(\mathrm{H} \& \mathrm{E}$, original objective magnification $=10 \mathrm{x}) .($ Image used with permission from Morgan et al., 2012). 
There is tremendous variation in the concentration and duration of inhalation exposure between job categories in the flavoring industry (Martyny et al., 2008; Morgan et al., 2008), increasing the difficulties of studying occupationally-relevant toxic concentrations of diacetyl and 2,3-pentanedione. Chronic exposures and delayed-onset of symptoms in factory workers also enhance the difficulties of developing flavoring-exposed animal models. Earlier exposure studies conducted at $\mathrm{NIOSH}$ demonstrated in rats that exposure to workplace concentrations of diacetyl vapor (203 to $371 \mathrm{ppm}$ ) for $6 \mathrm{~h}$ resulted in airway epithelial necrosis in the nasal passages $18 \mathrm{~h}$ after exposure (Hubbs et al., 2002). To further investigate delayed toxicity, rats inhaled 2,3-pentanedione (318 ppm) for $6 \mathrm{~h}$ and were sacrificed 0 to 2, 12 to 14 , or 18 to $20 \mathrm{~h}$ after exposure (Hubbs et al., 2012). Respiratory epithelial injury in the nasal cavity involved both apoptosis and necrosis $14 \mathrm{~h}$ after exposure. Apoptosis was significantly greater at $18 \mathrm{~h}$, as opposed to immediately after exposure (Hubbs et al., 2012). This $6 \mathrm{~h}$ exposure and $18 \mathrm{~h}$ delay in toxicity has been crucial in developing our assessment between exposure and pulmonary function endpoints (Specific Aim 1), as well as bioelectric effects on cultured epithelial cells (Specific Aim 3).

Exposure studies and diacetyl instillation in rats revealed symptoms of PWL similar to those observed in exposed humans (Palmer et al., 2011). However, it is important to note that anatomical differences in lungs between animals and humans give rise to different sites of injury in the airways after flavoring inhalation exposure. Epithelial damage caused by physiologicallyrelevant concentrations of diacetyl and 2,3-pentanedione in animal models tends to be localized to the nasal cavity, trachea and larger bronchioles as opposed to the deep lung of exposed workers (Hubbs et al., 2006, 2008; Morgan et al., 2008, 2012; Morris and Hubbs, 2009). Investigation of the inhalation dosimetry of diacetyl with use of a computational fluid dynamicphysiologically-based pharmacokinetic (PBPK) models described differences between rat and human with regard to the site of $\alpha$-diketone absorption in the respiratory tract (Morris and Hubbs, 
2009; Gloede et al., 2011; Morris, 2012). The dosimetry study provided an explanation for the observation that diacetyl caused predominantly upper airway damage in rodents, while in workers the flavorings predominantly affected the deep lung (Morris and Hubbs, 2009; Gloede et al., 2011; Morris, 2012; Hubbs et al., 2012). Because the employee's jobs in the popcorn factory may consist of light exercise and mouth breathing, the diacetyl tissue concentration in the bronchioles is estimated to be 40 -fold greater than the concentration in the bronchioles of a nose-breathing rat in an inhalation chamber (Gloede et al., 2011). The trachea in the rat has dimensions similar to the diameter of the $5^{\text {th }}$ generation human intrapulmonary airway (Yeh et al., 1976, 1979). Therefore, upper airway injury in flavoring exposed rats might be predictive of intrapulmonary injury in humans (Morris and Hubbs, 2009).

Dicarbonyl/L-xylulose reductase $(\mathrm{DCXR})$ is the enzyme that metabolizes diacetyl into the less reactive $\alpha$-hydroxyketone, acetoin (Carbone et al., 2005; Gloede et al., 2011; Hubbs et al., 2013). Due to efficient uptake and DCXR metabolism of $\alpha$-diketones such as diacetyl and 2,3pentanedione in the nasal passages, limited amounts of flavoring penetrate to the bronchioles of the rat airway, resulting in less severe injury to the epithelium in the lungs compared to humans (Gloede et al., 2011; Morris and Hubbs, 2009). These inhalation dosimetric differences may explain any human vs. rat differences in diacetyl-induced airway injury (Gloede et al., 2011). In addition, we questioned whether the metabolite, acetoin, had an additive effect on epithelial injury, which we investigated in Chapters 2 and 5.

The initial presentation of asthma in some exposed workers is consistent with in vitro studies conducted by Fedan et al. (2006), who demonstrated that exposure to diacetyl in the guinea-pig isolated trachea resulted in increased reactivity to mucosally-applied MCh (Fedan et al., 2006; Zlotolow et al., 2007). With knowledge that airway epithelium is severely damaged in rats following flavoring exposure and that several patients were initially diagnosed with reactive airways disease, we derived our investigation to assess changes in pulmonary function in rats after diacetyl and 2,3-pentanedione inhalation in vivo. 


\subsubsection{Relevance of our investigation}

Little is known of the pulmonary functional consequences of diacetyl or 2,3pentanedione inhalation, or of the pharmacological effects of the two flavorings in the airways. Recently, it was found that diacetyl exposure increases sensory innervation and substance P production in injured regions of tracheal epithelium, which may in turn affect airway responsiveness (Goravanahally et al., 2013). Therefore, functional information is critical to our understanding of the pulmonary toxicities of these flavorings.

In our studies, we have devoted substantial effort to defining the concentration-response relationships for vapor-induced damage to the epithelium and to understand better acute flavoring-induced toxicity in the airway epithelium and smooth muscle. Another major purpose of the study was to compare and contrast the effects of diacetyl and 2,3-pentanedione in the lung in terms of altered respiratory mechanics [airway resistance $\left(R_{L}\right)$ and compliance $\left(C_{d y n}\right)$ ] and reactivity to MCh (Zaccone et al., 2013). This overall project has provided information that can support low exposure limits to protect workers from harmful flavoring exposures, as well as provide information about mechanisms of lung toxicity of flavorings. This project addressed important data gaps that need to be clarified in order to prevent and understand flavorings' toxic effects in the airway and on the airway epithelium.

As discussed in Chapter 2 and Chapter 3, we investigated whether alterations in respiratory mechanics $\left(R_{L}\right.$ and $\left.C_{d y n}\right)$, as well as reactivity to inhaled $M C h$, occurred in rats following diacetyl or 2,3-pentanedione inhalation. In addition to negligible change in basal $R_{L}$

and $\mathrm{C}_{\mathrm{dyn}}$, flavoring exposure resulted in a slight decrease in reactivity to $\mathrm{MCh}$ in vivo. With the use of IPT preparations, and tracheal strips, we have demonstrated that butter flavorings have a direct effect on the ASM, eliciting relaxation. It is unknown whether the epithelial-independent relaxation reflects a non-specific toxic action or a specific pharmacological effect. We 
hypothesized that the G-protein-coupled receptors, TAS2R may mediate ASM relaxation and thus, flavoring-induced inhalation toxicity, as discussed in Chapter 3.

In Chapter 4, by exposing NHBEs to diacetyl or 2,3-pentanedione vapors, we demonstrated altered epithelial ion transport, at concentrations much lower than those required to induce epithelial damage in rats following inhalation. In exposing NHBEs to both diacetyl and 2,3-pentanedione, it was discovered that these cell cultures were capable of metabolizing the flavoring vapors and that this may be involved in toxicity, as discussed in Chapter $\mathbf{5}$. The final chapter, Chapter 6, is a general discussion section which includes future experiments involving the establishment of concentration-response relationships of flavoring-induced toxicity and identifying the pathophysiologic basis for PWL. 


\subsection{References}

Akpinar-Elci, M., Travis, W. D., Lynch, D. A., and Kreiss, K. 2004. Bronchiolitis obliterans syndrome in popcorn production plant workers. Eur. Respir. J. 24: 298-302.

Borders, C. L., Jr., and Riordan, J. F. 1975. An essential arginyl residue at the nucleotide binding site of creatine kinase. Biochemistry 14: 4699-4704.

Boylstein, R., Piacitelli, C., Grote, A., Kanwal, R., Kullman, G., and Kreiss, K. 2006. Diacetyl emissions and airborne dust from butter flavorings used in microwave popcorn production. J. Occup. Environ. Hyg. 3: 530-535.

Carbone, V., Ishikura, S., Hara, A., and El-Kabbani, O. 2005. Structure-based discovery of human L-xylulose reductase inhibitors from database screening and molecular docking. Bioorg. Med. Chem. 13: 301-312.

Cavalcanti Zdo, R., Albuquerque Filho, A. P., Pereira, C. A., and Coletta, E. N. 2012. Bronchiolitis associated with exposure to artificial butter flavoring in workers at a cookie factory in Brazil. J. Bras. Pneumol. 38: 395-399.

Cosio Piqueras, M. G., and Cosio, M. G. 2001. Disease of the airways in chronic obstructive pulmonary disease. Eur. Respir. J. Supplement 34: 41s-49s.

Day, G., LeBouf, R., Grote, A., Pendergrass, S., Cummings, K., Kreiss, K., and Kullman, G. 2011. Identification and measurement of diacetyl substitutes in dry bakery mix production. J. Occup. Environ. Hyg. 8: 93-103.

Egilman, D. S., Schilling, J. H., and Menendez, L. 2011. A proposal for a safe exposure level for diacetyl. Int. J. Occup. Med. Environ. Health 17: 122-134.

EPA (Environmental Protection Agency) 2013. Volatile organic compounds: technical review. [http://www.epa.gov/iaq/voc2.html]. Date accessed: December 2013.

Epler, G. R. 2007. Constrictive bronchiolitis obliterans: the fibrotic airway disorder. Expert Rev. Respir. Med. 1: 139-147. 
Epler, G. R. 2010. Diagnosis and treatment of constrictive bronchiolitis. F1000 Med. Rep. 2.

Epperly, B. R., and Dekker, E. E. 1989. Inactivation of Escherichia coli L-threonine dehydrogenase by 2,3-butanedione. Evidence for a catalytically essential arginine residue. J. Biol. Chem. 264: 18296-18301.

Estenne, M., and Hertz, M. I. 2002. Bronchiolitis obliterans after human lung transplantation. Am. J. Respir. Crit. Care Med. 166: 440-444.

Fedan, J. S., Millecchia, L. L., Johnston, R. A., Rengasamy, A., Hubbs, A., Dey, R. D., Yuan, L. X., Watson, D., Goldsmith, W. T., Reynolds, J. S., Orsini, L., Dortch-Carnes, J., Cutler, D., and Frazer, D. G. 2000. Effect of ozone treatment on airway reactivity and epithelium-derived relaxing factor in guinea pigs. J. Pharmacol. Exp. Ther. 293: 724-734

Fedan, J. S., Dowdy, J. A., Fedan, K. B., and Hubbs, A. F. 2006. Popcorn worker's lung: in vitro exposure to diacetyl, an ingredient in microwave popcorn butter flavoring, increases reactivity to methacholine. Toxicol. Appl. Pharm. 215: 17-22.

Glaab, T., Taube, C., Braun, A., and Mitzner, W. 2007. Invasive and noninvasive methods for studying pulmonary function in mice. Respir. Res. 8: 63.

Gloede, E., Cichocki, J. A., Baldino, J. B., and Morris, J. B. 2011. A validated hybrid computational fluid dynamics-physiologically based pharmacokinetic model for respiratory tract vapor absorption in the human and rat and its application to inhalation dosimetry of diacetyl. Toxicol. Sci. 123: 231-246.

Goravanahally, M. P., Hubbs, A. F., Fedan, J. S., Kashon, M. L., Battelli, L. A., Mercer, R. R., Goldsmith, W. T., Jackson, M. C., Cumpston, A., Frazer, D. G., and Dey, R. D. 2013. Diacetyl increases sensory innervation and substance $\mathrm{P}$ production in rat trachea. Toxicol. Pathol. Epub ahead of print.

Hallagan, J. B., and Hall, R. L. 2009. Under the conditions of intended use - New developments in the FEMA GRAS program and the safety assessment of flavor ingredients. Food and 
chemical toxicology: an international journal published for the Brit. Industr. Biol. Res. Assoc. 47: 267-278.

Harber, P., Saechao, K., and Boomus, C. 2006. Diacetyl-induced lung disease. Toxicol. Rev. 25: $261-272$.

Hay, D. W., Farmer, S. G., Raeburn, D., Robinson, V. A., Fleming, W. W., and Fedan, J. S. 1986. Airway epithelium modulates the reactivity of guinea-pig respiratory smooth muscle. Eur. J. Pharmacol. 129: 11-18.

Hubbs, A. F., Battelli, L. A., Goldsmith, W. T., Porter, D. W., Frazer, D., Friend, S., SchweglerBerry, D., Mercer, R. R., Reynolds, J. S., Grote, A., Castranova, V., Kullman, G., Fedan, J. S., Dowdy, J., and Jones, W. G. 2002. Necrosis of nasal and airway epithelium in rats inhaling vapors of artificial butter flavoring. Toxicol. Appl. Pharmacol. 185: 128-135.

Hubbs, A. F., Goldsmith, W. T., Kashon, M. L., Frazer, D., Mercer, R. R., Battelli, L. A., Kullman, G. J., Schwegler-Berry, D., Friend, S., and Castranova, V. 2008. Respiratory toxicologic pathology of inhaled diacetyl in Sprague-Dawley rats. Toxicol. Pathol. 36: 330-344.

Hubbs, A. F., Cumpston, A. M., Goldsmith, W. T., Battelli, L. A., Kashon, M. L., Jackson, M. C., Frazer, D. G., Fedan, J. S., Goravanahally, M. P., Castranova, V., Kreiss, K., Willard, P. A., Friend, S., Schwegler-Berry, D., Fluharty, K. L., and Sriram, K. 2012. Respiratory and olfactory cytotoxicity of inhaled 2,3-pentanedione in Sprague-Dawley rats. Am. J. Pathol. 181: 829-844.

Hubbs, A. F., Fluharty, K. L., Goravanahally, M. P., Edwards, R. J., Kashon, M. L., Sargent, L., Mercer, R. R., Jackson, M. C., Cumpston, A. M., Goldsmith, W. T., Fedan, J. S., Dey, R. D., Battelli, L. A., Munro, T., Moyers, W. B., Willard, P. A., McKinstry, K., Friend, S., and Sriram, K. 2013. Diacetyl-induced respiratory and olfactory toxicity in mice: influence of ubiquitination, gender, and dicarbonyl/L-xylulose reductase gene knockout. Toxicologist 132: 50. 
Kanwal, R., Kullman, G., Piacitelli, C., Boylstein, R., Sahakian, N., Martin, S., Fedan, K., and Kreiss, K. 2006. Evaluation of flavorings-related lung disease risk at six microwave popcorn plants. J. Occup. Environ. Med. 48: 149-157.

King, T. E., Jr. 1989. Bronchiolitis obliterans. Lung 167: 69-93.

Kovacic, P., and Cooksy, A. L. 2010. Electron transfer as a potential cause of diacetyl toxicity in popcorn lung disease. Rev. Environ. Contam. Toxicol. 204: 133-148.

Kreiss, K., Gomaa, A., Kullman, G., Fedan, K., Simoes, E. J., and Enright, P. L. 2002. Clinical bronchiolitis obliterans in workers at a microwave-popcorn plant. N. Engl. J. Med. 347: 330-338.

Kullman, G., Boylstein, R., Jones, W., Piacitelli, C., Pendergrass, S., and Kreiss, K. 2005. Characterization of respiratory exposures at a microwave popcorn plant with cases of bronchiolitis obliterans. J. Occup. Environ. Hyg. 2: 169-178.

Lockey, J. E., Hilbert, T. J., Levin, L. P., Ryan, P. H., White, K. L., Borton, E. K., Rice, C. H., McKay, R. T., and LeMasters, G. K. 2009. Airway obstruction related to diacetyl exposure at microwave popcorn production facilities. Eur. Respir. J. 34: 63-71.

Martyny, J. W., Van Dyke, M. V., Arbuckle, S., Towle, M., and Rose, C. S. 2008. Diacetyl exposures in the flavor manufacturing industry. J. Occup. Environ. Hyg. 5: 679-688.

Mathews, J. M., Watson, S. L., Snyder, R. W., Burgess, J. P., and Morgan, D. L. 2010. Reaction of the butter flavorant diacetyl (2,3-butanedione) with $\mathrm{N}$ - $\alpha$-acetylarginine: a model for epitope formation with pulmonary proteins in the etiology of obliterative bronchiolitis. $J$. Agric. Food Chem. 58: 12761-12768.

Mauad, T., Dolhnikoff, M., and Sao Paulo Bronchiolitis Obliterans Study. 2002. Histology of childhood bronchiolitis obliterans. Pediatr. Pulmonol. 33: 466-474.

More, S. S., Raza, A., and Vince, R. 2012. The butter flavorant, diacetyl, forms a covalent adduct with 2-deoxyguanosine, uncoils DNA, and leads to cell death. J. Agric. Food. Chem. 60: 3311-3317. 
Morgan, D. L., Flake, G. P., Kirby, P. J., and Palmer, S. M. 2008. Respiratory toxicity of diacetyl in C57BL/6 mice. Toxicol. Sci. 103: 169-180.

Morgan, D. L., Jokinen, M. P., Price, H. C., Gwinn, W. M., Palmer, S. M., and Flake, G. P. 2012. Bronchial and bronchiolar fibrosis in rats exposed to 2,3-pentanedione vapors: implications for bronchiolitis obliterans in humans. Toxicol. Pathol. 40: 448-465.

Morris, J. B. 2012. Biologically-based modeling insights in inhaled vapor absorption and dosimetry. Pharmacol. Therapeut. 136: 401-413.

Morris, J. B., and Hubbs, A. F. 2009. Inhalation dosimetry of diacetyl and butyric acid, two components of butter flavoring vapors. Toxicol. Sci. 108: 173-183.

Mueller, M. J., Samuelsson, B., and Haeggstrom, J. Z. 1995. Chemical modification of leukotriene A4 hydrolase. Indications for essential tyrosyl and arginyl residues at the active site. Biochemistry 34: 3536-3543

NIOSH. Criteria for a Recommended Standard: Occupational Exposure to Diacetyl and 2,3Pentanedione (Draft). Washington, DC:National Institute for Occupational Safety and Health, U.S. Centers for Disease Control and Prevention 2011.

OSHA. Occupational Exposure to Flavoring Substances: Health Effect and Hazard Control. Safety and Health Information Bulletin 10-14-2010. Washington, DC: Occupational Safety \& Health Administration, U.S. Department of Labor.

OSHA. 2007. Hazard Communication guidance for diacetyl and food flavorings containing diacetyl.

Palmer, S. M., Flake, G. P., Kelly, F. L., Zhang, H. L., Nugent, J. L., Kirby, P. J., Foley, J. F., Gwinn, W. M., and Morgan, D. L. 2011. Severe airway epithelial injury, aberrant repair and bronchiolitis obliterans develops after diacetyl instillation in rats. PloS One 6, e17644. 
Raeburn, D., Hay, D. W., Farmer, S. G., and Fedan, J. S. 1986. Epithelium removal increases the reactivity of human isolated tracheal muscle to methacholine and reduces the effect of verapamil. Eur. J. Pharmacol. 123: 451-453

Roux, E., Ouedraogo, N., Hyvelin, J. M., Savineau, J. P., and Marthan, R. 2002. In vitro effect of air pollutants on human bronchi. Cell Biol. Toxicol. 18: 289-299.

Sahakian, N., Kullman, G., Lynch, D., and Kreiss, K. 2008. Asthma arising in flavoring-exposed food production workers. Int. J.Occup. Med. Environ. Health 21: 173-177.

Schachter, E. N. 2002. Popcorn worker's lung. N. Engl. J. Med. 347: 360-361.

Siddiqui, M. T., Garrity, E. R., Martinez, R., and Husain, A. N. 1996. Bronchiolar basement membrane changes associated with bronchiolitis obliterans in lung allografts: a retrospective study of serial transbronchial biopsies with immunohistochemistry [corrected]. Mod. Pathol. 9: 320-328.

Spina, D.1998. Epithelium smooth muscle regulation and interactions. Am. J. Respir. Crit. Care Med. 158, S141-145.

van Rooy, F. G., Rooyackers, J. M., Prokop, M., Houba, R., Smit, L. A., and Heederik, D. J. 2007. Bronchiolitis obliterans syndrome in chemical workers producing diacetyl for food flavorings. Am. J. Respir. Crit. Care Med. 176: 498-504.

van Rooy, F. G., Smit, L. A., Houba, R., Zaat, V. A., Rooyackers, J. M., and Heederik, D. J. 2009. A cross-sectional study of lung function and respiratory symptoms among chemical workers producing diacetyl for food flavourings. Occup. Environ. Med. 66: 105110.

Vilchez, R. A., Dauber J., and Kusne, S. 2003. Infectious etiology of bronchiolitis obliterans: the respiratory viruses connection - myth or reality? Am. J. Transplant. 3: 245-249.

Wondrak, G. T., Cervantes-Laurean, D., Roberts, M. J., Qasem, J. G., Kim, M., Jacobson, E. L., and Jacobson, M. K. 2002. Identification of a-dicarbonyl scavengers for cellular protection against carbonyl stress. Biochem. Pharmacol. 63: 361-373. 
Yeh, H. C., Phalen, R. F., and Raabe, O. G. 1976. Factors influencing the deposition of inhaled particles. Environ. Health Perspect. 15: 147-156

Yeh, H. C., Schum, G. M., and Duggan, M. T. 1979. Anatomic models of the tracheobronchial and pulmonary regions of the rat. Anat. Rec. 195: 483-492

Zlotolow, R., Brautbar, N., and Wu, M. P. 2007. Occupational bronchiolitis obliterans in food flavoring. Presented during the $25^{\text {th }}$ Anniversary of the Collegium Ramazzini, Carpi, Italy, October 25-28.

Zaccone, E. J., Thompson, J. A., Ponnoth, D. S., Cumpston, A. M., Goldsmith, W. T., Jackson, M. C., Kashon, M. L., Frazer, D. G., Hubbs, A. F., Shimko, M. J., and Fedan, J. S. 2013. Popcorn flavoring effects on reactivity of rat airways in vivo and in vitro. J Toxicol. Env. Heal. A 76: 669-689. 


\section{Chapter 2}

\section{POPCORN FLAVORING EFFECTS ON REACTIVITY OF RAT AIRWAYS IN VIVO AND IN VITRO}

Eric J. Zaccone ${ }^{1}$, Janet A. Thompson², Dovenia S. Ponnoth ${ }^{2}$, Amy M. Cumpston ${ }^{2}$, W. Travis Goldsmith², Mark C. Jackson², Michael L. Kashon², David G. Frazer², Ann F. Hubbs², Michael J. Shimko ${ }^{1}$ and Jeffrey S. Fedan ${ }^{2}$

${ }^{1}$ Department of Basic Pharmaceutical Sciences, West Virginia University, Morgantown, West Virginia, USA

and

${ }^{2}$ Centers for Disease Control and Prevention, National Institute for Occupational Safety and Health, Morgantown, West Virginia, USA

Address for correspondence: Jeffrey S. Fedan

$\mathrm{NIOSH}$

1095 Willowdale Road

Morgantown, WV 26505

Phone: 304-285-5766

FAX: 304-285-5766

E-mail: jsf2@cdc.gov 


\subsection{Abstract}

"Popcorn workers' lung" is an obstructive pulmonary disease produced by inhalation of volatile artificial butter flavorings. In rats, inhalation of diacetyl, a major component of butter flavoring, and a diacetyl substitute, 2,3-pentanedione, produce similar damage to airway epithelium. The effects of diacetyl and 2,3-pentanedione and mixtures of diacetyl, acetic acid and acetoin, all components of butter flavoring, on pulmonary function and airway reactivity to methacholine $(\mathrm{MCh})$ were investigated. Lung resistance $\left(R_{L}\right)$ and dynamic compliance $\left(C_{d y n}\right)$ were negligibly changed $18 \mathrm{hr}$ after a 6-hr inhalation exposure to diacetyl or 2,3-pentanedione (100 - $360 \mathrm{ppm}$ ). Reactivity to MCh was not appreciably changed after diacetyl, but was modestly decreased after 2,3-pentanedione inhalation. Inhaled diacetyl exerted essentially no effect on reactivity to mucosally-applied $\mathrm{MCh}$, but 2,3-pentanedione (320 and $360 \mathrm{ppm}$ ) increased reactivity to $\mathrm{MCh}$, in the isolated, perfused trachea preparation (IPT). In IPT, diacetyl and 2,3-pentanedione $(\geq 3 \mathrm{mM})$ applied to the serosal and mucosal surfaces of intact and epithelium-denuded tracheas initiated transient contractions followed by relaxations. Inhaled acetoin (150 ppm) exerted no effect on pulmonary function and airway reactivity in vivo; acetic acid (27 ppm) produced hyperreactivity to MCh; and exposure to diacetyl + acetoin + acetic acid $(250+150+27 \mathrm{ppm})$ led to a diacetyl-like reduction in reactivity. Data suggest that the effects of 2,3-pentanedione on airway reactivity are greater than those of diacetyl, and that flavorings are airway smooth muscle relaxants and constrictors, thus indicating a complex mechanism.

Key words: Diacetyl; 2,3-Pentanedione; Acetoin; Acetic acid; Epithelium; Airway reactivity; Methacholine; Popcorn flavorings; Pulmonary function 
Abbreviations: $\mathrm{R}_{\mathrm{L}}$ : lung resistance; $\mathrm{C}_{\mathrm{dyn}}$ : dynamic compliance; $\mathrm{Cl}$ : confidence interval; $\mathrm{DCXR}$ : dicarbonyl/xylulose reductase; EL: extraluminal bath; IL: intraluminal bath; IPT: isolated, perfused trachea; MCh: methacholine 


\subsection{Introduction}

Employees at microwave popcorn manufacturing factories have developed "popcorn workers' lung" (Department of Health and Human Services 2004; Kreiss et al., 2002; Lockey et al., 2009; Schachter, 2002), a lung disease resembling bronchiolitis obliterans (King, 1989), following inhalation of butter flavoring. Sahakian et al. (2008) demonstrated that butter flavoring-exposed workers, have an increased risk of occupational asthma and exacerbated asthma symptoms. The flavorings in popcorn also find use in other foods (e.g., caramel, butterscotch and vanilla flavors, muffin and cake mixes; Day et al., 2011; Harber et al., 2006; Martyny et al., 2008). Employees in a cookie factory developed bronchiolitis obliterans after artificial butter flavoring exposure while preparing the cookie dough (Cavalcanti Zdo et al., 2012). One patient who had worked in a microwave popcorn factory was diagnosed initially with reactive airways disease with a positive methacholine ( $\mathrm{MCh}$ ) challenge test, only to be

diagnosed a few years later with bronchiolitis obliterans with no response to a bronchodilator (Zlotolow et al., 2007). Another patient with a positive MCh test eventually acquired bronchiolitis obliterans (Zlotolow et al., 2007). Flavoring inhalation can pose a respiratory risk to consumers as well. Upon opening a bag of microwave popcorn, sufficient butter flavoring is released into the air to cause respiratory disease (Egilman and Schilling, 2012).

Over 150 volatile agents are present in popcorn butter flavoring (Boylstein et al., 2006). The primary component in butter flavoring mixture that is thought to be toxic to the lungs of workers is diacetyl (2,3-butanedione; $\left.\mathrm{C}_{4} \mathrm{H}_{6} \mathrm{O}_{2}\right)$ (Hubbs et al., 2008; van Rooy et al., 2007). Diacetyl is a low molecular weight, four-carbon a-diketone largely responsible for the taste of butter (Harber et al., 2006; Hubbs et al., 2008). 2,3-Pentanedione (acetyl propionyl; $\mathrm{C}_{5} \mathrm{H}_{8} \mathrm{O}_{2}$ ), an a-diketone with a structure similar to diacetyl's, is used as a diacetyl substitute. This compound produces pulmonary toxicity in animal models, although its toxicity is not as wellcharacterized as that of diacetyl (Day et al., 2011; Hubbs et al., 2012; Morgan et al., 2012a, b). 
Both chemicals are volatile, yielding vapors that can be inhaled. Other volatile components in flavoring mixtures, alone or in combination with diacetyl, may exert pulmonary toxicity. In particular, acetoin and acetic acid are present in vapor mixtures associated with popcorn workers' lung (Boylstein et al., 2006; Kreiss et al., 2002; van Rooy et al., 2007, 2009).

Histological investigation in animal models demonstrated that a 6-hr inhalation exposure to diacetyl and 2,3-pentanedione causes some epithelial damage $0 \mathrm{hr}$ post-exposure which progresses in intensity by 18 to $20 \mathrm{hr}$ post-exposure (Hubbs et al., 2002, 2008, 2010, 2012; Morris and Hubbs, 2009; Morgan et al. 2008, 2012a, 2012b; Palmer et al., 2011). In addition, inhaled 2,3-pentanedione was found to result in olfactory neuroepithelial injury in rats (Hubbs et al., 2012) and, interestingly, diacetyl may induce long-lasting neurotoxicity by binding to $\beta$ amyloid and interfering with pleated sheet structures (More et al., 2012a). Thus, the toxicity of these volatile $\alpha$-diketones extends beyond the lung.

Functionally, acute diacetyl inhalation produces pulmonary irritation in mice but, surprisingly, high concentration diacetyl exposures result in desensitization of the sensory response to subsequent diacetyl inhalations (Larsen et al., 2009). The rat has been used to model the bronchiolitis-like changes in the lung following exposures to diacetyl or 2,3pentanedione (Morgan et al., 2012a; Palmer et al., 2011). Understanding the pulmonary function changes after acute diacetyl exposure in the rat is important because it is an established model of flavorings-related lung disease and the spectrum of flavorings-related lung disease recently expanded to include functionally important pulmonary conditions in addition to bronchiolitis obliterans and pulmonary function (Kreiss et al., 2002; Sahakian et al., 2008).

While intratracheal instillation of diacetyl is known to alter pulmonary function in rats at 7 days post-exposure when aberrant epithelial repair and intraluminal airway fibrosis have developed (Palmer et al., 2011), little is known regarding changes in rat pulmonary function and airway reactivity after acute inhalation exposures to diacetyl, 2,3-pentanedione, or diacetyl- 
containing mixtures of flavorings. This information is critical to understanding the full spectrum of toxicities associated with these flavorings.

Many studies demonstrated increased responsiveness of airway smooth muscle in vitro to contractile agonists such as acetylcholine and 5-hydroxytryptamine, as well as sensory neuropeptides, including substance $P$ and neurokinin $A$, following removal of the epithelium (Aarhus et al., 1984; Hay et al., 1986; Spina, 1998). Therefore, damage to the epithelium by flavorings would be expected to increase reactivity to contractile agonists in vivo and in vitro, especially after contractile agonists are applied to the mucosal surface. For example, ozone $\left(\mathrm{O}_{3}\right)$ inhalation results in injury to airway epithelial cells, and hyperreactivity to MCh in vitro and in vivo (Fedan et al., 2000; Savov et al., 2004). The increase in reactivity to inhaled MCh after $\mathrm{O}_{3}$ exposure was thought to be a consequence of greater accessibility of the drug through the airway wall to the smooth muscle and to loss of epithelial-derived relaxant factor (EpDRF)(Fedan et al., 2000).

The overall hypothesis of this study is popcorn flavorings that produce damage to the airway epithelium result in airway hyperreactivity to MCh in vivo and in vitro. A major purpose of the investigation was to compare and contrast the effects of diacetyl and 2,3-pentanedione in airways in vivo and in vitro. In the first series of experiments, alterations were determined in respiratory mechanics, i.e., lung resistance and dynamic compliance $\left(R_{L}\right.$ and $C_{d y n}$, respectively), as well as reactivity to inhaled MCh, following diacetyl or 2,3-pentanedione inhalation (Poole et al., 2009; Yao et al., 2010). It was of interest to identify the concentration range over which diacetyl and 2,3-pentanedione may produce such effects. In the second series of experiments, the isolated, perfused trachea (IPT) method was employed using tracheas from exposed rats to investigate and compare the effects of diacetyl or 2,3-pentanedione inhalation on airway reactivity to $\mathrm{MCh}$ in vitro, again with the goal of examining concentration-dependence of effects. It was postulated that reactivity to MCh applied to the mucosal surface bath of the perfused trachea would be increased following these exposures. In the third series of experiments, the 
IPT preparation was employed to investigate the direct effects of diacetyl and 2,3-pentanedione in rat airways in vitro. Earlier findings that diacetyl elicits contraction and relaxation of guineapig airways were extended (Fedan et al., 2006). The potential role of the epithelium in the development of these responses was investigated. Last, other flavorings, such as acetic acid and acetoin, are often present in abundant amounts in the vapors of butter flavorings and also were reported in a flavoring manufacturing workplace with affected workers (Boylstein et al., 2006; van Rooy et al., 2007, 2009). They are not currently regarded as being key compounds in the development of toxicity in humans. However, being inhaled along with diacetyl they could worsen or mitigate its toxic effects in the lung. Thus, studies also investigated the effects of acetic acid and acetoin, alone and in combination with inhaled diacetyl as a mixed exposure. 


\subsection{Materials and methods}

\subsubsection{Animals}

These studies were conducted in facilities accredited by the Association for the Assessment and Accreditation of Laboratory Animal Care International and were approved by the institutional Animal Care and Use Committee. Male Sprague-Dawley rats (Hilltop Lab Animals; Scottdale, PA; 300 - $450 \mathrm{~g}$ ) were housed in pairs in ventilated micro-isolator units supplied with HEPA-filtered laminar flow air (Thoren Caging Systems; Hazleton, PA), with autoclaved Alpha-DriTM virgin cellulose chips (Shepherd Specialty Papers, Watertown, TN) and hardwood Beta-chips (NEPCO; Warrensburg, NY) for bedding, and provided tap water and autoclaved HaCXan Teklad Global 18\% protein rodent diet (Harlan Teklad; Madison, WI) ad libitum. Rats were housed under controlled light cycle (12 hr light) and temperature $\left(22-25^{\circ} \mathrm{C}\right)$ conditions.

\subsubsection{Exposure of rats to diacetyl, 2,3-pentanedione, acetoin and acetic acid vapors}

Two inhalation systems were designed to expose rats to butter flavoring constituents. In the first system, the whole-body inhalation exposure system (Hubbs et al., 2008) was modified and automated to expose rats for $6 \mathrm{hr}$ to diacetyl $(100,200,300$ or 360 ppm) or 2,3pentanedione $(120,240,320$ or 360 ppm)(Figure 1). The concentrations of diacetyl and 2,3pentanedione were selected based upon previously described airway epithelial toxicity (Hubbs et al., 2008, 2012). Filtered air-breathing control animals were placed for $6 \mathrm{hr}$ in chambers that were similar to ones used for exposure to flavorings, with matched environmental conditions. A photo-ionization detector (PID, PGM-7600; RAE Systems, San Jose, CA) measured the realtime concentration levels of diacetyl and 2,3-pentanedione during the exposures, in which the measured concentrations of components were closely related to target concentrations (Table 1). Water-sealed, compressed air was dried, HEPA-filtered and charcoal-filtered and then passed 
through a mass flow controller (GFC37, Aalborg; Orangeburg, NY) and into a custom humidifier which maintained the relative humidity. Air flow was regulated at $20 \mathrm{l} / \mathrm{min}$, which corresponded to over 15 air changes per hr. Chamber $\mathrm{CO}_{2}$, ammonia, temperature, and relative humidity for both exposed and control rats were regulated within acceptable limits for animal comfort (Institute for Laboratory Animal Research, 2011). The air then entered a stainless steel mixer where it was heated. Liquid diacetyl or 2,3-pentanedione were injected into the airstream with a syringe pump (210, KD Scientific Inc.; Holliston, MA), where it vaporized in the heated air $\left(70^{\circ}\right.$ C). The diacetyl or 2,3-pentanedione vapor was passed into a custom stainless steel and glass exposure chamber (McKinney and Frazer, 2008) that could house up to 6 animals. PID measurements from the chamber were used in a feedback loop that adjusted the flow of the syringe pump to maintain the concentration at a constant, user-defined value (Table 1). Custom data acquisition and control software was developed which permitted the user to set parameters such as flavoring concentration and relative humidity. Data was acquired at a rate of 1 sample/sec and recorded for subsequent analysis. 

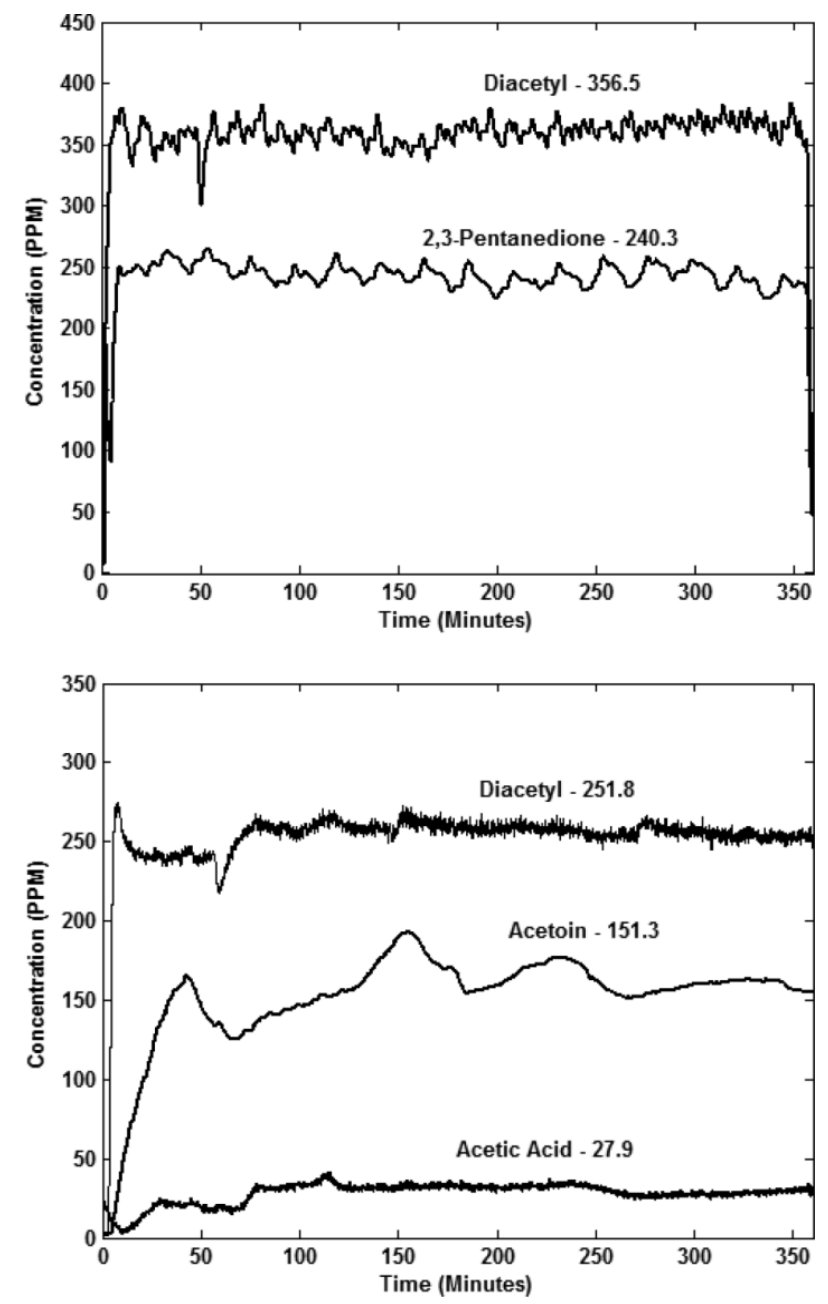

FIGURE 1. Top, typical recordings illustrating stable diacetyl and 2,3-pentanedione levels during a 6-h inhalation exposure. Bottom, typical recordings illustrating stable diacetyl and acetoin and acetic acid levels during a 6-h inhalation exposure. Numbers above the tracings are timeweighted values. 
TABLE 1. Target concentrations compared to measured concentrations during diacetyl and 2,3-pentanedione inhalation

\begin{tabular}{ll}
\hline Target $(\mathrm{ppm})$ & Measured $(\mathrm{ppm})$ \\
\hline Diacetyl & $100 \pm 0$ \\
100 & $200 \pm 0$ \\
200 & $295 \pm 1$ \\
300 & $354 \pm 2$ \\
360 & \\
$2,3-P e n t a n e d i o n e$ & $118 \pm 0.5$ \\
120 & $242 \pm 2$ \\
240 & $315 \pm 4$ \\
320 & $356 \pm 1$ \\
360 & \\
\hline
\end{tabular}

Animals were exposed to flavoring levels close to target concentrations at stable temperature and relative humidity. 
TABLE 2. Target concentrations compared to measured concentrations during diacetyl and acetoin and acetic acid single and mixed inhalation exposures

\begin{tabular}{lcl}
\hline Vapor & Target (ppm) & Measured (ppm) \\
\hline Single vapor & & \\
Diacetyl & 250 & $251.4 \pm 0.3$ \\
Acetoin & 150 & $149.5 \pm 0.1$ \\
Acetic acid & 27 & $25.9 \pm 3.4$ \\
Mixed exposure: "Three low" & \\
Diacetyl & 167 & $164.9 \pm 1.7$ \\
Acetoin & 100 & $99.5 \pm 1.0$ \\
Acetic acid & 18 & $18.6 \pm 0.1$ \\
Mixed exposure: "Three high" & \\
Diacetyl & 250 & $251.6 \pm 0.2$ \\
Acetoin & 150 & $143.6 \pm 7.7$ \\
Acetic acid & 27 & $28.2 \pm 0.3$ \\
\hline
\end{tabular}


The second inhalation system was similar to the first with additional alterations. This system was used to expose rats (Figure 1) to diacetyl (167 or 250 ppm), acetic acid (18 or 27 ppm) or acetoin (100 or 150 ppm) individually, or as three vapor mixtures containing low ("Three low:" 167 ppm diacetyl + 100 ppm acetoin + 18 ppm acetic acid) or high (“Three High:” 250 ppm diacetyl +150 ppm acetoin +27 ppm acetic acid) concentrations of the vapors (Table 2). To facilitate investigation of potentially enhanced toxicity to intrapulmonary airways resulting from combined exposures, the highest diacetyl concentration selected ( $250 \mathrm{ppm})$ was just below the lowest dose $(294.6 \mathrm{ppm})$ reported previously to produce cytotoxicity in intrapulmonary airways following acute single-agent exposure (Hubbs et al., 2008). Features of this inhalation system included: 1) three heated injection ports which were fed with separate syringe pumps (one for each vapor), 2) a different custom exposure chamber that could hold up to 12 animals (Goldsmith et al., 2011), 3) wet sponges which provided humidity instead of the custom humidifier, and 4) a Fourier transform infrared (FTIR) spectrometer gas analyzer (DX-4010, Gasmet Technologies Inc.; La Praire, Quebec) which monitored the concentration of each individual flavoring in the exposure chamber in real-time. Feedback loops were used to regulate the syringe pump flow for each of the three flavorings.

The PID was calibrated weekly to the flavoring of interest with a custom apparatus that delivered user-defined air temperature, relative humidity and flavoring concentrations. Measurements were taken with gravimetric filters, a scanning mobility particle sizer (SMPS, TSI; St. Paul, MN), and an aerodynamic particle sizer (APS, TSI) to determine if any of the vapor was in an aerosol form. All results indicated that negligible aerosol was present during the exposures. Figure 1 demonstrates that vapor levels during a 6-hr exposure were constant.

There was no mortality in the animals following flavoring exposures.

2.3.3. Effects of flavoring exposure on respiratory mechanics and reactivity to MCh in vivo 
Eighteen hr post-exposure, rats were anesthetized with $100 \mathrm{mg} / \mathrm{kg}$ ketamine and 10 $\mathrm{mg} / \mathrm{kg}$ xylazine given i.p. A mid-line incision was made in the neck and a cannula was placed into the trachea. Animals received supplemental ketamine $(50 \mathrm{mg} / \mathrm{kg}$ ) by administering the drug topically to the exposed muscle in the neck. Animals were placed on a warming bed in a plethysmograph for the assessment of lung $R_{L}$ and $C_{d y n}$ (FinePointe RC; Buxco Electronics, Inc; Wilmington, NC) and were ventilated using a digital rodent ventilator (Élan Series RC; Buxco Electronics, Inc.). Ventilation settings were: maximum mouth pressure, $40 \mathrm{~cm} \mathrm{H}_{2} \mathrm{O}$; maximum tidal volume, $3 \mathrm{ml}$; and respiratory rate, $90 \mathrm{bpm}$. After recording baseline values of $R_{L}$ and $C_{d y n}$ and after delivery of saline vehicle as a control, MCh aerosols were delivered from $20 \mu \mathrm{l}$ of solutions of the following concentrations: $0.3,1,1.73,3,5.75$ or $10 \mathrm{mg} / \mathrm{ml}$. Three, $5-\mathrm{ml}(45 \mathrm{~cm}$ $\mathrm{H}_{2} \mathrm{O}$ mouth pressure) deep inspirations were applied just before each MCh dose was delivered. Maximum $R_{L}\left(R_{L m a x}\right)$ values and minimum $C_{d y n}$ values $\left(C_{d y n m i n}\right)$ were logged at 5 -sec intervals to quantify responses to MCh. Following completion of the experiment, rats were euthanized by exsanguination.

2.3.4. Effects of diacetyl and 2,3-pentanedione inhalation on reactivity to MCh in the IPT preparations

This preparation has been described previously (Fedan et al. 2006; Fedan and Frazer 1992). Eighteen hr after the end of air or flavoring exposure, rats were anesthetized using sodium pentobarbital (65 mg/kg, i.p.) and euthanized by exsanguination. A 25-mm segment of trachea was removed and cleaned. The segment was mounted on a perfusion holder at its in situ length. The holder contained indwelling, side-hole catheters in the lumen that were connected to the positive (inlet) and negative (outlet) sides of a differential pressure transducer. The holder with mounted trachea was placed into an extraluminal (EL) bath containing modified Krebs-Henseleit solution (MKHS). The trachea was perfused at a constant rate $(25 \mathrm{ml} / \mathrm{min})$ with 
MKHS from a separate bath, the intraluminal (IL) bath, while measuring inlet minus outlet pressure difference $\left(\triangle \mathrm{P}, \mathrm{cm} \mathrm{H}_{2} \mathrm{O}\right)$ as an index of tracheal diameter. Transmural pressure was set to zero. The MKHS in the IL and EL baths was replaced at 15-min intervals with fresh solution, followed by a 30-min equilibration period in which the MKHS was not changed and the baseline was allowed to become stable. MKHS temperature was $37^{\circ} \mathrm{C}$ and was aerated with $95 \% \mathrm{O}_{2} / 5 \% \mathrm{CO}_{2}$ to give $\mathrm{pH}$ 7.4. After the equilibration period, MCh was added in stepwiseincreasing, cumulative concentrations $\left(10^{-5}-3 \times 10^{-2} \mathrm{M}\right)$ to the $\mathrm{IL}$ bath to induce contractile responses for the generation of concentration-response curves.

2.3.5. Reactivity to diacetyl and 2,3-pentanedione in the IPT; influence of the epithelium

Tracheas were prepared as described above. After the equilibration period, diacetyl or 2,3-pentanedione $(1-30 \mathrm{mM})$ was added in stepwise-increasing, cumulative concentrations to the IL or EL bath to initiate contractile responses. In order to examine the relaxant effects of the flavorings, preparations were pre-contracted with EL MCh $\left(3 \times 10^{-5} \mathrm{M}\right.$; EC50) to induce contraction before administering the flavoring. The potential involvement of the epithelium in responses to the flavorings was investigated using perfused tracheas, the epithelium of which was removed by inserting a tamper pin into the lumen and gently turning the pin three to four times.

\subsubsection{Solutions and reagents}

The composition of MKHS was: $\mathrm{NaCl}, 113 \mathrm{mM} ; \mathrm{KCl}, 4.8 \mathrm{mM} ; \mathrm{CaCl}_{2}, 2.5 \mathrm{mM} ; \mathrm{MgCl}_{2}$, $1.2 \mathrm{mM} ; \mathrm{KH}_{2} \mathrm{PO}_{4}, 1.2 \mathrm{mM}$; $\mathrm{NaHCO}_{3}, 25 \mathrm{mM}$ and glucose, $5.5 \mathrm{mM}$. All drugs and chemicals were obtained from Sigma-Aldrich (St. Louis, MO) and dissolved and diluted in saline. The purity of diacetyl (lot 03798LJ) and 2,3-pentanedione (lot 00130DJ) was 99.3\% and 97\%, respectively. 


\subsubsection{Statistical analysis}

The results are expressed as means \pm S.E.M. In vivo results were analyzed for differences using ANOVA for repeated measures. For the in vitro experiments the results were analyzed for differences using ANOVA. MCh concentration-response curves were normalized with respect to each preparation's maximum response. Geometric mean EC50 values for MCh were derived from least squares analysis of four-parameter logit curve fits and are expressed along with $95 \%$ confidence intervals. Statistical comparisons of EC50 values were conducted using normally distributed - $\operatorname{logEC50}$ values. Responses to in vitro application of diacetyl or 2,3pentanedione were normalized by calculating the percent relaxation of the contraction induced by MCh; $n$ is the number of separate experiments and $p<.05$ was considered significant. 


\subsection{Results}

2.4.1. Effect of diacetyl and 2,3-pentanedione inhalation on basal pulmonary function and reactivity to inhaled $\mathrm{MCh}$

Eighteen $\mathrm{h}$ following a 6-hr diacetyl exposure, other than a slight increase in basal $\mathrm{C}_{\mathrm{dyn}}$ at 360 ppm, diacetyl did not markedly affect $R_{L}$ and $C_{d y n}$ compared to air-exposed controls (Figure 2 ); this change is probably without biological significance.

Diacetyl inhalation reduced slightly but significantly the $R_{\mathrm{L}}$ response to $10 \mathrm{mg} / \mathrm{ml} \mathrm{MCh}$ at one concentration, $360 \mathrm{ppm}$. There were no marked effects of diacetyl on $\mathrm{C}_{\mathrm{dyn}}$ responses to MCh at any concentration of diacetyl (Figure 3). Thus, diacetyl inhalation, in doses that produce substantial epithelial damage (Hubbs et al., 2008), did not change reactivity to MCh. Eighteen hr following a 6-hr 2,3-pentanedione inhalation, basal $R_{L}$ and $C_{d y n}$ were largely unaffected (data not shown). 2,3-Pentanedione (120, 240 and $320 \mathrm{ppm}$ ) reduced RL responses at the highest doses of MCh (Figure 4); a comparable change at $360 \mathrm{ppm}$ was not significant. Other than at 10 $\mathrm{mg} / \mathrm{ml} \mathrm{MCh}$ at $240 \mathrm{ppm}$ 2,3-pentanedione, the flavoring exerted no marked effect on $\mathrm{C}_{\text {dyn. }}$. 

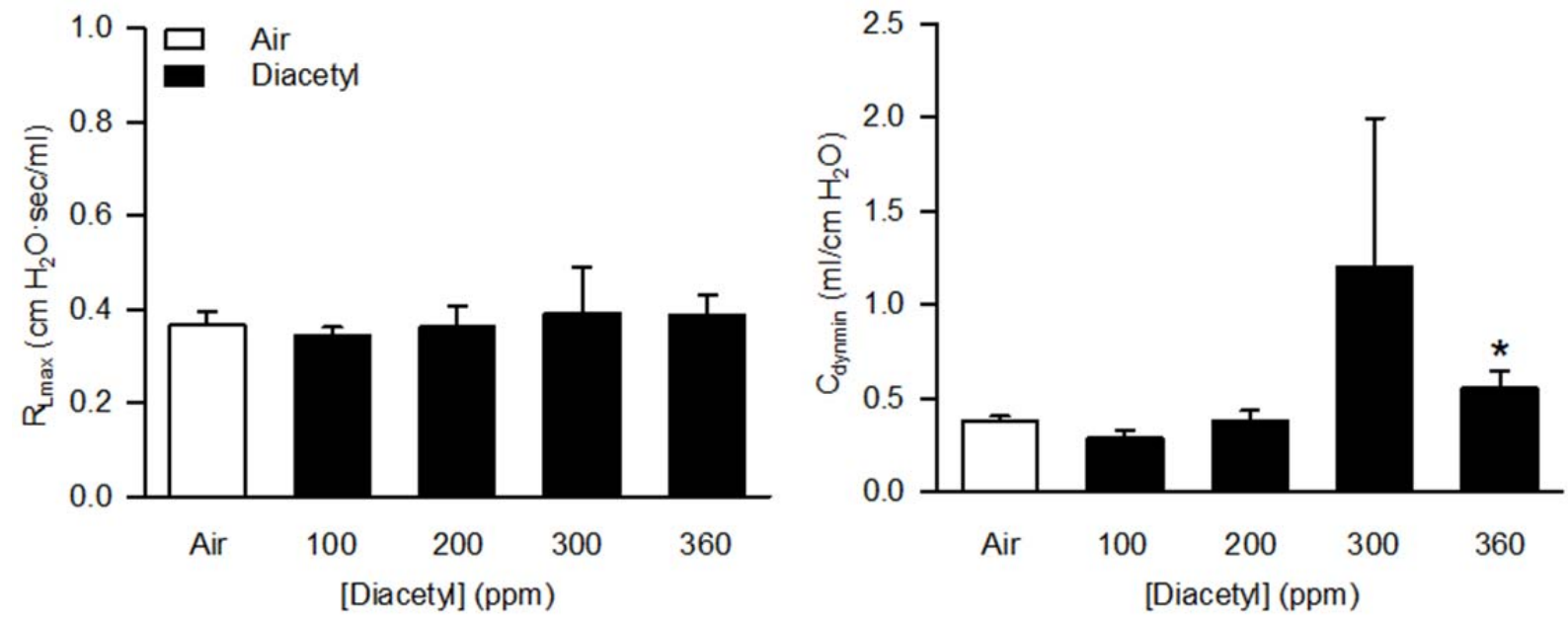

FIGURE 2. Basal values of $R_{L}$ (left panel) and $C_{d y n}$ (right panel) after inhalation exposure of rats to air or diacetyl. Left panel: $18 \mathrm{hr}$ following 6-hr exposure. Air, $n=24$; diacetyl, $n=6-9$ for each concentration. Right panel: $C_{\text {dyn. }}$ Air: $n=26$; diacetyl, $n=6-10$ for each concentration. ${ }^{*}$ Significantly different from air-exposed $(p<0.05)$. 

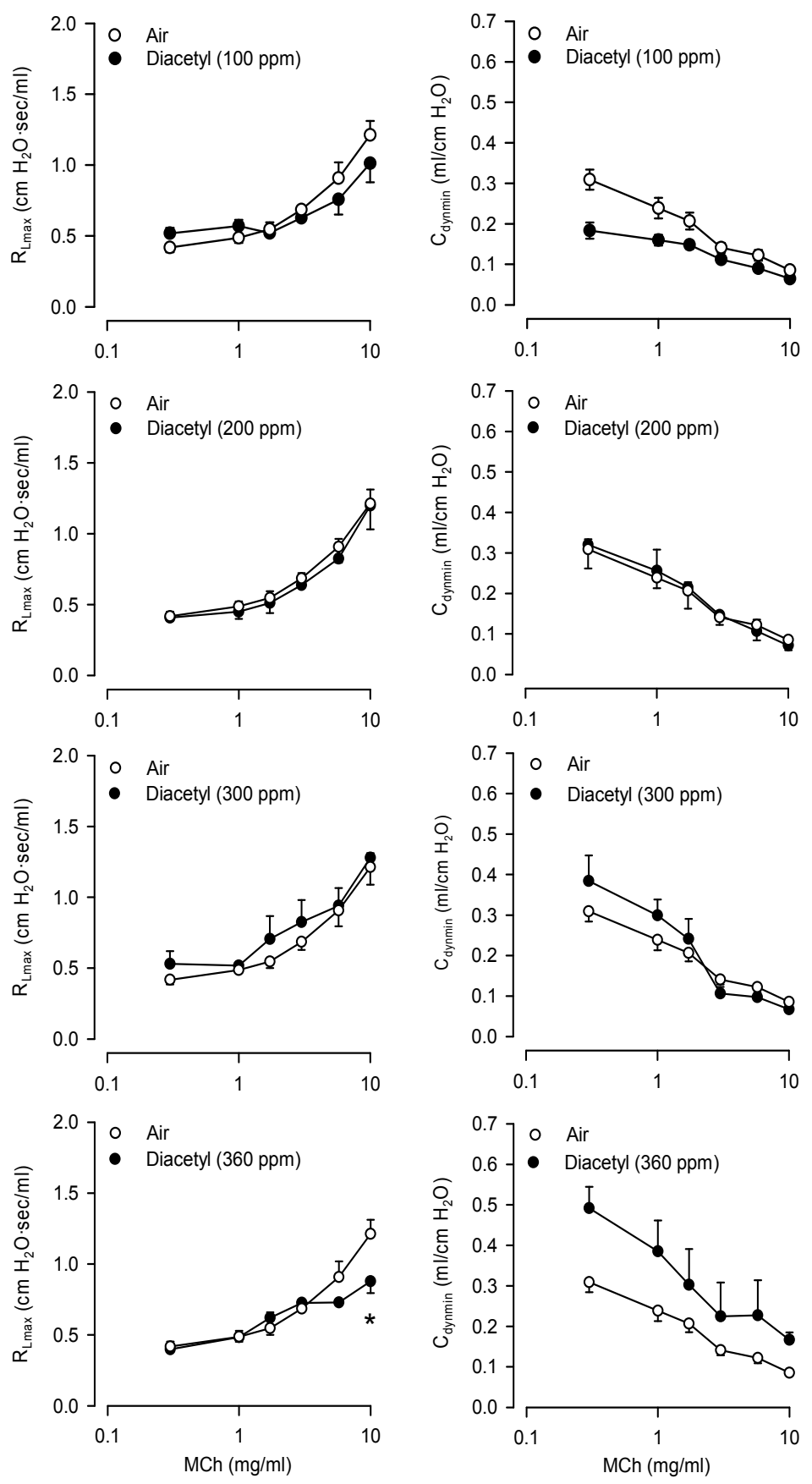

FIGURE 3. Effect of diacetyl inhalation $18 \mathrm{hr}$ following 6-hr exposure of rats on reactivity to inhaled MCh. Left panels: diacetyl on effect on $R_{L}$ responses. Right panels: diacetyl exposure on $\mathrm{C}_{\mathrm{dyn}}$. ${ }^{*}$ Significantly different from air-exposed $(p<0.05)$. 

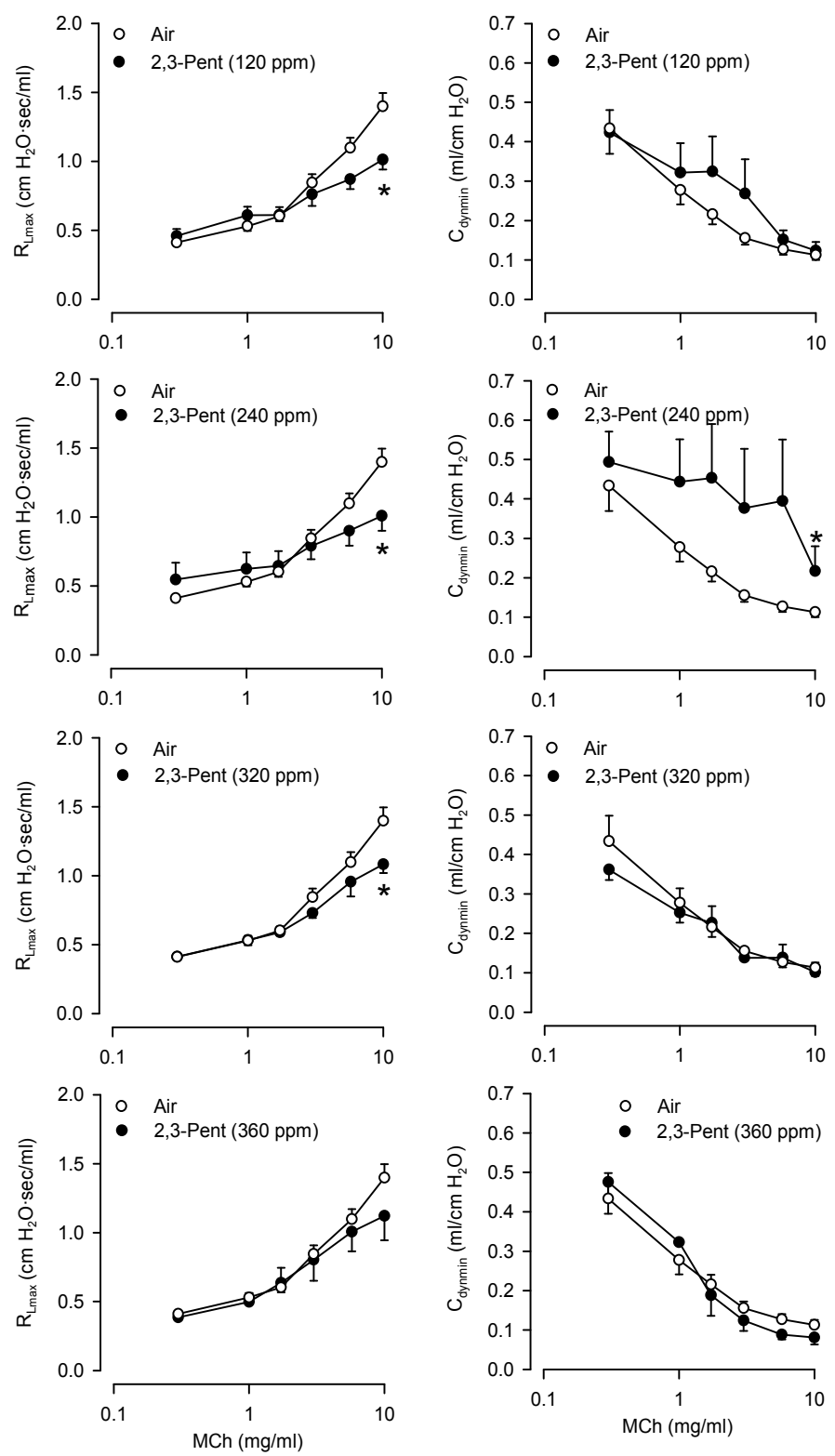

FIGURE 4. Effect of 2,3-pentanedione inhalation $18 \mathrm{hr}$

following 6-hr exposure of rats on reactivity to inhaled.

Left panel: $R_{L}$ responses to MCh after exposure to 120 ,

240 and 320 ppm 2,3-pentanedione. Right panels: effect

on $\mathrm{C}_{\mathrm{dyn}}$. Air: $n=24 ; 2,3$-pentanedione: $n=4-10$.

*Significantly different from air-exposed $(p<0.05)$. 
2.4.2. Effects of diacetyl and 2,3-pentanedione inhalation on reactivity in vitro of rat trachea to MCh

In the surprising absence of increases in vivo in reactivity to MCh after flavoring inhalation, evidence was sought for an alteration in reactivity to MCh in vitro using the IPT preparation. Before examining the effects of inhaled flavorings, reactivity to MCh was first compared in epithelium-containing and epithelium-denuded tracheas to establish what the consequences of severe epithelium damage might be. In the presence of the epithelium, the concentration-response curve obtained after adding MCh mucosally was shifted rightward of the EL curve and was characterized by a smaller maximum response (Figure 5 and Table 2). The lesser reactivity to MCh after IL addition in intact trachea is a reflection of the epithelial diffusion barrier as well as the release of epithelial-derived modulatory factors (Farmer et al., 1986, 1987; Fedan et al., 2006; Fedan and Frazer, 1992; Smith et al., 1993).
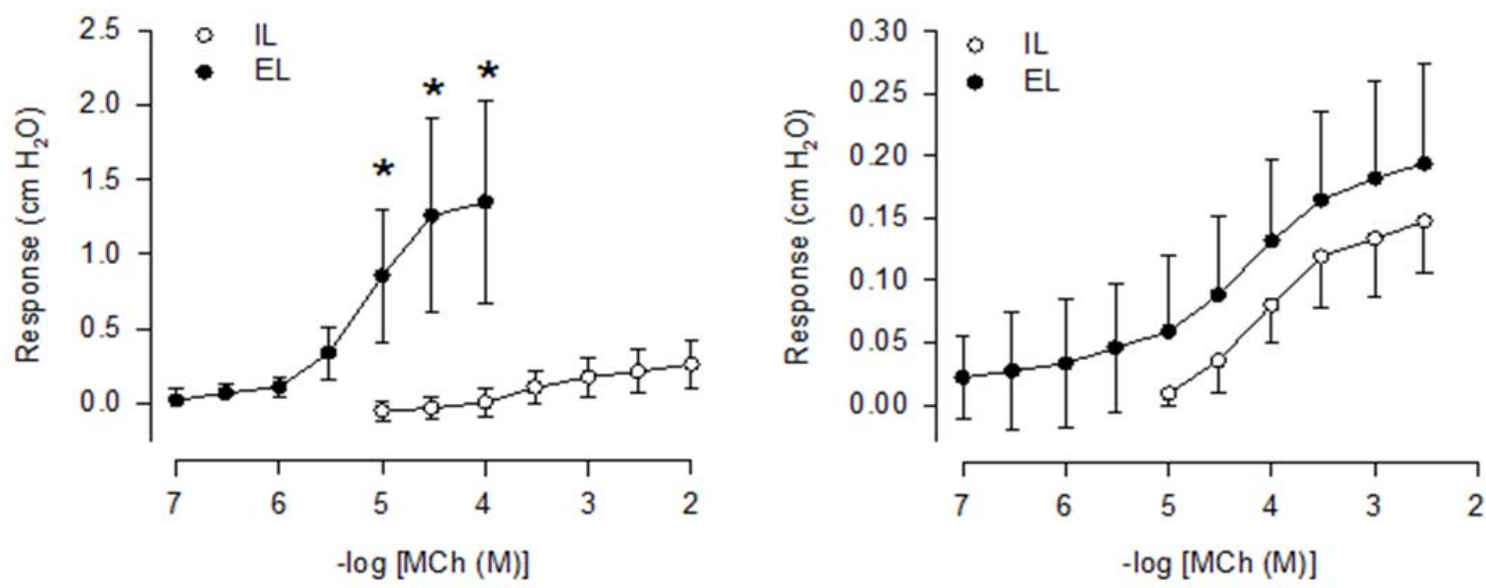

FIGURE 5. Effect of epithelium removal on reactivity to IL-applied MCh in IPT. Left panel: comparison of EL and IL MCh concentration-response curves obtained from epithelium-containing tracheas. EL, $n=6$; IL, $n=6$. Right panel: responses to MCh in tracheas from which the epithelium was removed. $\mathrm{EL}, n=5 ; \mathrm{IL}, n=5$. ${ }^{*}$ Significant difference between EL and IL responses $(p<0.05)$. 
In denuded tracheas, reactivities for the intraluminal and extraluminal administration of MCh were not different (Figure 5 and Table 2); that is, the IL curve was shifted leftward and upward to the location of the EL curve, as expected (Fedan and Frazer, 1992). The IL MCh concentration-response curve in the absence of the epithelium demonstrated the maximum effect on reactivity that flavorings could produce as a result of epithelial damage. It was postulated that the effects of epithelial damage produced by flavoring inhalation should resemble qualitatively and in varying degrees the increase in reactivity to IL-applied MCh after mechanical epithelial removal.

Eighteen hr after diacetyl inhalation, responses to MCh of tracheas from animals exposed to 300 and 360 ppm were potentiated (Figure 6). However, diacetyl exerted no marked effect on the EC50 values for MCh at these and the remaining diacetyl exposure levels (Table 3). Diacetyl-exposed tracheas demonstrated significant hyporeactivity compared to air controls at $100 \mathrm{ppm}$ at one $\mathrm{MCh}$ concentration. These results indicate that epithelial damage after diacetyl exposure is accompanied by modest changes in reactivity to IL MCh in vitro.

The two highest concentrations of 2,3-pentanedione increased significantly reactivity to IL MCh (Figure 7 and Table 3), evidenced as decreases in the EC50 values. The results indicate that the damage to the epithelium of rats following 2,3-pentanedione exposure is accompanied by an increase in reactivity to MCh in vitro. 

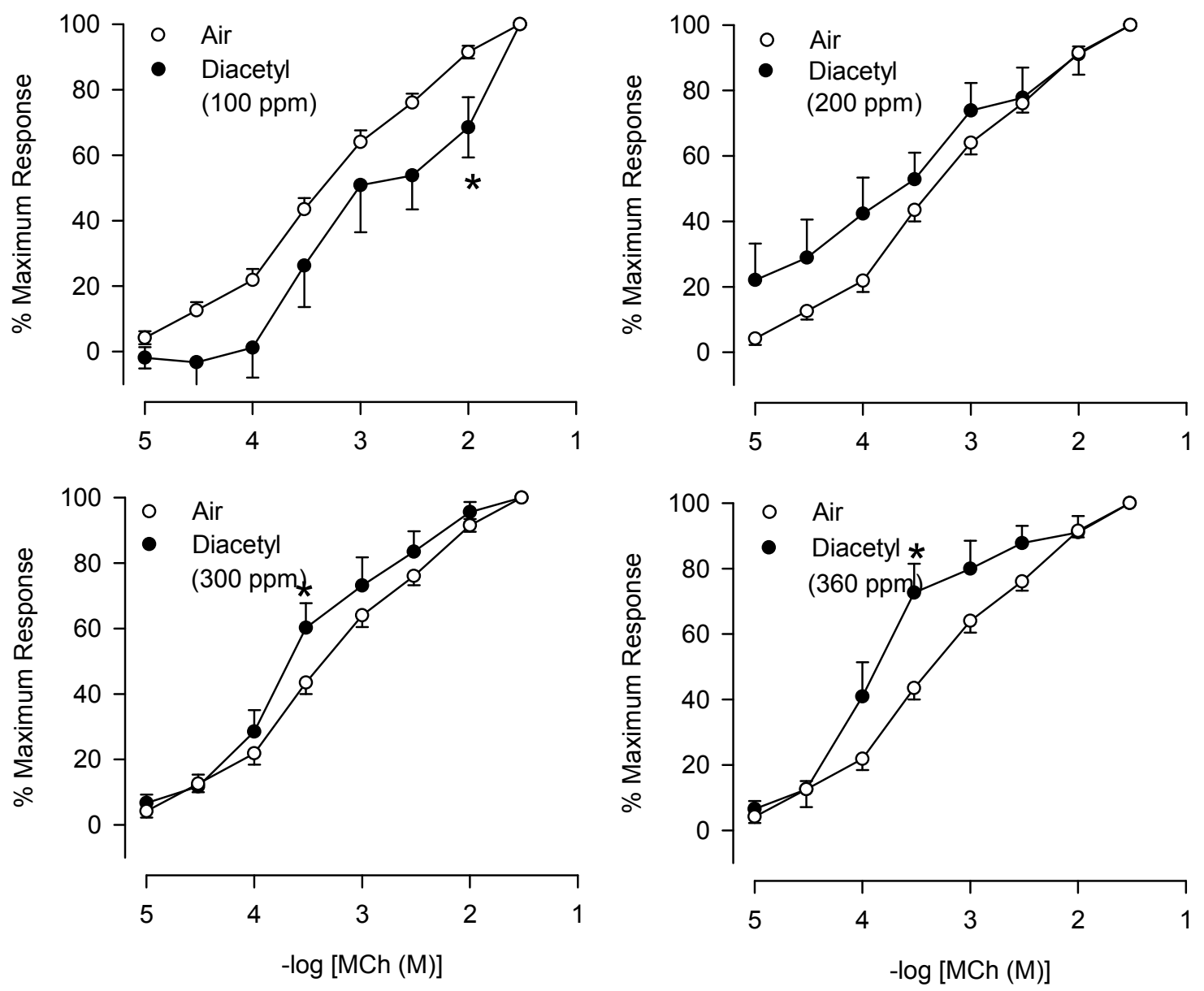

FIGURE 6. Effect of diacetyl inhalation on reactivity of IPT to IL MCh. MCh EC50 values and maximum responses are summarized in Table 3. Control, $n=50 ; 100 \mathrm{ppm}$, $n=10 ; 200 \mathrm{ppm}, n=9 ; 300 \mathrm{ppm}, n=14 ; 360 \mathrm{ppm}, n=8$. *Significantly different from air-exposed $(p<0.05)$. 

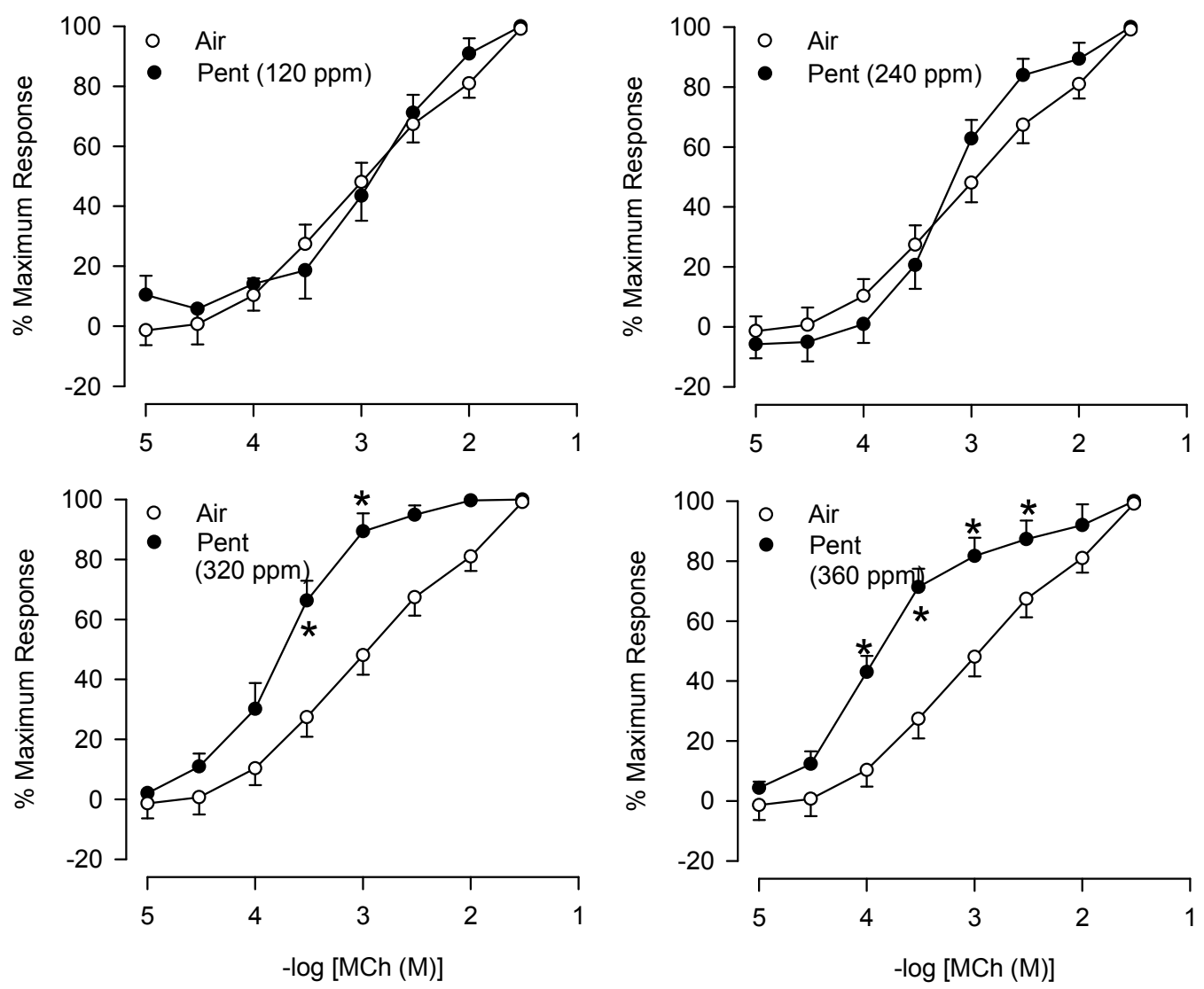

FIGURE 7. Effect of 2,3-pentanedione inhalation on reactivity IPT to IL MCh. MCh EC50 values and maximum responses are summarized in Table 3. Control, $n=29 ; 120 \mathrm{ppm}, n=7 ; 240 \mathrm{ppm}, n=6 ; 320 \mathrm{ppm}, n=5 ; 360 \mathrm{ppm}, n=8 .{ }^{*} \mathrm{EC} 50 \mathrm{~s}$ were significantly different from air-exposed $(p<0.05)$. 
TABLE 3.

Reactivity of rat IPT to MCh after inhalation exposure to diacetyl and 2,3-pentanedione

\begin{tabular}{|c|c|c|c|c|c|c|c|}
\hline Diacetyl $^{a}$ & EC50 (95\% Cl)(M) & $\frac{\text { EC50 Air }}{\text { EC50 Exposed }}$ & $\begin{array}{l}\text { Maximum } \\
\text { Response }^{b}\end{array}$ & $\begin{array}{l}\text { 2,3- } \\
\text { Pentanedione }\end{array}$ & EC50 $(95 \%$ Cl)(M) & $\frac{\text { EC50 Air }}{\text { EC50 Exposed }}$ & $\begin{array}{l}\text { Maximum } \\
\text { Response }^{b}\end{array}$ \\
\hline $0(\text { Air })^{c}$ & $1.0(0.2-0.5) \times 10^{-3}$ & - & $1.02 \pm 0.18$ & $0(\text { Air })^{c}$ & $1.3(0.7-2.2) \times 10^{-3}$ & - & $0.94 \pm 0.31$ \\
\hline 200 & $1.3(0.2-10.6) \times 10^{-3}$ & 0.77 & $0.57 \pm 0.14$ & 240 & $4.0(2.0-8.0) \times 10^{-4}$ & 3.25 & $0.21 \pm 0.07$ \\
\hline
\end{tabular}

${ }^{a}$ ppm during a 6-h exposure.

${ }^{\mathrm{b}} \mathrm{cm} \mathrm{H}_{2} \mathrm{O}$

${ }^{\circ}$ Control

*Significantly different from air-exposed.

$\mathrm{Cl}$, confidence interval 


\subsubsection{Effects of diacetyl and 2,3-pentanedione in the IPT}

In these experiments the flavorings were administered in vitro to investigate their direct pharmacological effects on the trachea and to determine whether responses to the flavorings could involve indirectly the epithelium. An earlier investigation (Fedan et al., 2006) in guinea-pig IPT indicated that, over its effective concentration range, the initial responses to the lowest effective concentrations of IL diacetyl consisted of contractions. At concentrations greater than $3 \mathrm{mM}(10 \mathrm{mM}$ and $30 \mathrm{mM})$, diacetyl applied to the IL bath resulted in contraction followed by net relaxation. Here we extended those findings to the rat and compared them to those obtained with 2,3-pentanedione. As demonstrated in Figure 8A, IL-applied 2,3-pentanedione (1 mM) elicited small contractions. Relaxation responses were elicited subsequently during the response to $3 \mathrm{mM}$ and higher 2,3pentanedione concentrations. Similar relaxation responses were evoked when diacetyl and 2,3-pentanedione were added to the $\mathrm{IL}$ or EL baths in the intact trachea (Figure 8B,C). The relaxant responses to $\mathrm{EL}$ diacetyl and 2,3-pentanedione were not significantly different (Figure 8D), although 2,3-pentanedione appeared to more fully relax the tracheas.

In the absence of the epithelium, both flavorings applied to the IL bath also resulted in relaxation responses that were nearly identical to those elicited after they were applied to the mucosal side of intact trachea (Figure 9A and 9B). A difference between the relaxant effects of the two flavorings added intraluminally to denuded tracheas was not evident (Figure 9C). Overall, these results suggest that responses to diacetyl and 2,3-pentanedione involve a direct effect on the airway smooth muscle and are independent of and are not mediated by epithelium. 

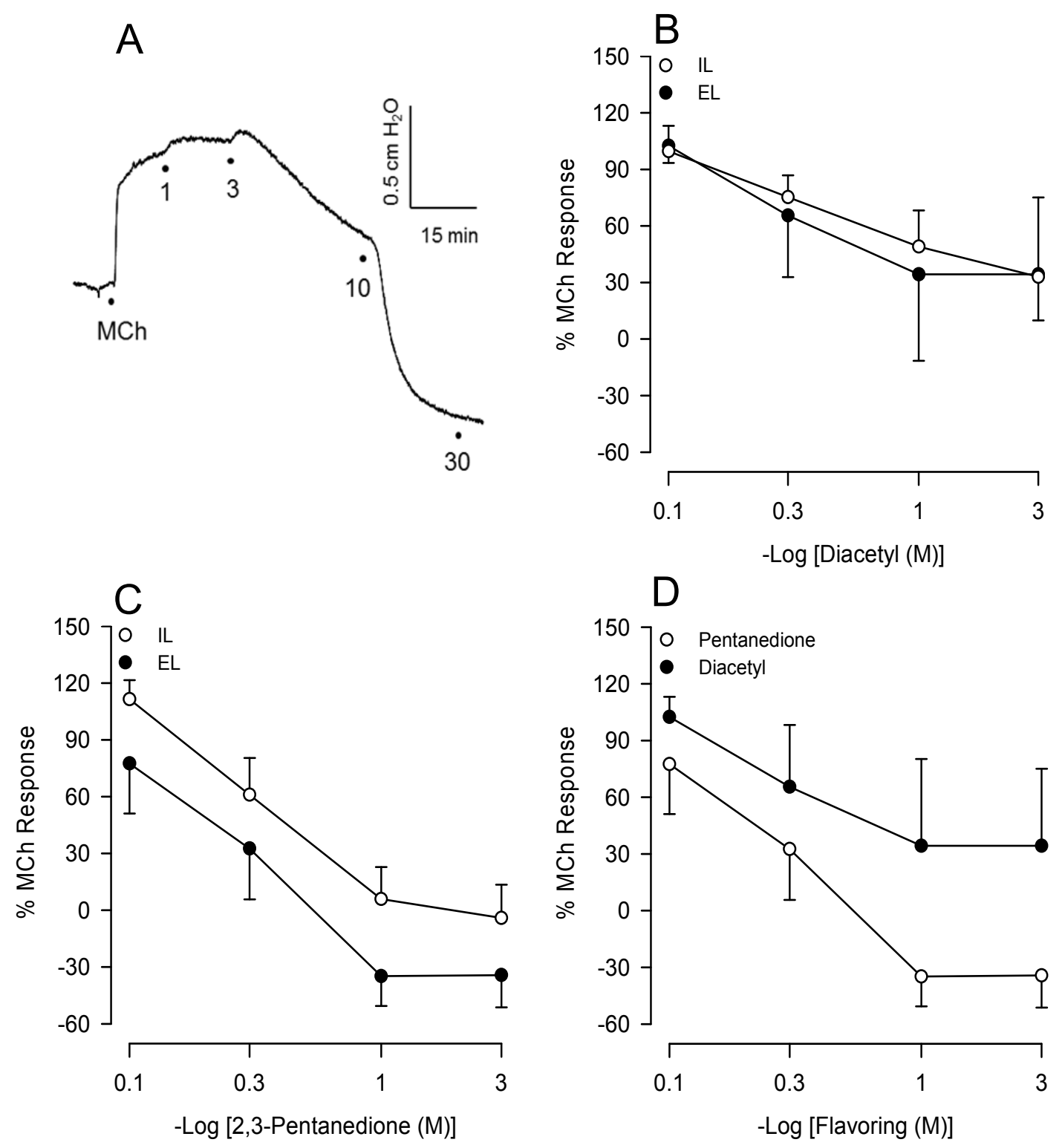

FIGURE 8. Effects of flavorings in MCh-contracted IPT. A, Representative responses to $1,3,10$ and 30 $\mathrm{mM}$ 2,3-pentanedione added intraluminally (at dots). Note that relaxation followed contraction at $3 \mathrm{mM}$ 2,3-pentanedione. The rat perfused trachea develops spontaneous tone; therefore, the relaxations to both flavorings reduced the level of $\triangle P$ below baseline before $M C h$ addition. Contraction and relaxation responses were also elicited after diacetyl administration and resembled those depicted in panel $\mathrm{A}$. The results following IL and EL diacetyl additions are summarized in panel B. Diacetyl administered to either EL or IL bath resulted in similar relaxation. IL, $n=8 ; E L, n=8$. The results following IL and EL 2,3pentanedione additions are summarized in panel C. D, Comparison of relaxant responses to EL diacetyl and 2,3-pentanedione. 

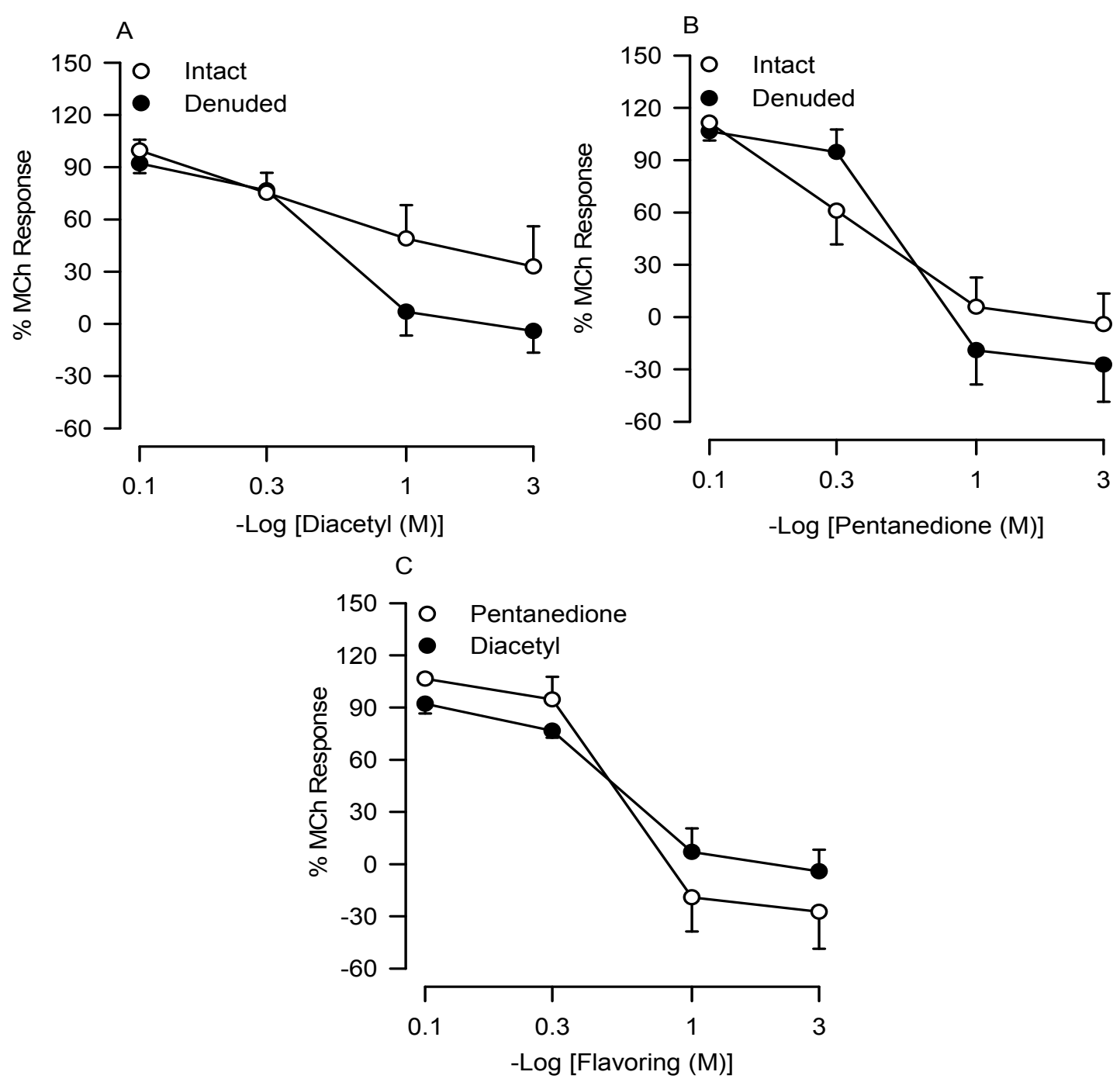

FIGURE 9. Responses of epithelium-denuded IPT to flavorings. A, Diacetyl applied to the IL bath elicited responses that were similar to what had been observed in intact trachea (see 9A). B, responses to IL 2,3-pentanedione in the absence of the epithelium were not different from responses to IL 2,3-pentanedione in intact trachea (see panel 9A). C, Comparison of responses to IL diacetyl and 2,3-pentanedione. Diacetyl, $n=5 ;$ 2,3-pentanedione, $n=6$. 
2.4.4. Effects of mixed inhalation exposure to diacetyl, acetic acid and acetoin on reactivity to $\mathrm{MCh}$ in vivo

While diacetyl has been implicated as a critical etiologic agent in the development of workplace butter flavoring-induced lung toxicity, workers are exposed to a multitude of inhaled volatile chemicals in addition to diacetyl. In particular, acetic acid and acetoin are abundant in butter flavoring vapor mixtures and also were found along with diacetyl in the less complex exposure in a flavoring manufacturing workplace with affected workers (van Rooy et al., 2007, 2009). It is critical to understand whether acetic acid and acetoin, as frequent adjunct agents, might mitigate or exacerbate the effects of diacetyl inhaled concomitantly. Therefore, the effects of a 6-hr mixed inhalation exposure to these three agents were investigated. First, the effects of the agents by themselves were evaluated; second, the effects of the mixtures were examined using the flavorings in "low" (Three Low: 167 ppm diacetyl + 100 ppm acetoin + 18 ppm acetic acid) and "high" (Three High: 250 ppm diacetyl +150 ppm acetoin +27 ppm acetic acid) concentrations. The absolute and relative concentrations of the three flavorings are relevant to their relative concentrations in butter flavoring vapors and were measured in the workplace (Hubbs et al., 2002). Because the 250 ppm diacetyl exposure was just below the lowest acute exposure reported to damage intrapulmonary airway epithelium (294.6 ppm) and above the lowest acute exposure reported to damage tracheal epithelium (224 ppm), while the 167 ppm level was below the lowest acute diacetyl exposure reported to damage tracheal epithelium, the concentration of diacetyl chosen for this experiment was one that would permit potentiating and inhibiting effects of acetoin and acetic acid to be realized were they to occur. Figure 10 illustrates that in this series of experiments, inhalation of only diacetyl resulted in a decrease in $\mathrm{R}_{\mathrm{L}}$; the other flavorings were without marked effect. Neither the low or high concentration flavoring mixtures altered $R_{L}$. The flavorings 
present in high concentration in the mixture increased $\mathrm{C}_{\mathrm{dyn}}$.

In this series of experiments, diacetyl (250 ppm) decreased the $R_{L}$ response to 10 $\mathrm{mg} / \mathrm{ml} \mathrm{MCh} \mathrm{(Figure} \mathrm{11);} \mathrm{in} \mathrm{the} \mathrm{earlier} \mathrm{series} \mathrm{of} \mathrm{experiments} \mathrm{(see} \mathrm{above)} \mathrm{this} \mathrm{effect} \mathrm{had}$ not been observed except at a higher concentration, i.e., $360 \mathrm{ppm}$. While the reason for the reduction at $250 \mathrm{ppm}$ here but not at $300 \mathrm{ppm}$ earlier is not understood, these findings buttress the observation that acute diacetyl inhalation reduces, rather than increases, airway reactivity. Inhalation of acetoin (150 ppm) exerted no marked effect on reactivity to MCh (Figure 11). This is a novel observation, as no prior study of acetoin's effects in the airways under similar experimental conditions was available. 

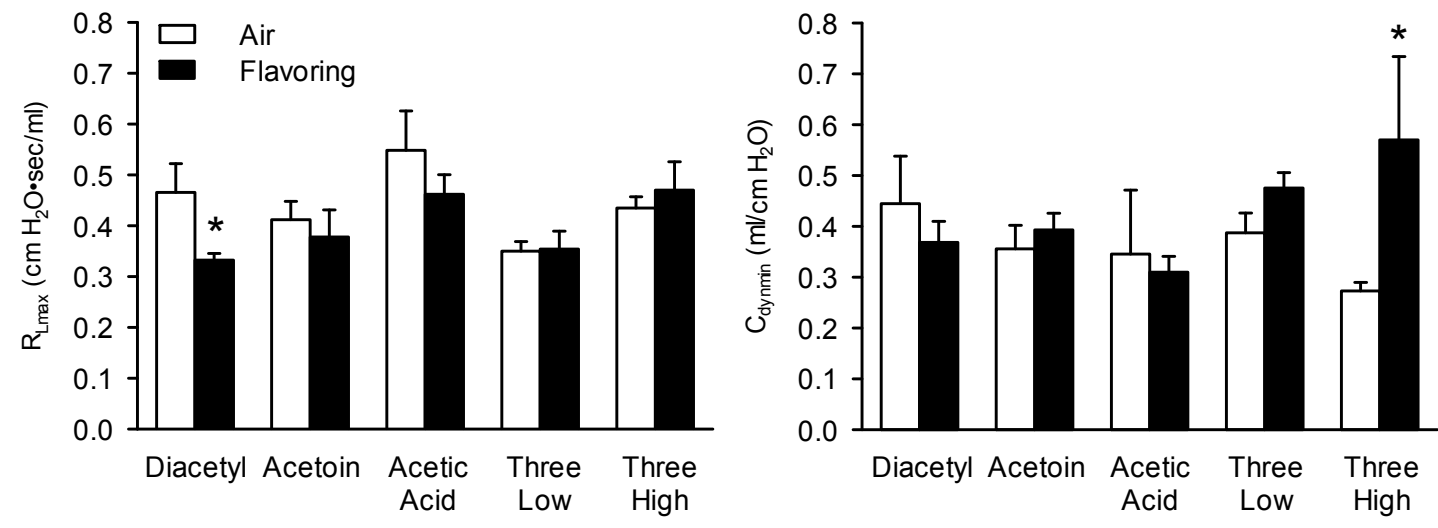

FIGURE 10. Basal values of $R_{L}$ (left panel) and $C_{\text {dyn }}$ (right panel) after inhalation exposure of rats to air, diacetyl (250 ppm), acetoin (150 ppm) and acetic acid (27 ppm) alone and in combinations involving the three flavorings present in low (Three Low) or high (Three High) concentrations. The Three Low concentrations were: 167 ppm diacetyl +100 ppm acetoin +18 ppm acetic acid. The Three High concentrations were: $250 \mathrm{ppm}$ diacetyl $+150 \mathrm{ppm}$ acetoin $+27 \mathrm{ppm}$ acetic acid. Air control animals from the same shipment were run in parallel with the flavoringexposed animals. The $n$ values for the exposed animals and air controls, respectively, were: diacetyl (250 ppm) alone, 6 and 6; acetoin (150 ppm) alone, 7 and 7; acetic acid (27 ppm) alone, 3 and 7; Three Low, 7 and 7; and Three High, 6 and 6. Diacetyl $\left(250 \mathrm{ppm}\right.$ ) decreased $\mathrm{R}_{\mathrm{L}}$; Three High increased $\mathrm{C}_{\mathrm{dyn}}$. ${ }^{*}$ Significantly different from air-exposed $(p<0.05)$. 

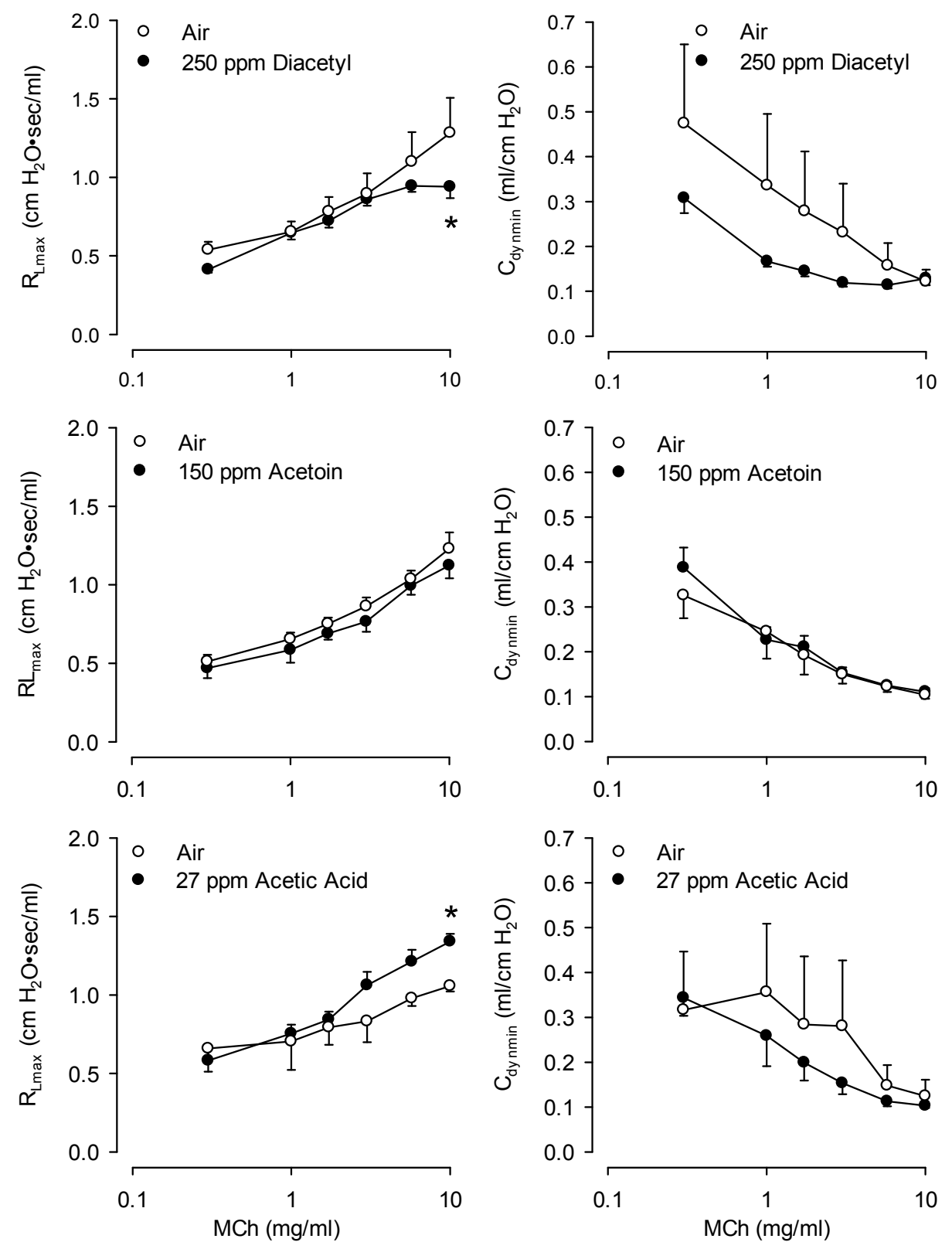

FIGURE 11. Effect of inhalation of diacetyl (250 ppm), acetoin (150 ppm) and acetic acid (27 ppm) $18 \mathrm{hr}$ following 6-hr exposure of rats on reactivity to inhaled MCh. Left panels: diacetyl decreased $R_{L}$ responses; acetic acid increased $R_{L}$ responses. *Significantly different from air-exposed $(p<0.05)$. 
Inhalation of $27 \mathrm{ppm}$ acetic acid produced airway hyperreactivity to MCh (Figure 11). Acetic acid effects in the airways were reported only in the context of the use of the agent as a cough-inducing stimulus (Shimizu et al., 1997) or to examine its acute effects (Ernstgard et al., 2006; Stanek et al., 2001). The development of airway hyperreactivity to MCh after extended acetic acid inhalation appears to be a new finding.

Having characterized the effects of each flavoring, the effects of mixed exposures were investigated. Figure 12 illustrates that the low concentration mixture exerted no marked effect on $R_{L}$ responses to $M C h$, but that $C_{d y n}$ responses were increased. The high concentration mixture resulted in hyporeactivity to $M C h\left(R_{L}\right)$, as observed with diacetyl inhalation alone (see above), and an increase in $C_{d y n}$. Thus, the hyperreactivity observed after acetic acid exposure alone was nullified when diacetyl was included in the mixed exposure. 

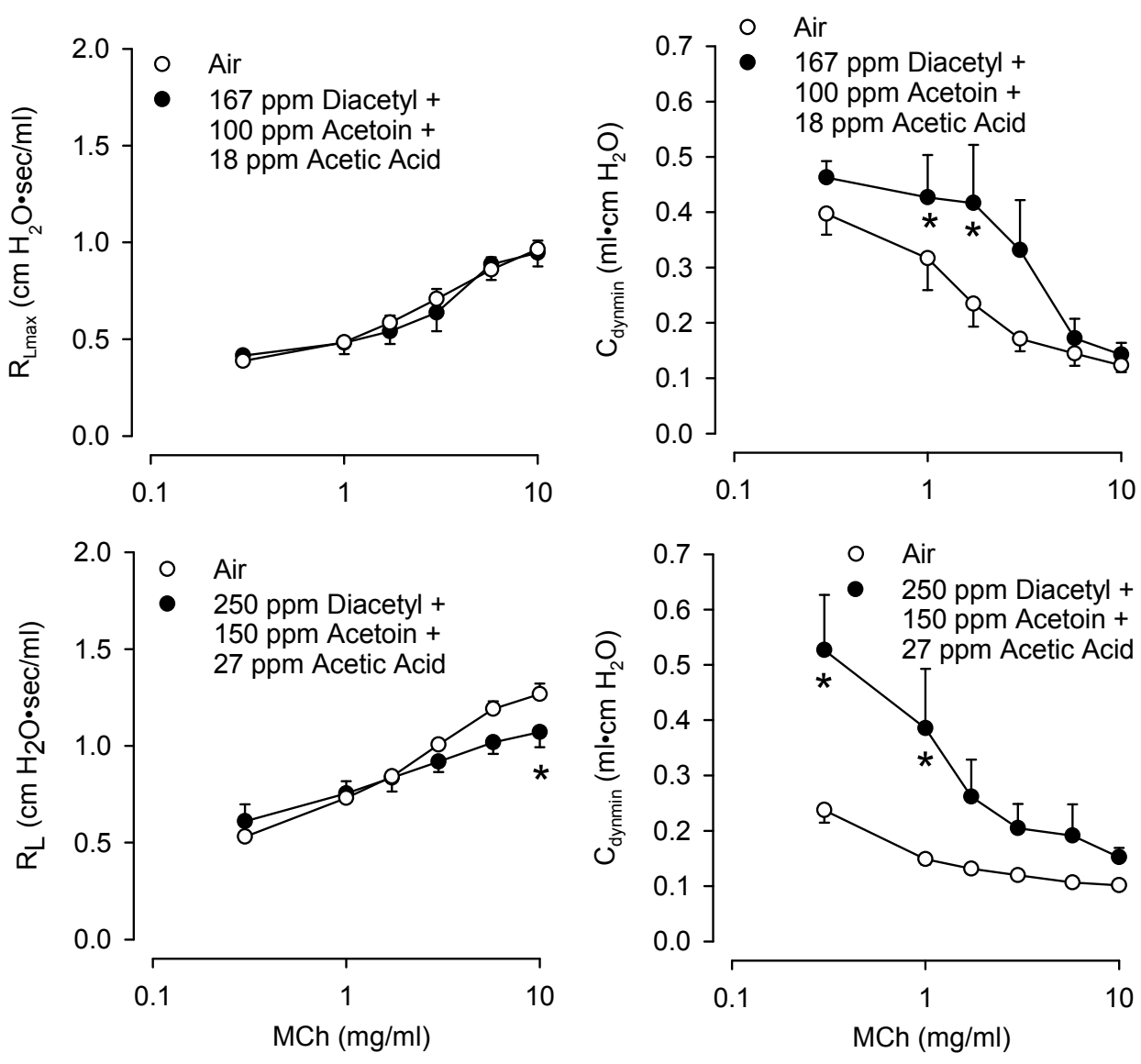

FIGURE 12. Effect of Three Low (top two panels) and Three High (bottom two panels) mixed exposures $18 \mathrm{hr}$ following a 6-hr exposure of rats on reactivity to inhaled $M C h$. The Three High exposure reduced $R_{L}$ responses to MCh; both the Three Low and the Three High exposures increased $C_{d y n}$. The $n$ values for the exposed animals and air controls, respectively, were: Three Low, 6 and 6; Three High, 7 and 7. *Significantly different from air-exposed. 


\subsection{Discussion}

In this study, the effects of acute diacetyl and 2,3-pentanedione inhalation were investigated and compared for their effects on pulmonary function and airway reactivity in vivo and in vitro, the pharmacological effects of both flavorings on airways in vitro, and the consequences in vivo of inhaling a mixture of diacetyl, acetoin and acetic acid - three common and abundant components of butter flavorings.

Despite demonstration of substantial epithelial damage in upper airways of the rat observed in previous investigations (Hubbs et al., 2008, 2012), basal $R_{L}$ and $C_{d y n}$ were unaffected by inhalation of diacetyl or 2,3-pentanedione. This contrasts with intratracheally-instilled diacetyl, which resulted in significantly increased airway $R_{L}$ and decreased $C_{d y n}$ in rats 7 days after exposure (Palmer et al., 2011). Even more surprisingly, acute inhalation of the flavorings did not lead to airway hyperreactivity. Inhaled diacetyl reduced reactivity $\left(R_{\mathrm{L}}\right)$ to $\mathrm{MCh}$ at one exposure concentration, and 2,3pentanedione decreased responsiveness at three exposure concentrations. No marked effects on $\mathrm{C}_{\mathrm{dyn}}$ responses to $\mathrm{MCh}$ were produced by either flavoring, with the exception that 240 ppm 2,3-pentanedione significantly increased $C_{\text {dyn }}$ responses to MCh. A clear, graded dose-dependency in the effects of inhaled diacetyl or 2,3-pentanedione on $R_{L}$ was not apparent at the inhalation doses used in this investigation. However, it can be estimated that the threshold for diacetyl, in terms of reactivity to inhaled MCh, is greater than $300 \mathrm{ppm}$ and less than $360 \mathrm{ppm}$ (Figure 3). On the other hand, the threshold for 2,3-pentanedione would appear to be less than 120 ppm (Figure 4). Thus, 2,3pentanedione evoked alterations in reactivity to inhaled MCh at lower inhalation exposure doses than in the case of diacetyl. The fact that the agents decreased reactivity to MCh suggests they exerted toxic effects in lower airways.

The reduced reactivity to MCh one day after inhaling diacetyl or 2,3-pentanedione 
is reminiscent of the reduced sensory irritant response to a second diacetyl exposure that was noted in mice that had inhaled $790 \mathrm{ppm}$ or $1154 \mathrm{ppm}$ diacetyl for two hr the previous day (Larsen et al., 2009). Since MCh directly affects airway smooth muscle, our data suggest that smooth muscle reactivity of rat airways is reduced after a high level acute exposures to either diacetyl or 2,3-pentanedione. Together with the previous study of the acute airway effects of diacetyl inhalation in mice (Larsen et al., 2009), these findings suggest that airway functional changes are not limited to the epithelium of $\alpha$-diketoneexposed airways and that exposure also leads to reduced smooth muscle reactivity.

A reductionist approach was used to investigate whether flavoring inhalation and resultant epithelial damage would affect reactivity to MCh in vitro to a degree that mimics partly or fully the effects of epithelium removal. In tracheas that were removed from flavoring-exposed animals and perfused in vitro, treatment with diacetyl resulted in increases in reactivity that were quite modest compared to the change observed after epithelium removal (Fedan and Frazer, 1992). The inhalation dose at which diacetyl's effect on reactivity to MCh in the IPT occurred is judged to be greater than $200 \mathrm{ppm}$ and less than $300 \mathrm{ppm}$. This is rough concordance with the doses that altered reactivity to inhaled MCh. In contrast, inhalation of 2,3-pentanedione led to larger increases in in vitro reactivity to IL MCh at concentrations of 2,3-pentanedione greater than $240 \mathrm{ppm}$ and less than 320 ppm. 2,3-Pentanedione, therefore, was more potent at decreasing reactivity to inhaled MCh than at increasing reactivity to MCh in vitro.

Diacetyl or 2,3-pentanedione inhalation by rats (>150 ppm; 6 hr/day, 5 days/week for 12 exposures over 2 weeks) resulted in increases in lung resistance and decreases in compliance (diacetyl) (Morgan et al., 2012a). Those findings are comparable to functional changes reported one week after diacetyl aspiration in the rat (Palmer et al., 2011). These changes corresponded with the development of airway fibrosis and 
epithelial remodeling. Early measurements, such as those made here as well as reactivity to $\mathrm{MCh}$, were not reported in those studies. On the other hand, in the present investigation, $18 \mathrm{hr}$ after acute exposure, none of the agents examined affected $R_{L}$ and $\mathrm{C}_{\text {dyn. }}$. This is consistent with a role for airway fibrosis and/or epithelial remodeling in the development of clinical bronchiolitis obliterans and increased $R_{L}$ and decreased $C_{d y n}$ after sub-chronic exposures, which are not present after acute exposure to diacetyl or 2,3pentanedione.

It was postulated that the totality of flavoring's effects on the airways would include more than epithelial damage and involve pharmacological effects in the airway wall. Diacetyl is believed to diffuse rapidly across the epithelium (Morris and Hubbs, 2009; Morris, 2012). An earlier investigation (Fedan et al., 2006) demonstrated that diacetyl applied to the mucosal surface of guinea-pig IPT preparations elicited contractions in lower concentrations, relaxation in higher concentrations, increased reactivity to mucosally-applied $\mathrm{MCh}$, and reduced transepithelial potential difference and resistance. In the rat IPT preparation both diacetyl and 2,3-pentanedione elicited transient contraction and relaxation in the absence and presence of the epithelium, irrespective of the route of application, i.e., IL or EL. Thus, the pharmacologic profile of diacetyl is similar in the two species (2,3-pentanedione was not investigated in the guinea pig). During inhalation the flavorings may have crossed epithelium and induced bronchodilation that ameliorated bronchoconstriction in response to $\mathrm{MCh}$. It is likely that epithelial integrity began to be compromised from the onset of exposure, worsening during the 6-hr period and facilitating progressive and greater access of the flavoring to the smooth muscle. These two factors may have led to a reduction in reactivity to MCh. This notion is concordant with the lack of effect of flavorings on basal pulmonary function in our experiments. 
Preparations were relaxed by flavoring concentrations that have been calculated to exist in the airway wall of exposed humans (Morris and Hubbs, 2009; Morris, 2012). It is unknown whether the relaxation reflects a non-specific toxic action or a specific pharmacological effect, and whether or not it is reversible. The latter possibility is under investigation in our laboratory, but if it is determined to be irreversible, one can posit that a long-lasting effect on airway smooth muscle abrogates the ability of the smooth muscle to contract in response to inhaled MCh, regardless of the degree of epithelium integrity. Such an effect would have to be powerful enough to offset the gain in reactivity that would otherwise occur due to epithelial damage alone.

Current evidence implicates diacetyl as being a critical chemical in toxicity following butter flavoring inhalation, and the pulmonary toxicity of diacetyl has by now been clearly demonstrated (Hubbs et al., 2002, 2008, 2010; Morris and Hubbs, 2009; Morgan et al., 2008, 2012b; Palmer et al., 2011). One or more of the other flavorings in the mixture, however, could contribute to the overall toxicity of butter flavoring. An examination of the pulmonary toxicity of all the chemicals in flavoring mixtures, alone and in combination with diacetyl, has not thus far been accomplished. Many flavorings are less abundant than diacetyl (Boylstein et al., 2006) but they may be more potent. However, because they frequently accompany diacetyl exposures in the workplace and are plentiful, acetoin and acetic acid were given initial attention using workplace-relevant inhalation exposures. It was first observed that $150 \mathrm{ppm}$ acetoin was without effect on pulmonary function and airway reactivity to $M C h\left(R_{L}\right)$. On the other hand, acetic acid, though without effect on $R_{L}$ and $C_{d y n}$, increased reactivity to inhaled $M C h\left(R_{L}\right)$. It was a surprising finding that the "diacetyl effect" dominated the reactivity change of the high dose mixed exposure. The explanation for this flavoring interaction is not known at present. 
The flavoring effects described in this study reflect cytotoxicity in the airway wall, probably to both epithelium and smooth muscle, at the least. Diacetyl and similar $\alpha$ diketones are highly selective for the modification of arginyl residues in proteins (Borders and Riordan, 1975; Epperly and Dekker, 1989; Mueller et al., 1995) and enzymes responsible for protecting cells from oxidative damage (Borders et al., 1985). Injury to the epithelium may involve covalent bonding of a-diketones with arginine-containing proteins, altering protein ternary structure and function (Mathews et al., 2010). Apoptosis may result from DNA modification resulting from diacetyl covalently binding to guanyl nucleotides (More et al., 2012b). Activated caspase 3 reflects apoptosis as seen in main stem bronchus epithelium (Gardiner et al., 2009) and in olfactory nerve bundles (Hubbs et al., 2012) indicates that apoptosis also occurs in vivo. a-Diketones may disrupt normal electron transfer processes and generate reactive oxygen species (Kovacic and Cooksy, 2010), which are well known to result in cell injury.

Dicarbonyl/xylulose reductase (DCXR), which metabolizes diacetyl and 2,3pentanedione in rat nasal and tracheal tissues (Gardiner et al., 2009; Hubbs et al., 2012), may also augment cytotoxicity and death in cells that have DCXR activity (Hubbs et al., 2012; Matsunaga et al., 2008). Thus, a multitude of changes in the airways may coalesce and contribute to the development of airway hyporeactivity to MCh after a-diketone inhalation. 


\subsection{Conclusions}

Collectively, our findings indicate that a 6-hr inhalation of diacetyl or 2,3pentanedione leads to airway hyporeactivity in vivo and airway hyperreactivity in vitro. The results suggest that 2,3-pentanedione elicits greater effects than diacetyl in the airways in vivo and in vitro. The a-diketones have complex pharmacological characteristics, being able to produce mild contraction and profound relaxation in concentrations that have been calculated to exist in the airway wall of humans during inhalation exposures. In mixed inhalation exposures neither acetoin nor acetic acid appreciably influenced the effects of diacetyl itself.

\section{Acknowledgements}

Mention of brand name does not constitute product endorsement. The findings and conclusions in this report are those of the authors and do not necessarily represent the views of the National Institute for Occupational Safety and Health.

\section{Conflict of interest statement}

The authors declare no conflicts of interest. 


\subsection{References}

Aarhus, L. L., Rimele, T. J., and Vanhoutte, P. M. 1984. Removal of epithelium causes bronchial supersensitivity to acetylcholine and 5-hydroxytryptamine. Fed. Proc. 43: 995.

Borders, C. L., Jr., and Riordan, J. F. 1975. An essential arginyl residue at the nucleotide binding site of creatine kinase. Biochemistry 14: 4699-4704.

Borders, C. L., Jr., Saunders, J. E., Blech, D. M., and Fridovich, I. 1985. Essentiality of the active-site arginine residue for the normal catalytic activity of $\mathrm{Cu}, \mathrm{Zn}$ superoxide dismutase. Biochem. J. 230: 771-776.

Boylstein, R., Piacitelli, C., Grote, A., Kanwal, R., Kullman, G., and Kreiss, K. 2006. Diacetyl emissions and airborne dust from butter flavorings used in microwave popcorn production. J. Occup. Environ. Hyg. 3: 530-535.

Cavalcanti Zdo, R., Albuquerque Filho, A. P., Pereira, C. A., and Coletta, E. N. 2012. Bronchiolitis associated with exposure to artificial butter flavoring in workers at a cookie factory in Brazil. J. Bras. Pneumol. 38: 395-399.

Day, G., LeBouf, R., Grote, A., Pendergrass, S., Cummings, K., Kreiss, K., and Kullman, G. 2011. Identification and measurement of diacetyl substitutes in dry bakery mix production. J. Occup. Environ. Hyg. 8: 93-103.

Department of Health and Human Services. Centers for Disease Control and Prevention. National Institute for Occupational Safety and Health. 2004. NIOSH Health Hazard Evaluation Report. HETA \# 2-3-0112-2949. ConAgra Snack Foods. Marion, Ohio.

Egilman, D. S. and Schilling, J. H. 2012. Bronchiolitis obliterans and consumer exposure to butter-flavored microwave popcorn: a case series. Int. J. Occup. Environ. Health 18: $29-42$. 
Epperly, B. R., and Dekker, E. E. 1989. Inactivation of Escherichia coli L-threonine dehydrogenase by 2,3-butanedione. Evidence for a catalytically essential arginine residue. J. Biol. Chem. 264: 18296-18301.

Ernstgard, L., Iregren, A., Sjogren, B., and Johanson, G. 2006. Acute effects of exposure to vapours of acetic acid in humans. Toxicol. Lett. 165: 22-30.

Farmer, S. G., Fedan, J. S., Hay, D. W., and Raeburn, D. 1986. The effects of epithelium removal on the sensitivity of guinea-pig isolated trachealis to bronchodilator drugs. $\mathrm{Br}$. J. Pharmacol. 89: 407-414.

Farmer, S. G., Hay, D. W., Raeburn, D., and Fedan, J. S. 1987. Relaxation of guinea-pig tracheal smooth muscle to arachidonate is converted to contraction following epithelium removal. Br. J. Pharmacol. 92: 231-236.

Fedan, J. S., Dowdy, J. A., Fedan, K. B., and Hubbs, A. F. 2006. Popcorn worker's lung: In vitro exposure to diacetyl, an ingredient in microwave popcorn butter flavoring, increases reactivity to methacholine. Toxicol. Appl. Pharmacol. 215: 17-22.

Fedan, J. S., and Frazer, D. G. 1992. Influence of epithelium on the reactivity of guinea pig isolated, perfused trachea to bronchoactive drugs. J. Pharmacol. Exp. Ther. 262: 741-750.

Fedan, J. S., Millecchia, L .L., Johnston, R. A., Rengasamy, A., Hubbs, A., Dey, R. D., Yuan, L. X., Watson, D., Goldsmith, W. T., Reynolds, J. S., Orsini, L., Dortch-Carnes, J., Cutler, D., and Frazer, D. G. 2000. Effect of ozone treatment on airway reactivity and epithelium-derived relaxing factor in guinea pigs. J. Pharmacol. Exp. Ther. 293: 724-734.

Gardiner, D. W., Goldsmith, W., Morris, J. B., Battelli, L. A., Friend, S., Castranova, V., and Hubbs, A. 2009. Adhesion molecule expression in diacetyl exposed rat lungs. Toxicol. Sci. 108: 432-433. 
Goldsmith, W. T., McKinney, W., Jackson, M., Law, B., Bledsoe, T., Siegel, P., Cumpston, J., and Frazer, D. 2011. A computer-controlled whole-body inhalation exposure system for the oil dispersant Corexit EC9500A. J. Toxicol. Env. Heal. A 74: 1368-1380.

Harber, P., Saechao, K., and Boomus, C. 2006. Diacetyl-induced lung disease. Toxicol. Rev. 25: 261-272.

Hay, D. W., Farmer, S. G., Raeburn, D., Robinson, V. A., Fleming, W. W., and Fedan, J. S. 1986. Airway epithelium modulates the reactivity of guinea-pig respiratory smooth muscle. Eur. J. Pharmacol. 129: 11-8.

Hubbs, A. F., Battelli, L. A., Goldsmith, W. T., Porter, D. W., Frazer, D., Friend, S., Schwegler-Berry, D., Mercer, R. R., Reynolds, J. S., Grote, A., Castranova, V., Kullman, G., Fedan, J. S., Dowdy, J., and Jones, W. G. 2002. Necrosis of nasal and airway epithelium in rats inhaling vapors of artificial butter flavoring. Toxicol. Appl. Pharmacol. 185: 128-135.

Hubbs, A. F., Cumpston, A. M., Goldsmith, W. T., Battelli, L. A., Kashon, M. L., Jackson, M. C., Frazer, D. G., Fedan, J. S., Goravanahally, M. P., Castranova, V., Kreiss, K., Willard, P. A., Friend, S., Schwegler-Berry, D., Fluharty, K. L., and Sriram, K. 2012. Respiratory and olfactory cytotoxicity of inhaled 2,3-pentanedione in Sprague-Dawley rats. Am. J. Pathol. 181: 829-844.

Hubbs, A. F., Goldsmith, W. T., Kashon, M. L., Frazer, D., Mercer, R. R., Battelli, L. A., Kullman, G. J., Schwegler-Berry, D., Friend, S., and Castranova, V. 2008. Respiratory toxicologic pathology of inhaled diacetyl in Sprague-Dawley rats. Toxicol. Pathol. 36: $330-344$.

Hubbs, A. F., Moseley, A. E., Goldsmith, W. T., Jackson, M. C., Kashon, M. L., Battelli, L. A., Schwegler-Berry, D., Goravanahally, M. P., Frazer, D., Fedan, J. S., Kreiss, K., 
and Castranova, V. 2010. Airway epithelial toxicity of the flavoring agent, 2,3pentanedione. Toxicol. Sci. 114(Suppl): 319.

Institute for Laboratory Animal Research. 2011. Guide for the Care and Use of Laboratory Animals. 8th ed. Washington, D.C.: The National Academies Press.

King, T. E., Jr. 1989. Bronchiolitis obliterans. Lung 167: 69-93.

Kovacic, P., and Cooksy, A. L. 2010. Electron transfer as a potential cause of diacetyl toxicity in popcorn lung disease. Rev. Environ. Contam. Toxicol. 204: 133-148.

Kreiss, K., Gomaa, A., Kullman, G., Fedan, K., Simoes, E. J., and Enright, P. L. 2002. Clinical bronchiolitis obliterans in workers at a microwave-popcorn plant. N. Engl. J. Med. 347: 330-338.

Larsen, S. T., Alarie, Y., Hammer, M., and Nielsen, G. D. 2009. Acute airway effects of diacetyl in mice. Inhal. Toxicol. 21: 1123-1128.

Lockey, J. E., Hilbert, T. J., Levin, L. P., Ryan, P. H., White, K. L., Borton, E. K., Rice, C. H., McKay, R. T., and LeMasters, G. K. 2009. Airway obstruction related to diacetyl exposure at microwave popcorn production facilities. Eur. Respir. J. 34: 63-71.

Martyny, J. W., Van Dyke, M. V., Arbuckle, S., Towle, M., and Rose, C. S. 2008. Diacetyl exposures in the flavor manufacturing industry. J. Occup. Environ. Hyg. 5: 679-688.

Mathews, J. M., Watson, S. L., Snyder, R. W., Burgess, J. P, and Morgan, D. L. 2010. Reaction of the butter flavorant diacetyl (2,3-butanedione) with $\mathrm{N}$ - $\alpha$-acetylarginine: $\mathrm{A}$ model for epitope formation with pulmonary proteins in the etiology of obliterative bronchiolitis. J. Agric. Food Chem. 58: 12761-12768.

Matsunaga, T., Kamiya, T., Sumi, D., Kumagai, Y., Kalyanaraman, B., and Hara, A. 2008. L-Xylulose reductase is involved in 9,10-phenanthrenequinone-induced apoptosis in human T lymphoma cells. Free Radic. Biol. Med. 44: 1191-1202. 
McKinney, W., and Frazer, D. 2008. Computer-controlled ozone inhalation exposure system. Inhal. Toxicol. 20: 43-48.

More, S. S., Raza, A., and Vince, R. 2012b. The butter flavorant, diacetyl, forms a covalent adduct with 2-deoxyguanosine, uncoils DNA, and leads to cell death. J. Agric. Food. Chem. 60: 3311-3317.

More, S. S., Vartak, A. P., and Vince, R. 2012a. The butter flavorant, diacetyl, exacerbates $\beta$-amyloid cytotoxicity. Chem. Res. Toxicol. 25: 2083-2091.

Morgan, D. L., Flake, G. P., Kirby, P. J., and Palmer, S. M. 2008. Respiratory toxicity of diacetyl in C57BL/6 mice. Toxicol. Sci. 103: 169-180.

Morgan, D. L, Jokinen, M. P., Johnson, C. L., Gwinn, W. M., Price, H. C., and Flake, G. P. 2012a. Bronchial fibrosis in rats exposed to 2,3-butanedione and 2 3-pentanedione vapors. Toxicol. Sci. 126: 186.

Morgan, D. L., Jokinen, M. P., Price, H. C., Gwinn, W. M, Palmer, S. M., and Flake, G. P. 2012b. Bronchial and bronchiolar fibrosis in rats exposed to 2,3-pentanedione vapors: implications for bronchiolitis obliterans in humans. Toxicol. Pathol. 40: 448-465.

Morris, J. B. 2012. Biologically-based modeling insights in inhaled vapor absorption and dosimetry. Pharmacol. Ther. 136: 401-413.

Morris, J. B., and Hubbs, A. F. 2009. Inhalation dosimetry of diacetyl and butyric acid, two components of butter flavoring vapors. Toxicol. Sci. 108: 173-183.

Mueller, M. J., Samuelsson, B., and Haeggstrom, J. Z. 1995. Chemical modification of leukotriene A4 hydrolase. Indications for essential tyrosyl and arginyl residues at the active site. Biochemistry 34: 3536-3543.

Palmer, S. M., Flake, G. P., Kelly, F. L., Zhang, H. L., Nugent, J. L., Kirby, P. J., Foley, J. F., Gwinn, W. M., and Morgan, D. L. 2011. Severe airway epithelial injury, aberrant 
repair and bronchiolitis obliterans develops after diacetyl instillation in rats. PLoS One 6:e17644.

Poole, J. A., Wyatt, T. A., Oldenburg, P. J., Elliott, M. K., West, W. W., Sisson, J. H., Von Essen, S. G., and Romberger, D. J. 2009. Intranasal organic dust exposure-induced airway adaptation response marked by persistent lung inflammation and pathology in mice. Am. J. Physiol. Lung-C. 296: L1085-L1095.

Sahakian, N., Kullman, G., Lynch, D., and Kreiss, K. 2008. Asthma arising in flavoringexposed food production workers. Int. J. Occup. Med. Environ. Health 21: 173-177.

Savov, J. D., Whitehead, G. S., Wang, J., Liao, G., Usuka, J., Peltz, G., Foster, W. M., and Schwartz, D. A. 2004. Ozone-induced acute pulmonary injury in inbred mouse strains. Am. J. Respir. Cell. Mol. Biol. 31: 69-77.

Schachter, E. N. 2002. Popcorn worker's lung. N. Engl. J. Med. 347: 360-361.

Shimizu, T., Mochizuki, H., and Morikawa, A. 1997. Effect of influenza A virus infection on acid-induced cough response in children with asthma. Eur. Respir. J. 10:71-74.

Smith, J. A., Frazer, D. G., and Fedan, J. S. 1993. Alteration in the modulatory role of respiratory epithelium after exposure of guinea pigs to respirable cotton dust. $\mathrm{J}$. Pharmacol. Exp. Ther. 264: 683-688.

Spina, D. 1998. Epithelium smooth muscle regulation and interactions. Am. J. Respir. Crit. Care Med. 158: S141-S145.

Stanek, J., Symanowicz, P. T., Olsen, J. E., Gianutsos, G., and Morris, J. B. 2001. Sensory-nerve-mediated nasal vasodilatory response to inspired acetaldehyde and acetic acid vapors. Inhal. Toxicol. 13: 807-822.

van Rooy, F. G., Rooyackers, J. M., Prokop, M., Houba, R., Smit, L. A., and Heederik, D. J. 2007. Bronchiolitis obliterans syndrome in chemical workers producing diacetyl for food flavorings. Am. J. Respir. Crit. Care Med. 176: 498-504. 
van Rooy, F. G., Smit, L. A., Houba, R., Zaat, V. A., Rooyackers, J. M., and Heederik, D. J. 2009. A cross-sectional study of lung function and respiratory symptoms among chemical workers producing diacetyl for food flavourings. Occup. Environ. Med. 66: 105-110.

Yao, X., Fredriksson, K., Yu, Z. X., Xu, X., Raghavachari, N., Keeran, K, J., Zywicke, G. J., Kwak, M., Amar, M. J., Remaley, A. T., and Levine, S. J. 2010. Apolipoprotein E negatively regulates house dust mite-induced asthma via a low-density lipoprotein receptor-mediated pathway. Am. J. Respir. Crit. Care Med. 182: 1228-1238.

Zlotolow, R., Brautbar, N., and Wu, M. P. 2007. Occupational bronchiolitis obliterans in food flavoring. Presented during the 25th Anniversary of the Collegium Ramazzini, Carpi, Italy, October 25-28, 2007. 


\title{
Chapter 3
}

\section{Butter flavoring-elicited relaxation of airway smooth muscle and bioelectric responses of epithelium in rat airways are independent of TAS2R}

Eric J. Zaccone ${ }^{1}$, Michael J. Shimko ${ }^{1}$, Janet A. Thompson ${ }^{2}$, and Jeffrey S. Fedan ${ }^{1,2}$

\author{
${ }^{1}$ Department of Basic Pharmaceutical Sciences, West Virginia University, \\ Morgantown, West Virginia, USA \\ and \\ ${ }^{2}$ Pathology and Physiology Research Branch, Centers for Disease Control and \\ Prevention, National Institute for Occupational Safety and Health, Morgantown, West \\ Virginia, USA
}

Address for correspondence: Jeffrey S. Fedan

$\mathrm{NIOSH}$

1095 Willowdale Road

Morgantown, WV 26505

Phone: 304-285-5766

FAX: 304-285-5938

E-mail: jsf2@cdc.gov 


\subsection{Abstract}

"Popcorn workers' lung" is an obstructive pulmonary disease resulting in humans following inhalation of flavoring vapors and their effect on the airway epithelium. Recently, we demonstrated using isolated, perfused rat trachea preparations, that the butter flavorings, diacetyl and 2,3-pentanedione, result in airway smooth muscle (ASM) relaxation in vitro. Bitter taste receptors, TAS2Rs, mediate relaxation of ASM in response to agonists by increasing the concentration of intracellular $\mathrm{Ca}^{2+}$, and opening iberiotoxin (lbTx)-sensitive large-conductance $\mathrm{Ca}^{2+}$-activated $\mathrm{K}^{+}\left(\mathrm{BK}_{\mathrm{Ca}}\right)$ channels. The purpose of this in vitro study was to investigate the potential involvement of the TAS2R in relaxant responses of rat tracheal ASM and bioelectric responses of rat tracheal epithelial cells in response to denatonium (1 $\mathrm{mM})$, a TAS2R agonist, and diacetyl (3 mM) and 2,3pentanedione $(3 \mathrm{mM})$. In rat tracheal strips contracted with methacholine $\left(3 \times 10^{-5} \mathrm{M}\right)$, IbTx significantly reduced the relaxation response to denatonium suggesting that denatoniuminduced ASM relaxation is mediated by TAS2R; however, responses to diacetyl and 2,3pentanedione were not antagonized by IbTx. In tracheal epithelium, denatonium and the flavorings reduced short circuit current $\left(I_{\mathrm{sc}}\right)$; these responses were not blocked in the presence of IbTx, suggesting that they were not mediated by TAS2R. Overall, these results indicate that TAS2R receptors are present in rat tracheal ASM but do not mediate flavoring-induced relaxation. Bioelectric responses to denatonium and the flavorings are not mediated by TAS2R.

Key words: Diacetyl; 2,3-Pentanedione; TAS2R; Airway epithelium; Airway smooth muscle

Abbreviations: ASM: Airway smooth muscle; IbTx: iberiotoxin; MCh: methacholine; $\mathrm{BK}_{\mathrm{Ca}}$ : large-conductance $\mathrm{Ca}^{2+}$-activated $\mathrm{K}^{+}$channels; SCC: solitary chemosensory cells 


\subsection{Introduction}

Bitter taste receptor types (TAS2Rs) enable bitter taste sensation in humans (Conte et al., 2002; Kuhn et al., 2010; Meyerhof et al., 2010). Several TAS2R-selective agonists exist, e.g., denatonium, dextromethorphan, saccharin and thiamine; many drugs (e.g., chloroquine, erythromycin, and ofloxacin; An et al., 2012; Clark et al., 2012) taste bitter and activate TAS2R. Denatonium relaxes airway smooth muscle (ASM) from guinea pigs, humans and mice (Belvisi et al., 2011; Clark et al., 2012; Deshpande et al., 2010; Pulkkinen et al., 2012; Zhang et al., 2013), but the agent's effects have not been studied in rat ASM. The $\mathrm{BK}_{\mathrm{Ca}}$ channel antagonist, iberiotoxin (IbTx), inhibited denatoniuminduced relaxation in guinea-pig ASM (Pulkkinen et al., 2012).

TAS2Rs are also expressed in the human airway epithelium, e.g., solitary chemosensory cells (SCC) and ciliated epithelial cells (Pulkkinen et al., 2012; Shah et al., 2009; Tizzano et al., 2011). Stimulation of TAS2Rs on the epithelium increases ciliary beat frequency, a likely defensive mechanism against inhaled compounds (Chandrashekar et al., 2000; Clark et al., 2012; Glendinning 1994; Lindemann, 1996; Meyerhof et al., 2010; Pulkkinen et al., 2012).

Microwave popcorn manufacturing employees who inhale butter flavoring $\alpha$ -

diketones, such as diacetyl and 2,3-pentanedione, experience decrements in lung function and may develop a respiratory disease resembling bronchiolitis obliterans, known as "popcorn workers' lung" (Boylstein et al., 2006; Kreiss et al., 2002; van Rooy et al., 2007, 2009). Both diacetyl and 2,3-pentanedione produce airway epithelial toxicity in animal models (Day et al., 2011; Fedan et al., 2006; Hubbs et al., 2002, 2008, 2010, 2012; Morgan et al., 2008, 2012; Morris and Hubbs, 2009; Palmer et al., 2011; Schachter, 2002). No information exists as to whether taste receptors are involved in the toxicity of 
diacetyl and 2,3-pentanedione. Recently, we investigated the effects of inhaled diacetyl and 2,3-pentanedione on methacholine ( $\mathrm{MCh}$ )-contracted rat isolated, perfused trachea (Zaccone et al., 2013). Preparations were relaxed by flavorings in concentrations that have been calculated to exist in the airway wall of exposed humans (Morris and Hubbs 2009; Morris, 2012). While it is independent of the epithelium, it is unknown whether the relaxation reflects non-specific toxicity or a receptor-mediated effect. It has been reported that diacetyl depolarizes airway epithelial cells (Fedan et al., 2006).

The purpose of this study was to determine whether butter flavorings interact with TAS2Rs to elicit relaxation of ASM and bioelectric responses of airway epithelium. The TAS2R-agonist denatonium and the effects of flavorings were investigated to determine whether responses were antagonized by IbTx. We hypothesized that these G-proteincoupled receptors may play a role in mediating flavoring-induced responses of airway tissues. 


\subsection{Materials and methods}

\subsubsection{Animals}

These studies were conducted in facilities accredited by the Association for the Assessment and Accreditation of Laboratory Animal Care International and were approved by the institutional Animal Care and Use Committee. Male Sprague-Dawley rats (Hilltop Lab Animals; Scottdale, PA; 250 - $350 \mathrm{~g}$ ) were housed in pairs in ventilated micro-isolator units supplied with HEPA-filtered laminar flow air (Thoren Caging Systems; Hazleton, PA), with autoclaved Alpha-DriTM virgin cellulose chips (Shepherd Specialty Papers, Watertown, TN) and hardwood Beta-chips (NEPCO; Warrensburg, NY) for bedding, and provided tap water and irradiated Teklad Global 18\% protein rodent diet (Harlan Teklad; Madison, WI) ad libitum. Rats were housed under controlled light cycle (12 hr light) and temperature $\left(22-25^{\circ} \mathrm{C}\right)$ conditions.

\subsubsection{Preparation of rat tracheal strips for tension studies}

Naïve Sprague-Dawley rats were anesthetized with i.p. sodium pentobarbital (>100 mg/kg) and sacrificed by exsanguination. A midline incision was made in the neck and the trachea was removed. Two cartilage ring-wide tracheal strips were cut, opened opposite of the smooth muscle, tied at one end to a holder, placed in an organ chamber $\left(37^{\circ} \mathrm{C}\right)$ containing aerated $\left(95 \% \mathrm{O}_{2} / 5 \% \mathrm{CO}_{2}\right)$ modified Krebs-Henseleit solution (MKHS), and tied at the other end to an isometric force transducer (Kent Scientific Corp; Torrington, CT) for the measurement of isometric tension responses. All preparations were equilibrated for $30 \mathrm{~min}$ and maintained at $1 \mathrm{~g}$ tension during the course of

experiment before being contracted with $\mathrm{MCh}\left(3 \times 10^{-5} \mathrm{M}\right.$; EC50). Preparations were incubated $(30 \mathrm{~min})$ in the absence or presence of $\mathrm{IbTx}(100 \mathrm{nM})$ before administering the TAS2R agonist, denatonium (1 mM), or the flavorings, diacetyl (3 mM) or 2,3- 
pentanedione (3 $\mathrm{mM})$, to the organ bath.

\subsubsection{Preparation of rat tracheal segments for bioelectric studies}

Naïve rats were anesthetized using i.p. sodium pentobarbital $(>100 \mathrm{mg} / \mathrm{kg})$ and sacrificed by exsanguination. A 25-mm segment of trachea was removed, cleaned of connective tissue, and cut along the smooth muscle band before being mounted over the aperture $\left(0.1 \mathrm{~cm}^{2}\right)$ between two hemichambers of an Ussing chamber (Physiological Instruments; San Diego, CA). Tissues were bathed in MKHS, aerated with $95 \% \mathrm{O}_{2} / 5 \%$ $\mathrm{CO}_{2}$ in both apical and basolateral chambers, and maintained at $37^{\circ} \mathrm{C}$. Tissues were stabilized under open-circuit conditions before recording the basal transepithelial potential difference $\left(\mathrm{V}_{\mathrm{t}} ;-2.83 \pm 0.36 \mathrm{mV}\right)$ and applying a $0 \mathrm{mV}$ voltage-clamp using an EVC 4000 automatic voltage/current amplifier (World Precision Instruments; Sarasota, FL) to monitor short-circuit current $\left(I_{\mathrm{sc}}\right)$. $\mathrm{R}_{\mathrm{t}}$ was evaluated to investigate whether responses to agents were due to changes in transcellular or paracellular ion transport. This was accomplished by delivering $5 \mathrm{~s}$ long, $1 \mathrm{mV}$ pulses every $55 \mathrm{~s}$ and calculating $\mathrm{R}_{\mathrm{t}}$ using Ohm's law. After stabilization of $I_{\mathrm{sc}}$, tissues were incubated $(30 \mathrm{~min}$ ) in the absence or presence of apically-applied IbTx $(100 \mathrm{nM})$, during which serosally-applied MCh $\left(3 \times 10^{-5}\right.$ M) was administered followed by apically-applied denatonium (1 $\mathrm{mM}$ ) or butter flavorings (3 mM).

\subsubsection{Solutions and reagents}

The composition of MKHS was: $\mathrm{NaCl}, 113 \mathrm{mM}$; $\mathrm{KCl}, 4.8 \mathrm{mM} ; \mathrm{CaCl}_{2}, 2.5 \mathrm{mM}$; $\mathrm{MgCl}_{2}, 1.2 \mathrm{mM} ; \mathrm{KH}_{2} \mathrm{PO}_{4}, 1.2 \mathrm{mM} ; \mathrm{NaHCO}_{3}, 25 \mathrm{mM}$ and glucose, $5.5 \mathrm{mM}$. All drugs and chemicals were obtained from Sigma-Aldrich (St. Louis, MO) and dissolved and diluted in saline. The purity of diacetyl (lot 03798LJ) and 2,3-pentanedione (lot 00130DJ) was 
$99.3 \%$ and $97 \%$, respectively.

\subsubsection{Statistical analysis}

The results are expressed as means \pm S.E.M. Responses to in vitro application of denatonium, diacetyl or 2,3-pentanedione to tracheal strips were normalized by calculating the \% relaxation of the contraction induced by MCh. Results for bioelectric studies were expressed as $\% \triangle$ of the $I_{\mathrm{sc}}$ in the presence of MCh. Significant differences were evaluated using a one-way ANOVA. $n$ is the number of animals in each experiment. $p<0.05$ was considered significant.

\subsection{Results}

\subsubsection{Effects of denatonium and butter flavorings on tracheal strips}

Denatonium and the flavorings relaxed tracheal strips (Figure 1). Relaxation by denatonium $(60.5 \pm 9.8 \%)$ was significantly reduced in the presence of IbTx (Figure 1a). There were no significant differences in diacetyl- or 2,3-pentanedione-induced responses in the absence $(83.1 \pm 12.4$ and $80.3 \pm 16.2 \%$, respectively) or presence $(73.2 \pm 12.4$ and $74.9 \pm 12.7 \%$, respectively) of IbTx (Figure $1 \mathrm{~b}$ and $1 \mathrm{c}$ ). 
A

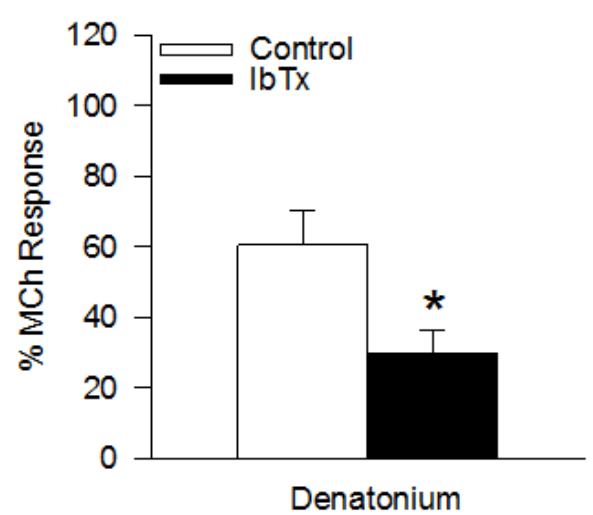

B

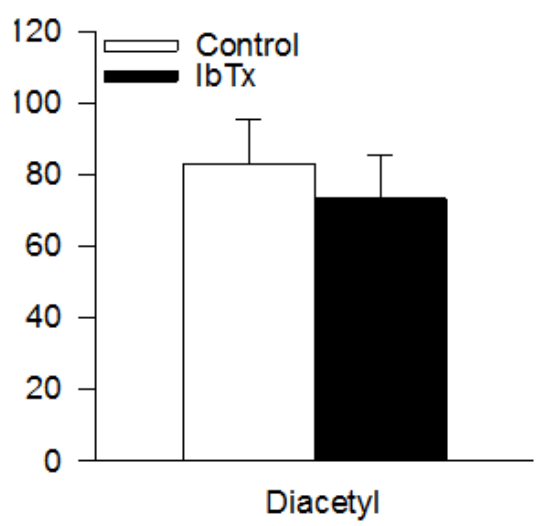

C

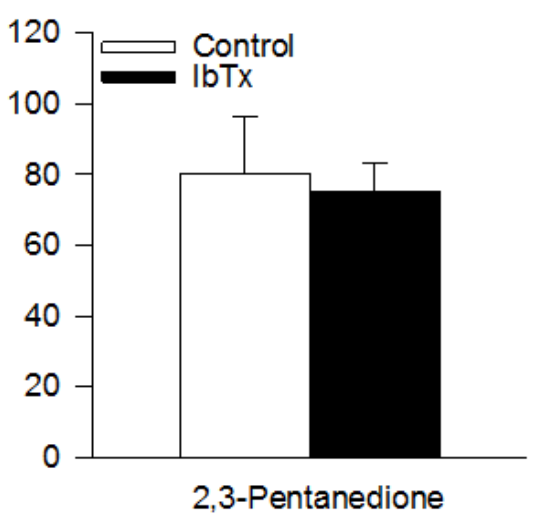

FIGURE 1. Relaxation of rat tracheal-strips in response to denatonium (1 mM, A), diacetyl ( $3 \mathrm{mM}$, B), and 2,3-pentanedione (3 mM, C) in the absence (control) or presence of IbTx (100 nM). Data are expressed as the percentage of the $\mathrm{MCh}\left(3 \times 10^{-5} \mathrm{M}\right)$-induced contractile response. Denatonium: control, $n=8 ;$ IbTx, $n=6$; diacetyl: control, $n=8 ;$ IbTx, $n=7 ;$ 2,3-pentanedione: control, $n=10$; IbTx: $n=7 .{ }^{*}$ Significantly different from control $(p<0.05)$.

3.4.2. Bioelectric effects of denatonium and butter flavorings on airway epithelium

The effects of denatonium and butter flavoring on the bioelectric response of airway epithelial cells were examined in the presence of basolateral $\mathrm{MCh}\left(3 \times 10^{-5} \mathrm{M}\right)$ for consistency with tracheal strip experimental conditions. MCh resulted in a slight reduction in $I_{\mathrm{sc}}(12.0 \pm 2.4 \%)$. In no case did the presence of IbTx have any effect on baseline $I_{\mathrm{sc}}$ or the $\mathrm{MCh}$ response $(12.0 \pm 2.0 \%)$. All three compounds reduced $I_{\mathrm{sc}}$ (Figure 2 ). In the absence of IbTx, denatonium, diacetyl, and 2,3-pentanedione reduced $I_{\text {sc }}$ by $40.9 \pm 10.0 \%$, $79.3 \pm 28.7 \%$ and $53.5 \pm 12.3 \%$, respectively. Incubation with IbTx had no effect on these responses (Figure 3). $R_{t}$ values were not significantly affected by IbTx, MCh, denatonium or the flavorings in the absence or presence of IbTx (Table 1). 


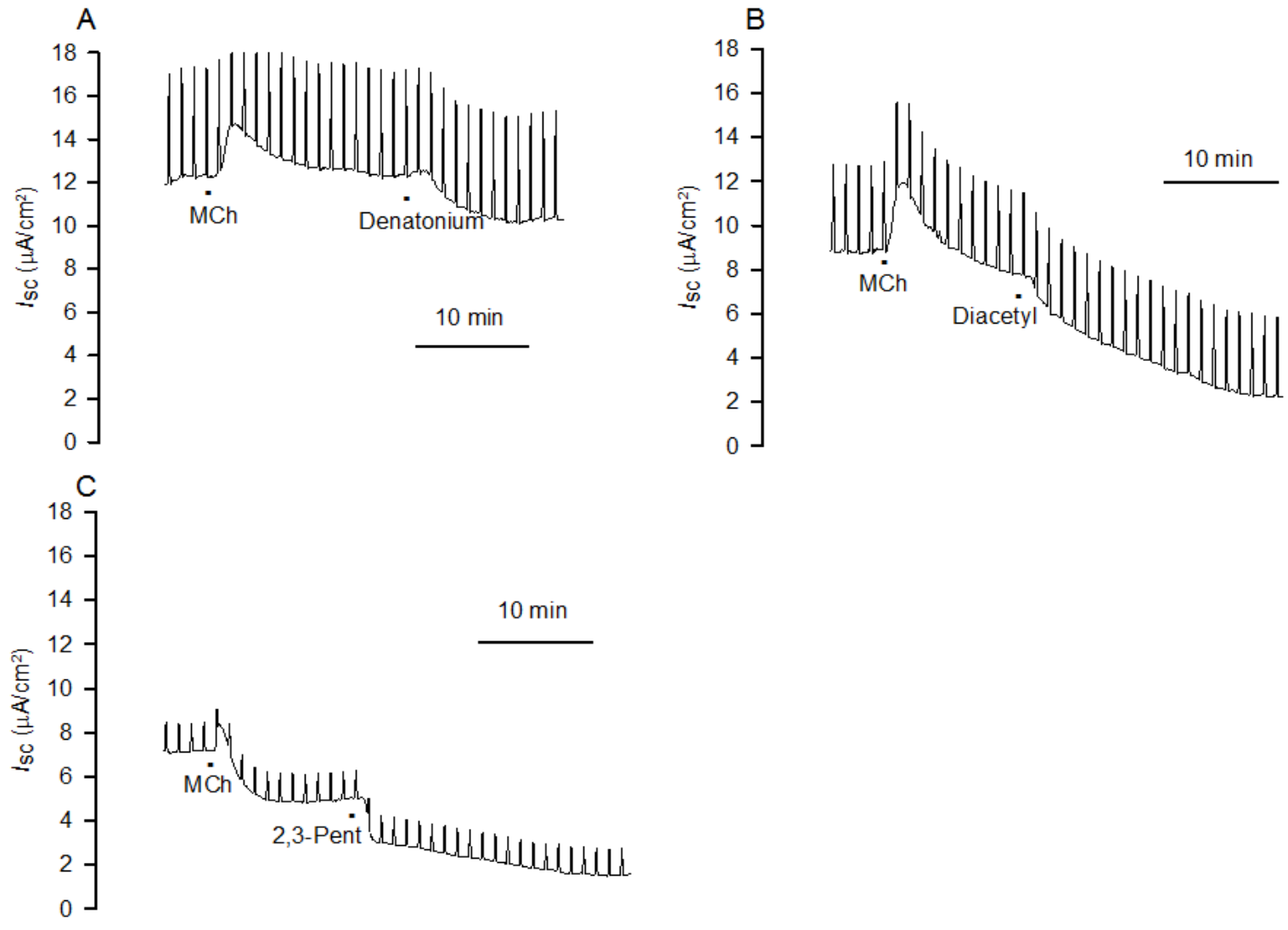

FIGURE 2. Representative bioelectric responses to denatonium, diacetyl and 2,3pentanedione $\left(2,3-\right.$ pent). Serosal MCh $\left(3 \times 10^{-5} \mathrm{M}\right)$ was administered prior to the apical additions of $(A)$ denatonium (1 mM), (B) diacetyl (3 mM) and (C) 2,3-pentanedione (3 mM). The verticle $I_{\mathrm{sc}}$ deflections represent $I_{\mathrm{sc}}$ responses to the delivery of $1 \mathrm{mV}$ pulses for calculation of $\mathrm{R}_{\mathrm{t}}$. 
A

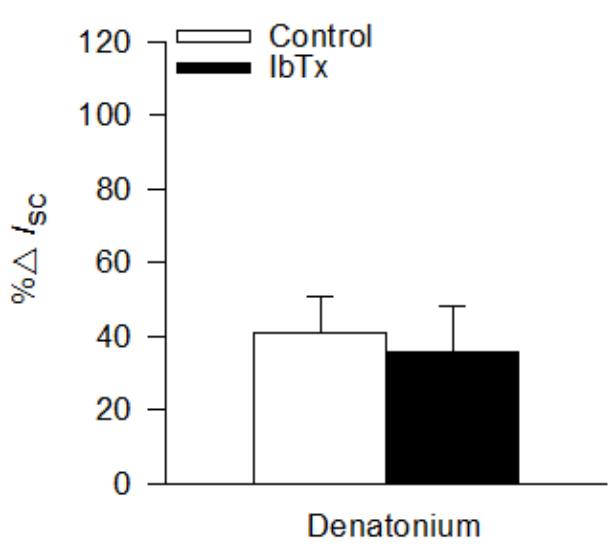

B

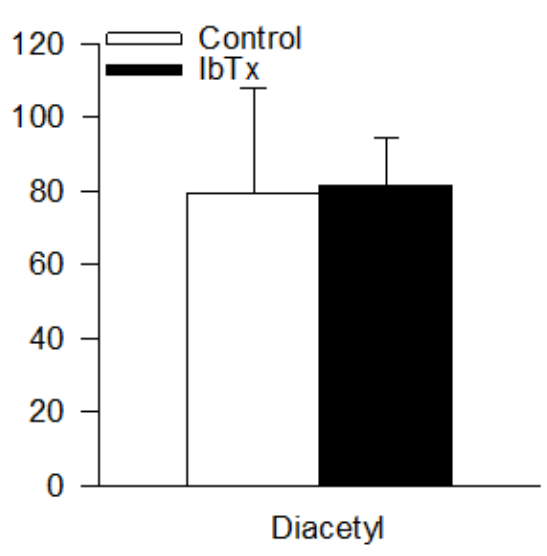

C

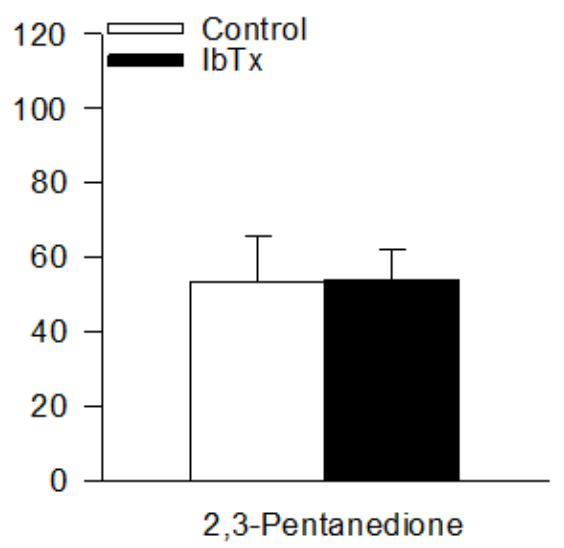

FIGURE 3. Effects of IbTx on bioeletric responses of epithelium to denatonium ( $1 \mathrm{mM}, \mathrm{A})$, diacetyl ( $3 \mathrm{mM}$, B) and 2,3-pentanedione $(3 \mathrm{mM}, \mathrm{C})$ in the absence (control) or presence of $\mathrm{IbTx}(100 \mathrm{nM})$. Data are expressed as the percentage change $(\% \triangle)$ of the $I_{\mathrm{sc}}$ value in the presence of $\mathrm{MCh}$. Denatonium: control, $\mathrm{n}$ $=8 ; \mathrm{IbTx}, \mathrm{n}=6$; diacetyl: control, $\mathrm{n}=8$; IbTx, $\mathrm{n}=8$; 2,3-pentanedione: control, $\mathrm{n}=5 ; \mathrm{lbTx}, \mathrm{n}=4$. 
TABLE 1.

Effects of MCh, denatonium, diacetyl and 2,3-pentanedione

(2,3-pent) on $R_{t}$ in the absence (control) and presence of IbTx.

\begin{tabular}{|c|c|c|}
\hline & Control & IbTx \\
\hline \multirow{2}{*}{\multicolumn{3}{|c|}{$\mathrm{R}_{\mathrm{t}}\left(\Omega \cdot \mathrm{cm}^{2}\right)$}} \\
\hline & & \\
\hline Basal & $3063 \pm 52$ & $3223 \pm 13$ \\
\hline $\mathrm{MCh}$ & $3115 \pm 24$ & $3256 \pm 10$ \\
\hline Denatonium & $3154 \pm 72$ & $2830 \pm 37$ \\
\hline$\triangle \mathrm{R}_{\mathrm{t}}^{\mathrm{a}}$ & $120 \pm 45$ & $602 \pm 34$ \\
\hline$\% \triangle \mathrm{R}_{\mathrm{t}}$ & $5 \pm 2$ & $16 \pm 34$ \\
\hline \multicolumn{3}{|l|}{ Diacetyl } \\
\hline Basal & $3992 \pm 18$ & $2616 \pm 36$ \\
\hline $\mathrm{MCh}$ & $4011 \pm 36$ & $2693 \pm 53$ \\
\hline Diacetyl & $4332 \pm 46$ & $2934 \pm 33$ \\
\hline$\triangle R_{t}^{b}$ & $321 \pm 14$ & $370 \pm 19$ \\
\hline$\% \triangle R_{t}$ & $10 \pm 5$ & $16 \pm 9$ \\
\hline \multicolumn{3}{|l|}{ 2,3-Pent } \\
\hline Basal & $1471 \pm 16$ & $2189 \pm 29$ \\
\hline $\mathrm{MCh}$ & $1581 \pm 18$ & $2362 \pm 19$ \\
\hline 2,3-Pent & $1746 \pm 13$ & $2413 \pm 33$ \\
\hline$\triangle R_{t}^{c}$ & $165 \pm 13$ & $508 \pm 16$ \\
\hline$\% \triangle R_{t}$ & $7 \pm 4$ & $4 \pm 2$ \\
\hline \multicolumn{3}{|c|}{ Denatonium: control, $\mathrm{n}=7$; lbTx, $\mathrm{n}=6$; diacetyl: control, $\mathrm{n}=5$; } \\
\hline \multicolumn{3}{|c|}{ IbTx, n=7; 2,3-pentanedione: control, n=4; lbTx, n=4. } \\
\hline \multicolumn{3}{|c|}{${ }^{\mathrm{a}} \mathrm{MCh}$ vs. denatonium } \\
\hline \multicolumn{3}{|c|}{${ }^{\mathrm{b}} \mathrm{MCh}$ vs. diacetyl } \\
\hline
\end{tabular}




\subsection{Discussion}

In the first part of our study, we demonstrated that denatonium, diacetyl and 2,3pentanedione elicited relaxation of contracted rat tracheal strips. Denatonium-induced relaxation was inhibited in the presence of $\mathrm{IbTx}$, demonstrating mediation of the responses via TAS2Rs, as it has been reported for mouse (Deshpande et al., 2010) and guinea-pig (Pulkkinen et al., 2012) airways. In contrast, IbTx had no effects on relaxations in response to diacetyl or 2,3-pentanedione, indicating that these responses did not involve TAS2Rs. Therefore, butter flavorings evoke smooth muscle relaxation through a different mechanism from that utilized by denatonium. As such, the mechanisms underlying the flavoring-induced relaxations currently remain unknown and require further investigation.

In the second part of the study, we investigated the role of TAS2Rs in bioelectric responses of tracheal epithelium to denatonium, diacetyl and 2,3-pentanedione. Our findings indicate that denatonium and the butter flavorings decreased $I_{\mathrm{sc}}$. IbTx itself did not have a significant effect on $I_{\mathrm{sc}}$, nor did it inhibit bioelectric responses to denatonium, diacetyl, and 2,3-pentanedione. Thus, TAS2R did not mediate the $I_{\mathrm{sc}}$ responses. Based on previous findings using guinea-pig tracheal epithelium (Fedan et al., 2006), there was the possibility that diacetyl and 2,3-pentanedione might damage airway epithelium by altering tight junction integrity and, therefore, the effects of the agents on $R_{t}$ was assessed. Thus, in contrast to the results seen in guinea-pig airways, $R_{t}$ was not affected by diacetyl and 2,3-pentanedione. The decreases in $I_{\text {sc }}$ caused by denatonium, diacetyl and 2,3-pentanedione did not result from changes in the paracellular ion transport pathway. Fedan et al. (2006) demonstrated that diacetyl depolarized guinea-pig tracheal epithelial cells, i.e., decreased $I_{\mathrm{sc}}$. Therefore, while the qualitative nature of the $I_{\mathrm{sc}}$ responses to diacetyl and 2,3-pentanedione in rat and guinea-pig epithelium are similar, 
the effects of the flavorings on paracellular ion transport are dissimilar. There have been no previous investigations of the bioelectric effects of these agents in rat airway epithelium or the potential role of TAS2R. This study has demonstrated for the first time that denatonium, diacetyl and 2,3-pentanedione evoke bioelectric responses of rat epithelium, though not through TAS2R.

It is not currently understood whether diacetyl or 2,3-pentanedione act via receptors to elicit ASM relaxation, and which receptors those might be. It has been demonstrated that both diacetyl and 2,3-pentanedione can bind to olfactory GPCRs in the nematode. The $C$. elegans genome encodes several hundred GPCRs which are believed to respond to volatile organic ligands. ODR-10 is only found in nematodes and diacetyl is the only volatile ligand that has been reported to activate this subfamily of GPCRs (Bargmann et al., 1993; Sengupta et al., 1996; Zhang et al.,1997). In addition, the seventransmembrane olfactory receptor srsx-3-expressing neuron, AWC ${ }^{\text {OFF }}$, detects 2,3pentanedione (Lesch and Bargmann, 2010; Troemel et al., 1999, Wes and Bargmann 2001). It is known that ketone bodies in mice can directly regulate sympathetic nervous system activity via the Gi/o-coupled GPCR, GPR41 (Kimura et al., 2011). Had the flavoring-elicited ASM relaxation and epithelial $I_{\mathrm{sc}}$ responses been inhibited by $\mathrm{lbTx}$, evidence would have been obtained that TAS2Rs were involved, but this was not observed.

Pulkkinen et al. (2012) demonstrated that denatonium, an agonist for TAS2R4 and TAS2R10, and dextromethorphan, an agonist for TAS2R1 and TAS2R10 both induced relaxation of guinea-pig tracheal tissue precontracted with carbachol. Because TAS2R1 is not expressed in guinea-pigs tracheal tissue, and both denatonium and dextromethorphan act on TAS2R10, these findings support the notion that the relaxant effect of denatonium is mediated through the TAS2R10 (Pulkkinen et al., 2012). Through 
a GßY-, PLC $\beta$ - and IP $\mathrm{P}_{3}$-receptor pathway, denatonium binding to TAS2R elevates levels of $\left[\mathrm{Ca}^{2+}\right]_{i}$ from the sarcoplasmic reticulum in ASM cells (Deshpande et al., 2010; Yan et al., 2001; Zhang et al., 2013). In addition, TAS2R agonists block activated L-type voltage-

dependent $\mathrm{Ca}^{2+}$ channels via activation of gustducin $\mathrm{G} \beta \gamma$, inducing bronchodilation of contracted smooth muscle tissue (Zhang et al., 2013). Whether denatonium acts specifically on TAS2R10 in rat tracheal strips is unknown, but our studies indicate that TAS2R in rat ASM is $\mathrm{lbTx}$-sensitive. This receptor is apparently absent from rat airway epithelium.

\section{Acknowledgements}

Mention of brand name does not constitute product endorsement. The findings and conclusions in this report are those of the authors and do not necessarily represent the views of the National Institute for Occupational Safety and Health.

Funding: NIH Cardiovascular and Pulmonary Disease Training Grant 5T32HL090610-05 and the National Institute for Occupational Safety and Health

\section{Conflict of interest statement}

The authors declare no conflicts of interest. 


\subsection{References}

An, S. S., Wang, W. C., Koziol-White, C. J., Ahn, K., Lee, D. Y., Kurten, R. C., Panettieri, R. A. Jr., and Liggett, S. B. 2012. TAS2R activation promotes airway smooth muscle relaxation despite $\beta_{2}$-adrenergic receptor tachyphylaxis. Am. J. Physiol. Lung-C. 303: L304-11.

Bargmann, C. I., Hartwieg, E., and Horvitz, H. R. 1993. Odorant-selective genes and neurons mediate olfaction in C. elegans. Cell 74: 515-27.

Behrens, M., Brockhoff, A., Kuhn, C., Bufe, B., Winnig, M., and Meyerhof, W. 2004. The human taste receptor hTAS2R14 responds to a variety of different bitter compounds. Biochem. Bioph. Res. Co. 319: 479-85.

Belvisi, M. G., Dale, N., Birrell, M. A., and Canning, B. J. 2011. Bronchodilator activity of bitter tastants in human tissue. Nat. Med. 17: 776; author reply 776-8.

Born, S., Levit, A., Niv, M. Y., Meyerhof, W., and Behrens, M. 2013. The human bitter taste receptor TAS2R10 is tailored to accommodate numerous diverse ligands. J. Neurosci. 33: 201-13.

Boylstein, R., Piacitelli, C., Grote, A., Kanwal, R., Kullman, G., and Kreiss, K. 2006. Diacetyl emissions and airborne dust from butter flavorings used in microwave popcorn production. J. Occup. Environ. Hyg. 3: 530-5.

Brockhoff, A., Behrens, M., Massarotti, A., Appendino, G., and Meyerhof, W. 2007. Broad tuning of the human bitter taste receptor hTAS2R46 to various sesquiterpene lactones, clerodane and labdane diterpenoids, strychnine, and denatonium. J. Agr. Food Chem. 55: 6236-43.

Bufe, B., Hofmann, T., Krautwurst, D., Raguse, J. D., and Meyerhof, W. 2002. The human TAS2R16 receptor mediates bitter taste in response to $\beta$-glucopyranosides. Nat. Genet. 32: 397-401. 
Chandrashekar, J., Hoon, M. A., Ryba, N. J., and Zuker, C. S. 2006. The receptors and cells for mammalian taste. Nature 444: 288-94.

Chandrashekar, J., Mueller, K. L., Hoon, M. A., Adler, E., Feng, L., Guo, W., Zuker, C. S., and Ryba, N. J. 2000. T2Rs function as bitter taste receptors. Cell 100: 703-11.

Clark, A. A., Liggett, S. B., and Munger, S. D. 2012. Extraoral bitter taste receptors as mediators of off-target drug effects. FASEB J. 26: 4827-31.

Conte, C., Ebeling, M., Marcuz, A., Nef, P., and Andres-Barquin, P. J. 2002. Identification and characterization of human taste receptor genes belonging to the TAS2R family. Cytogenet. Genome Res. 98: 45-53.

Day, G., Lebouf, R., Grote, A., Pendergrass, S., Cummings, K., Kreiss, K., and Kullman, G. 2011. Identification and measurement of diacetyl substitutes in dry bakery mix production. J. Occup. Environ. Hyg. 8: 93-103.

Deshpande, D. A., Wang, W. C., Mcilmoyle, E. L., Robinett, K. S., Schillinger, R. M., An, S. S., Sham, J. S., and Liggett, S. B. 2010. Bitter taste receptors on airway smooth muscle bronchodilate by localized calcium signaling and reverse obstruction. Nat. Med. 16: 1299-304.

Drewnowski, A., and Gomez-Carneros, C. 2000. Bitter taste, phytonutrients, and the consumer: A review. Am. J. Clin. Nutr. 72: 1424-35.

Eisenhut, M. 2006. Changes in ion transport in inflammatory disease. J. Inflamm. (Lond) 3: 5 .

Fedan, J. S., Dowdy, J. A., Fedan, K. B., and Hubbs, A. F. 2006. Popcorn worker's lung: In vitro exposure to diacetyl, an ingredient in microwave popcorn butter flavoring, increases reactivity to methacholine. Toxicol. Appl. Pharm. 215: 17-22.

Glendinning, J. I. 1994. Is the bitter rejection response always adaptive? Physiol. Behav. 56: $1217-27$. 
Greene, T. A., Alarcon, S., Thomas, A., Berdougo, E., Doranz, B. J., Breslin, P. A., and Rucker, J. B. 2011. Probenecid inhibits the human bitter taste receptor TAS2R16 and suppresses bitter perception of salicin. PLoS One 6: e20123.

Hubbs, A. F., Battelli, L. A., Goldsmith, W. T., Porter, D. W., Frazer, D., Friend, S., Schwegler-Berry, D., Mercer, R. R., Reynolds, J. S., Grote, A., Castranova, V., Kullman, G., Fedan, J. S., Dowdy, J., and Jones, W. G. 2002. Necrosis of nasal and airway epithelium in rats inhaling vapors of artificial butter flavoring. Toxicol. Appl. Pharm. 185: 128-35.

Hubbs, A. F., Cumpston, A. M., Goldsmith, W. T., Battelli, L. A., Kashon, M. L., Jackson, M. C., Frazer, D. G., Fedan, J. S., Goravanahally, M. P., Castranova, V., Kreiss, K., Willard, P. A., Friend, S., Schwegler-Berry, D., Fluharty, K. L., and Sriram, K. 2012. Respiratory and olfactory cytotoxicity of inhaled 2,3-pentanedione in Sprague-Dawley rats. Am. J. Pathol. 181: 829-44.

Hubbs, A. F., Goldsmith, W. T., Kashon, M. L., Frazer, D., Mercer, R. R., Battelli, L. A., Kullman, G. J., Schwegler-Berry, D., Friend, S., and Castranova, V. 2008. Respiratory toxicologic pathology of inhaled diacetyl in Sprague-Dawley rats. Toxicol. Pathol. 36: 330-44.

Hubbs, J. L., Boyd, J. A., Hollis, D., Chino, J. P., Saynak, M., and Kelsey, C. R. 2010. Factors associated with the development of brain metastases: Analysis of 975 patients with early stage nonsmall cell lung cancer. Cancer 116: 5038-46.

Kimura, I., Inoue, D., Maeda, T., Hara, T., Ichimura, A., Miyauchi, S., Kobayashi, M., Hirasawa, A., and Tsujimoto, G. 2011. Short-chain fatty acids and ketones directly regulate sympathetic nervous system via $\mathrm{G}$ protein-coupled receptor 41 (GPR41). P. Natl. Acad. Sci. USA 108: 8030-8035. 
Kreiss, K., Gomaa, A., Kullman, G., Fedan, K., Simoes, E.J., and Enright, P.L. 2002. Clinical bronchiolitis obliterans in workers at a microwave-popcorn plant. New Engl. J. Med. 347: 330-8.

Kuhn, C., Bufe, B., Batram, C., and Meyerhof, W. 2010. Oligomerization of TAS2R bitter taste receptors. Chem. Senses 35: 395-406.

Lesch, B. J., and Bargmann, C. I. 2010. The homeodomain protein hmbx-1 maintains asymmetric gene expression in adult C. elegans olfactory neurons. Gene. Dev. 24: $1802-15$.

Lindemann, B. 1996. Taste reception. Physiol. Rev. 76: 718-66.

Meyerhof, W., Batram, C., Kuhn, C., Brockhoff, A., Chudoba, E., Bufe, B., Appendino, G., and Behrens, M. 2010. The molecular receptive ranges of human TAS2R bitter taste receptors. Chem. Senses 35: 157-70.

Morgan, D. L., Flake, G. P., Kirby, P. J., and Palmer, S. M. 2008. Respiratory toxicity of diacetyl in c57bl/6 mice. J. Toxicol. Sci. 103: 169-80.

Morgan, D. L., Jokinen, M. P., Price, H. C., Gwinn, W. M., Palmer, S. M., and Flake, G. P. 2012. Bronchial and bronchiolar fibrosis in rats exposed to 2,3-pentanedione vapors: Implications for bronchiolitis obliterans in humans. Toxicol. Pathol. 40: 448-65.

Morris, J. B. 2012. Biologically-based modeling insights in inhaled vapor absorption and dosimetry. Pharmacol. Therapeut. 136: 401-13.

Morris, J. B., and Hubbs, A. F. 2009. Inhalation dosimetry of diacetyl and butyric acid, two components of butter flavoring vapors. Toxicol. Sci. 108: 173-83.

Palmer, S. M., Flake, G. P., Kelly, F. L., Zhang, H. L., Nugent, J. L., Kirby, P. J., Foley, J .F., Gwinn, W. M. and Morgan, D. L. 2011. Severe airway epithelial injury, 
aberrant repair and bronchiolitis obliterans develops after diacetyl instillation in rats. PLoS One 6: e17644.

Pulkkinen, V., Manson, M. L., Safholm, J., Adner, M., and Dahlen, S. E. 2012. The bitter taste receptor (TAS2R) agonists denatonium and chloroquine display distinct patterns of relaxation of the guinea pig trachea. Am. J. Physiol. Lung-C. L956-66.

Sainz, E., Cavenagh, M. M., Lopezjimenez, N. D., Gutierrez, J. C., Battey, J. F., Northup, J. K., and Sullivan, S. L. 2007. The G-protein coupling properties of the human sweet and amino acid taste receptors. Dev. Neurobiol. 67: 948-59.

Schachter, E. N. 2002. Popcorn worker's lung. New Engl. J. Med. 347: 360-1.

Sengupta, P., Chou, J. H., and Bargmann, C. I. 1996. Odr-10 encodes a seven transmembrane domain olfactory receptor required for responses to the odorant diacetyl. Cell 84: 899-909.

Shah, A. S., Ben-Shahar, Y., Moninger, T. O., Kline, J. N., and Welsh, M. J. 2009. Motile cilia of human airway epithelia are chemosensory. Science 325: 1131-4.

Tizzano, M., Cristofoletti, M., Sbarbati, A., and Finger, T. E. 2011. Expression of taste receptors in solitary chemosensory cells of rodent airways. BMC Pulm. Med. 11: 3.

Troemel, E. R., Sagasti, A., and Bargmann, C. I. 1999. Lateral signaling mediated by axon contact and calcium entry regulates asymmetric odorant receptor expression in C. elegans. Cell 99: 387-98.

van Rooy, F. G., Rooyackers, J. M., Prokop, M., Houba, R., Smit, L. A., and Heederik, D. J. 2007. Bronchiolitis obliterans syndrome in chemical workers producing diacetyl for food flavorings. Am. J. Resp. Crit. Care 176: 498-504.

van Rooy, F. G., Smit, L. A., Houba, R., Zaat, V. A., Rooyackers, J. M., and Heederik, D. J. 2009. A cross-sectional study of lung function and respiratory symptoms among 
chemical workers producing diacetyl for food flavourings. Occup. Environ. Med. 66: $105-110$.

Wes, P. D., and Bargmann, C. I. 2001. C. elegans odour discrimination requires asymmetric diversity in olfactory neurons. Nature 410: 698-701.

Yan, W., Sunavala, G., Rosenzweig, S., Dasso, M., Brand, J. G., and Spielman, A. I. 2001. Bitter taste transduced by PLC- $\beta_{2}$-dependent rise in $\mathrm{IP}_{3}$ and $\alpha$-gustducindependent fall in cyclic nucleotides. Am. J. Physiol.-Cell Ph. 280: C742-51.

Zaccone, E. J., Thompson, J. A., Ponnoth, D. S., Cumpston, A. M., Goldsmith, W. T., Jackson, M. C., Kashon, M. L., Frazer, D. G., Hubbs, A. F., Shimko, M. J., and Fedan, J. S. 2013. Popcorn flavoring effects on reactivity of rat airways in vivo and in vitro. J. Toxicol. Env. Heal. A 76: 669-89.

Zhang, Y., Chou, J. H., Bradley, J., Bargmann, C. I., and Zinn, K. 1997. The Caenorhabditis elegans seven-transmembrane protein odr-10 functions as an odorant receptor in mammalian cells. P. Natl. Aca. Sci. USA 94: 12162-7.

Zhang, C. H., Lifshitz, L. M., Uy, K. F., Ikebe, M., Fogarty, K. E., and Zhuge, R. 2013. The cellular and molecular basis of bitter tastant-induced bronchodilation. PLOS Biology 11: e1001501. 


\title{
Chapter 4
}

\section{Effects of butter flavoring vapor exposure on human cultured bronchial/tracheal epithelial cell ion transport}

\author{
Eric J. Zaccone ${ }^{1}$, W.T. Goldsmith ${ }^{2}$, Michael J. Shimko ${ }^{1}$, Ray Wells ${ }^{2}$, Diane Schwegler- \\ Berry $^{2}$, Patsy A. Willard ${ }^{2}$, Shannon L. Case ${ }^{2}$, Janet A. Thompson ${ }^{2}$, and Jeffrey S. Fedan ${ }^{1,2}$ \\ ${ }^{1}$ Department of Pharmaceutical Sciences, West Virginia University, \\ Morgantown, West Virginia, USA \\ and \\ ${ }^{2}$ Pathology and Physiology Research Branch, National Institute for Occupational Safety \\ and Health, Morgantown, West Virginia, USA
}

Address for correspondence: Jeffrey S. Fedan

$\mathrm{NIOSH}$

1095 Willowdale Road

Morgantown, WV 26505

Phone: 304-285-5766

FAX: 304-285-5938

E-mail: jsf2@cdc.gov

Running head: $\quad$ a-Diketone effects on ion transport 


\subsection{Abstract}

In the microwave popcorn industry, inhalation of butter flavoring may result in PWL, a disease resembling bronchiolitis obliterans. Rats exposed for $6 \mathrm{~h}$ to vapor from butter flavorings, diacetyl and 2,3-pentanedione, demonstrate flavoring concentrationdependent damage of the upper airway epithelium. Because epithelial ion transport is essential for maintenance of transcellular electric potential, fluid transport and cellular volume, we investigated the effects of acute flavoring vapor exposure on ion transport in cultured NHBEs. We hypothesized that epithelial ion transport may be among the earliest targets associated with the onset of butter flavoring toxicity. Using a novel exposure system designed for cultured cells, NHBEs were exposed for $6 \mathrm{~h}$ to diacetyl or 2,3pentanedione vapors (25 or >60 ppm). After exposure, cells were placed in an Ussing system to record $I_{\mathrm{sc}} 0 \mathrm{~h}$ or $18 \mathrm{~h}$ after exposure. Both diacetyl and 2,3-pentanedione (25 ppm) exposure reduced apically-applied amiloride $\left(3.5 \times 10^{-5} \mathrm{M}\right)$-sensitive $\mathrm{Na}^{+}$transport, without affecting the response to NPPB $\left(10^{-4} \mathrm{M}\right)$, a $\mathrm{Cl}^{-}$channel blocker, or ouabain $\left(10^{-4}\right.$ M), a $\mathrm{Na}^{+}, \mathrm{K}^{+}$-ATPase blocker. This change in $\mathrm{Na}^{+}$conductance was not accompanied by changes in $\mathrm{R}_{\mathrm{t}}$ and recovered $18 \mathrm{~h}$ after exposure. Exposure to concentrations of diacetyl and 2,3-pentanedione of $\geq 60 \mathrm{ppm}$ resulted in cell death. Our results demonstrate that flavoring vapor exposure at $25 \mathrm{ppm}$ reduces apical $\mathrm{Na}^{+}$conductance in airway epithelium.

Key words: Diacetyl; 2,3-Pentanedione; Ion transport; Epithelial cell culture

Abbreviations: ASL: airway surface liquid; ECC: Exposure chamber control; NHBEs: normal human bronchial/tracheal epithelial cell; NPPB: 5-Nitro-2-(3phenylpropylamino)benzoic acid; PWL: popcorn workers' lung 


\subsection{Introduction}

Exposure to inhalation hazards such as tobacco smoke and inhaled pollutants can lead to chronic bronchitis, emphysema and chronic obstructive lung disease (Harris 1996). Microwave popcorn manufacturing employees who inhale butter flavoring vapor may develop PWL, an obstructive pulmonary disease which can produce clinical bronchiolitis obliterans (Kreiss et al., 2002), in which the airway epithelium is the initial target of injury (Hubbs et al., 2002, 2008, 2012; Morris and Hubbs, 2009; Morgan et al., 2008, 2012; Palmer et al., 2011). Inhalation of volatile a-diketones in popcorn flavoring mixtures, such as diacetyl and 2,3-pentanedione, leads to appreciable airway epithelial damage in animal models and is thought to be the primary contributing factor to PWL (Akpinar-Elci et al., 2004; Day et al., 2011; Fedan et al., 2006; Hubbs et al., 2002; Kreiss et al., 2002; Lockey et al., 2009; Morgan et al., 2008, 2012; Morris, 2009, 2012; Palmer et al., 2011; van Rooy et al., 2007, 2009).

Due to the airway toxicity in rats after diacetyl and 2,3-pentanedione exposure, the effects of $6 \mathrm{~h}$ flavoring exposure on lung function were investigated. Hyperreactivity to MCh both in vivo (inhaled MCh aerosol) and in vitro (isolated, perfused trachea) were anticipated to occur at flavoring concentrations where morphological changes were evident and not evident (Zaccone et al., 2013). Thus, these methods allowed evaluation of concentration-response relationships for flavoring toxicity on the airway epithelium. Despite epithelial damage in the airways in rats, inhaled diacetyl reduced reactivity to inhaled MCh aerosols $18 \mathrm{~h}$ after exposure to the highest concentration (360 ppm). 2,3Pentanedione decreased in vivo responsiveness after exposure to the majority of exposure concentrations that were used, including $320 \mathrm{ppm}$. Eighteen $\mathrm{h}$ after diacetyl inhalation, responses to MCh of perfused tracheas from animals exposed to 300 and 360 
ppm were potentiated. Only higher concentrations (320 and $360 \mathrm{ppm})$ of 2,3pentanedione resulted in hyperreactivity to MCh in vitro (Zaccone et al., 2013). Thus, the inhalation exposure to primarily high concentrations of diacetyl or 2,3-pentanedione resulted in changes in reactivity to $\mathrm{MCh}$.

Regulation of the ASL viscosity and volume is one of the most important functions of the epithelium (Hollenhorst et al., 2011). In humans, all epithelial cells throughout the respiratory tract are involved in $\mathrm{Na}^{+}$absorption and $\mathrm{Cl}^{-}$secretion and regulate $\mathrm{ASL}$ height (Hamann et al., 2010; Hollenhorst et al., 2011). $\mathrm{Na}^{+}$absorption occurs on the apical surface, mostly through amiloride-sensitive $\mathrm{Na}^{+}$channels. In the basolateral surface of the cell, $\mathrm{Na}^{+}$is pumped outwardly by $\mathrm{Na}^{+}, \mathrm{K}^{+}$-ATPase (Matthay et al., 2002). Ion transport disruption may result in respiratory infection and diseases including cystic fibrosis (CF) and pulmonary edema (Harris 1996; Hollenhorst et al., 2011), as well as airway obstruction (Danahay et al., 2002; Eisenhut, 2006; Houtmeyers et al., 1999). In CF, cystic fibrosis transmembrane conductance regulator gene mutations lead to altered $\mathrm{Cl}^{-}$and $\mathrm{Na}^{+}$transport, resulting in impaired mucociliary clearance defense mechanisms (Knowles et al., 1995; Houtmeyers et al., 1999). Reduced transepithelial $\mathrm{Na}^{+}$transport in the airways has been demonstrated to result in pulmonary edema (Egli et al., 2004).

The airways of mammals consist of a layer of pseudostratified epithelium, containing various cell types with different morphologies and functions (Hollenhorst et al., 2011; Jeffery and Reid, 1975). NHBEs under apical air-interface culture conditions have been utilized to yield ciliated, pseudostratified cells which resemble in situ tracheal and bronchial cells. Previous findings using guinea-pig tracheal epithelium demonstrated that diacetyl administered directly to the tissue results in transepithelial depolarization as well as altered tight junction integrity (Fedan et al., 2006). At present the ion transport pathways targeted by diacetyl or similar compounds, such as 2,3-pentanedione, are 
unknown. Therefore, in this investigation NHBEs were exposed for $6 \mathrm{~h}$ to vapors from diacetyl or 2,3-pentanedione (25 or >60 ppm) using an exposure system we designed for cultured cells (Figure 1). The higher doses (100 - 360 ppm) were vapor concentrations similar to those used in our previous in vivo (inhaled MCh aerosol) and in vitro (isolated, perfused trachea) studies. This novel exposure chamber has been demonstrated to maintain a steady vapor concentration for at least $6 \mathrm{~h}$ (Figure 2). We hypothesized that, following exposure to diacetyl and 2,3-pentandione, apical amiloride-sensitive $\mathrm{Na}^{+}$and apical NPPB-sensitive $\mathrm{Cl}^{-}$conductance would become altered. A major goal of this investigation was to compare the vapor concentrations that produce toxicity in vivo after inhalation to the concentrations which are toxic to NHBEs. We anticipated that changes in ion transport would occur at concentration lower than those that resulted in changes in reactivity to $\mathrm{MCh}$ in vivo and in vitro. In addition, we investigated the duration of the changes in ion transport after exposure. Our goals were to investigate the ion transporters that are affected by the BFVs, and to clarify a possible relationship between altered ion transport and epithelial cellular injury, and to understand the effects of BFVs on airway epithelial cells that are not adherent to the airway wall. 


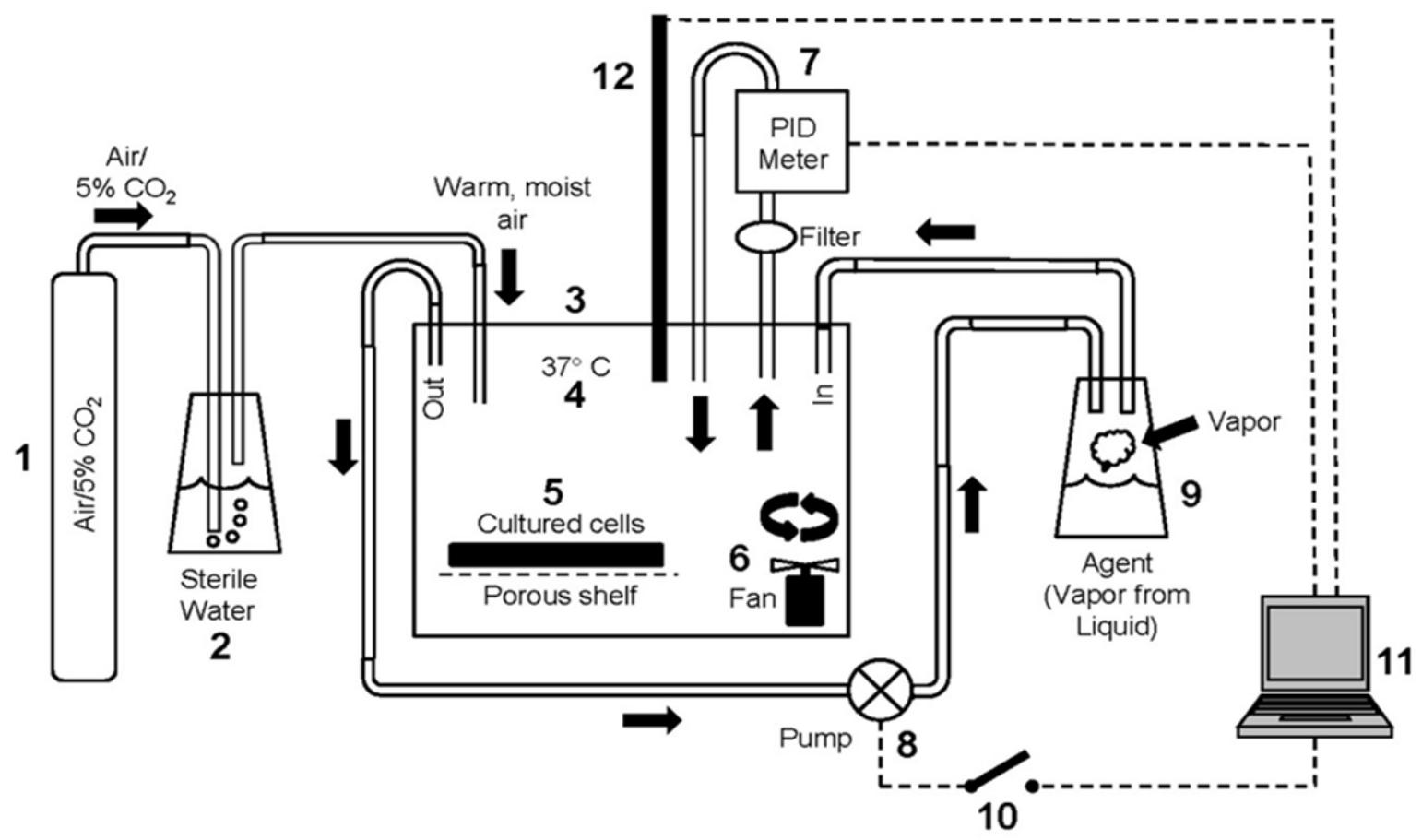

FIGURE 1. The custom-made vapor generator and a volatile organic compound photoionization detector (PID) to detect $\alpha$-diketone concentrations was used for exposing NHBEs to flavoring vapor. Once the cell plate was placed in the exposure chamber, it was filled with (1) air/5\% $\mathrm{CO}_{2}$, which passed through an external water flask (2) containing sterile, distilled water to humidify the inside of the exposure chamber (3) to reach $85 \%$ relative humidity. (4) Temperature was maintained at $37^{\circ} \mathrm{C}$, creating an incubator-like environment for the cultured NHBEs (5) inside the chamber. (6) A fan was used to ensure evenly distributed flavoring vapor circulation within the chamber. (7) PID measured concentration levels of flavorings during the exposure. The PID pumped air from the chamber and returned it while measuring vapor level in the chamber, thereby maintaining a closed system. PID measurements from the chamber were used in a feedback loop that adjusted the flow of the pump (8), which pumped flavoring vapor (9) (indicated by arrows) into the exposure chamber to maintain the concentration levels at a constant, userdefined value. The computer software activated/deactivated a switch (10) to engage or disengage the pump, while proprietary software (11) was used to monitor vapor levels in the chamber and deliver more flavoring vapor as needed to maintain a steady concentration. A temperature-humidity probe (12) was continuously monitored by computer software. 


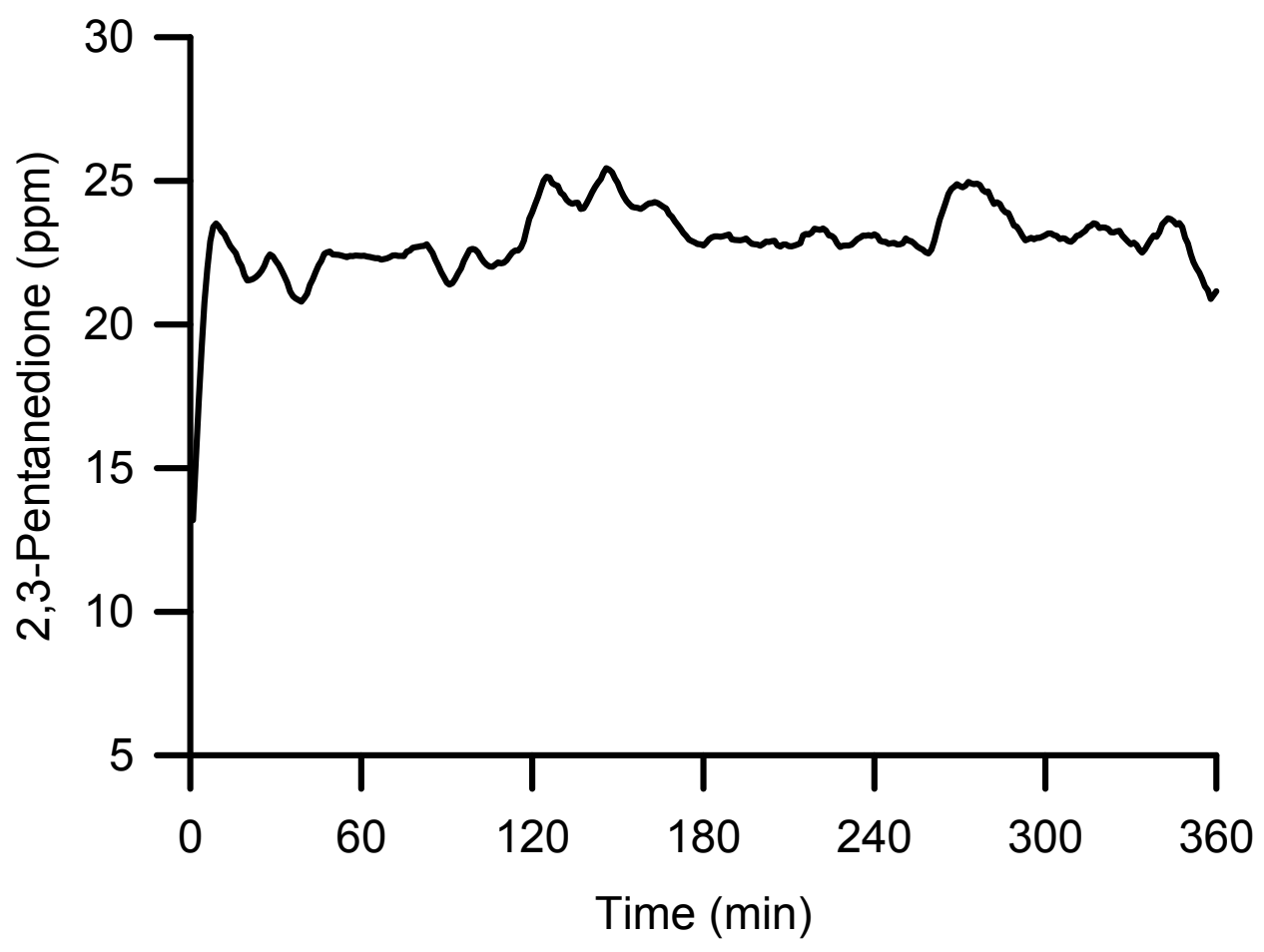

FIGURE 2. Representative recording illustrating the exposure chamber delivering constant, stable flavoring (2,3-pentanedione) vapor levels for 6 $h$ to the NHBEs. The average flavoring level in this tracing was $22.8 \pm 0.1$ ppm, with the target concentration being $25 \mathrm{ppm}$. Similar results were obtained for diacetyl, as well as for other flavoring concentrations use in this study. 


\subsection{Materials and methods}

\subsubsection{Cell culture}

Primary cultured NHBEs (Lonza, Walkersville, MA) were seeded in plastic T-75 flasks and were grown in B-ALI growth media (Lonza) until cells were $80 \%$ confluent. The confluent monolayer was trypsinized and seeded onto rat tail (BD Biosciences, San Jose, CA) collagen-coated polyester ( $0.4 \mu \mathrm{m}$ filter) transwell inserts (Corning, Corning, NY) at a density of 50,000 cells per insert. Cells were maintained at $37^{\circ} \mathrm{C}$ in an air $/ 5 \% \mathrm{CO}_{2}$ mixture in an incubator. Cells were submerged for three days in B-ALI growth media (100 $\mu \mathrm{l}$ apical; $500 \mu \mathrm{l}$ basal chamber) before $500 \mu \mathrm{l}$ of B-ALI differentiation medium was added to the basal chamber and the apical chamber emptied to initiate the air-liquid interface (ALI) culture conditions. Medium was changed every $48 \mathrm{~h} . \mathrm{R}_{\mathrm{t}}$ was measured with $\mathrm{EVOM}^{2}$ epithelial volt-ohm meter STX² electrodes (World Precision Instruments, Sarasota, FL) to assess growth to confluence from an increase in the transepithelial resistance. Cells were used after 21 days in air-liquid interface when $R_{t}$ reached a value of at least $700 \Omega \cdot \mathrm{cm}^{2}$ (Figure 3).

\subsubsection{Cell imaging}

Differentiated morphology of pseudostratified epithelium was confirmed through a series of imaging and staining techniques. The membrane inserts were fixed in $10 \%$ buffered formalin, rinsed in Hank's balanced salt solution $\left(37^{\circ} \mathrm{C}\right)$, dehydrated in a graded series of ethanol, cleared in xylene, and infiltrated and embedded in paraffin. Sections (5 $\mu \mathrm{m})$ were placed on microscope slides and stained with H\&E. The samples were imaged on an Olympus IX70 photomicroscope (Shinjuku, Tokyo).

Mucus production was confirmed using alcian blue staining (Figure 4A). Membrane inserts were stained apically with a $1 \%$ alcian blue solution ( $3 \%$ acetic acid, $\mathrm{pH} 2.5)$ for 30 
sec. The alcian blue solution was removed, and cells were imaged on a Zeiss Axiovert 100 microscope (Oberkochen, Germany) equipped with a Pixera Pro 150ES camera (Santa Clara, California).

The presence of cilia was confirmed using immunostaining of $\beta$-tubulin (Figure 4B) and scanning electron microscopy (SEM; Figure 4C). Transmission electron microscopy (TEM) was also used to confirm the presence of cilia, demonstrating the presence of the $9+2$ doublet arrangement, characteristic of microtubules in cilia (Figure 5). For $\beta$-tubulin immunofluorescence membrane inserts were washed with PBS, fixed with apically applied methanol $\left(4^{\circ} \mathrm{C}\right)$, and stained using a monoclonal anti-tubulin-FITC antibody (F2043, Sigma-Aldrich, St. Louis, MO). Immunofluorescence was measured using an Axiovert 100 microscope equipped with a Pixera Pro 150ES camera. For SEM, the samples were fixed in $4 \%$ paraformaldehyde fixative and post-fixed in osmium tetroxide. The cells were dehydrated in an ethanol series, dried using hexamethyldisalizane as the final solution, and coated with gold/palladium. The samples were imaged on a Hitachi 4800 field emission scanning electron microscope (Chiyoda, Tokyo). For TEM, the samples were fixed in Karnovsky's fixative (2.5\% gluteraldehyde, $2.5 \%$ paraformaldehyde in $0.1 \mathrm{M}$ sodium cacodylic buffer), post-fixed in osmium tetroxide, mordanted in $1 \%$ tannic acid and stained en bloc in $0.5 \%$ uranyl acetate. The cells were dehydrated in an ethanol series and embedded in epon, sectioned and stained with Reynold's lead citrate and an aqueous uranyl acetetate. The sections were imaged on a JEOL 1220 transmission electron microscope (Peabody, MA).

\subsubsection{Exposure of NHBEs to flavorings}

Once the NHBEs had differentiated and reached optimal $R_{t}$, cells were exposed for 6 h to vapors from diacetyl $(25,60,100,200,300,360$ ppm) or 2,3-pentanedione (25 ppm). 
Basal chamber medium was replaced immediately after exposure. NHBEs were exposed using the custom-made exposure chamber described in Figure 1, which housed the cells. Exposure chamber control (ECC) cells were placed in the exposure chamber for $6 \mathrm{~h}$ and were exposed only to air.

4.3.4. Investigation of alterations in NHBE ion transport after flavoring exposure

Immediately $(0 \mathrm{~h})$ and $18 \mathrm{~h}$ after the flavoring-vapor exposure, inserts were placed into a Ussing chamber in order to measure $I_{s c}$ and $R_{t}$ to assess alterations in epithelial ion transport due to flavoring exposure, as described in Wu et al. (2004). Inserts were placed in the Ussing chamber and bathed in MKHS in both apical and basolateral chambers, maintained at $37^{\circ} \mathrm{C}$, and aerated with $95 \% \mathrm{O}_{2} / 5 \% \quad \mathrm{CO}_{2}$. Cells were allowed to stabilize under open-circuit conditions before recording the transepithelial potential difference $\left(\mathrm{V}_{t}\right.$ 9.5 $\pm 1.6 \mathrm{mV}$ ) and applying a $0 \mathrm{mV}$ voltage-clamp using an EVC 4000 automatic voltage/current amplifier (World Precision Instruments, Sarasota, FL). Square-wave voltage pulses ( $1 \mathrm{mV}, 5 \mathrm{sec}$ ) were delivered every $55 \mathrm{sec}$ to yield a voltage response for calculation of $R_{t}$ from Ohm's law. After stabilization of baseline $I_{\text {sc }}(11.9 \pm 4.7 \mu \mathrm{A})$, electrophysiological studies were conducted using apically-applied amiloride $\left(3.5 \times 10^{-5} \mathrm{M}\right)$, apically-applied 5-nitro-2-(3-phenylpropylamino)-benzoic acid (NPPB; $10^{-4} \mathrm{M}$ ), and serosally-applied ouabain $\left(10^{-4} \mathrm{M}\right)$, as demonstrated in Figure 6.

\subsubsection{Solutions and reagents}

The composition of MKHS was: $\mathrm{NaCl}, 113 \mathrm{mM} ; \mathrm{KCl}, 4.8 \mathrm{mM} ; \mathrm{CaCl}_{2}, 2.5 \mathrm{mM} ; \mathrm{MgCl}_{2}$, $1.2 \mathrm{mM} ; \mathrm{KH}_{2} \mathrm{PO}_{4}, 1.2 \mathrm{mM} ; \mathrm{NaHCO}_{3}, 25 \mathrm{mM}$ and glucose, $5.5 \mathrm{mM}$. All drugs and chemicals were obtained from Sigma-Aldrich (St. Louis, MO) and dissolved and diluted in saline. The purity of diacetyl (lot 03798LJ) and 2,3-pentanedione (lot 00130DJ) was 
$99.3 \%$ and $97 \%$, respectively.

\subsubsection{Statistical analysis}

The results are expressed as means \pm S.E.M. Electrophysiology results were expressed as a percent change from baseline $I_{\text {sc. }}$. Significant differences were evaluated using a one-way ANOVA. Each donor was considered an $n$ value of 1 . All Ussing experiments included two donors with each donor having a minimum of three replicates of each experimental condition. $p<0.05$ was considered significant.

\subsection{Results}

The culturing of NHBEs in air-interface was utilized to yield differentiated epithelial cells resembling in situ cells. NHBEs grew to confluence and generated high $\mathrm{R}_{\mathrm{t}}$ (Figure 3). Alcian blue staining (Figure 4A) and $\beta$-tubulin immunoflorescence (Figure 4B) confirmed the presence of mucus and cilia. SEM (Fig. 4C) and TEM imaging (Fig. 5) also confirmed the presence of ciliated NHBEs. Cells were also characterized with respect to ion transport blocker responses (Figure 6).

The purpose of these studies was to investigate flavoring vapor effects on ion transport in NHBEs. The cells could be housed in the exposure apparatus for $6 \mathrm{~h}$ without resulting in cell death, altering cell morphology (Figure 7) or altering ion transport blocker responses (Figure 8). In assessing NHBE morphology after 25 ppm flavoring exposure, SEM images demonstrated similar confluent, differentiated cells as compared to controls (Figure 9). This was also confirmed by H\&E staining (Figure 10). Six-h exposure concentrations at $60 \mathrm{ppm}$ abolished $\mathrm{V}_{\mathrm{t}}$ and $\mathrm{R}_{\mathrm{t}}$ in NHBEs, as did higher exposure levels. These higher concentrations led to cell death, as confirmed using SEM images (Figure 
11) and H\&E staining (Figure 12). Evaluation of the effects of flavorings on ion transport involved using much lower exposure levels $(25 \mathrm{ppm})$ before changes in ion transport, absent from any morphological changes, could be investigated.

Our results indicated that exposure to diacetyl and 2,3-pentanedione (25 ppm) significantly reduced the amiloride-sensitive $I_{\text {sc }}$. Immediately after exposure, both diacetyl and 2,3-pentanedione reduced amiloride-sensitive $\mathrm{Na}^{+}$transport (Figure 13) while $\mathrm{R}_{\mathrm{t}}$ values were not significantly affected. Eighteen $\mathrm{h}$ after the exposure, $I_{\mathrm{sc}}$ was measured to assess potential delayed-toxicity and alterations in ion transport. Compared to controls, the amiloride responses were unaltered $18 \mathrm{~h}$ after diacetyl and 2,3-pentanedione exposures (Figure 13). Neither flavoring altered the apical $\mathrm{Cl}^{-}$conductance, demonstrated by the absence of a change in NPPB responses at $0 \mathrm{~h}$ or $18 \mathrm{~h}$ post-exposure (Figure 14). There were no changes in the $\mathrm{Na}^{+}, \mathrm{K}^{+}$-ATPase activity, as judged by the responses to ouabain, at the $0 \mathrm{~h}$ or $18 \mathrm{~h}$ time point (Figure 15).

These results indicate that epithelial amiloride-sensitive $\mathrm{Na}^{+}$transport was decreased significantly after exposure to a low concentration of flavoring. In addition to the loss of apical $\mathrm{Na}^{+}$conductance at a $0 \mathrm{~h}$ post-exposure time point, our results indicate this effect on $\mathrm{Na}^{+}$transport was reversible with time, at least at the $25 \mathrm{ppm}$ exposure level, at a concentration that did not cause frank cell death. 


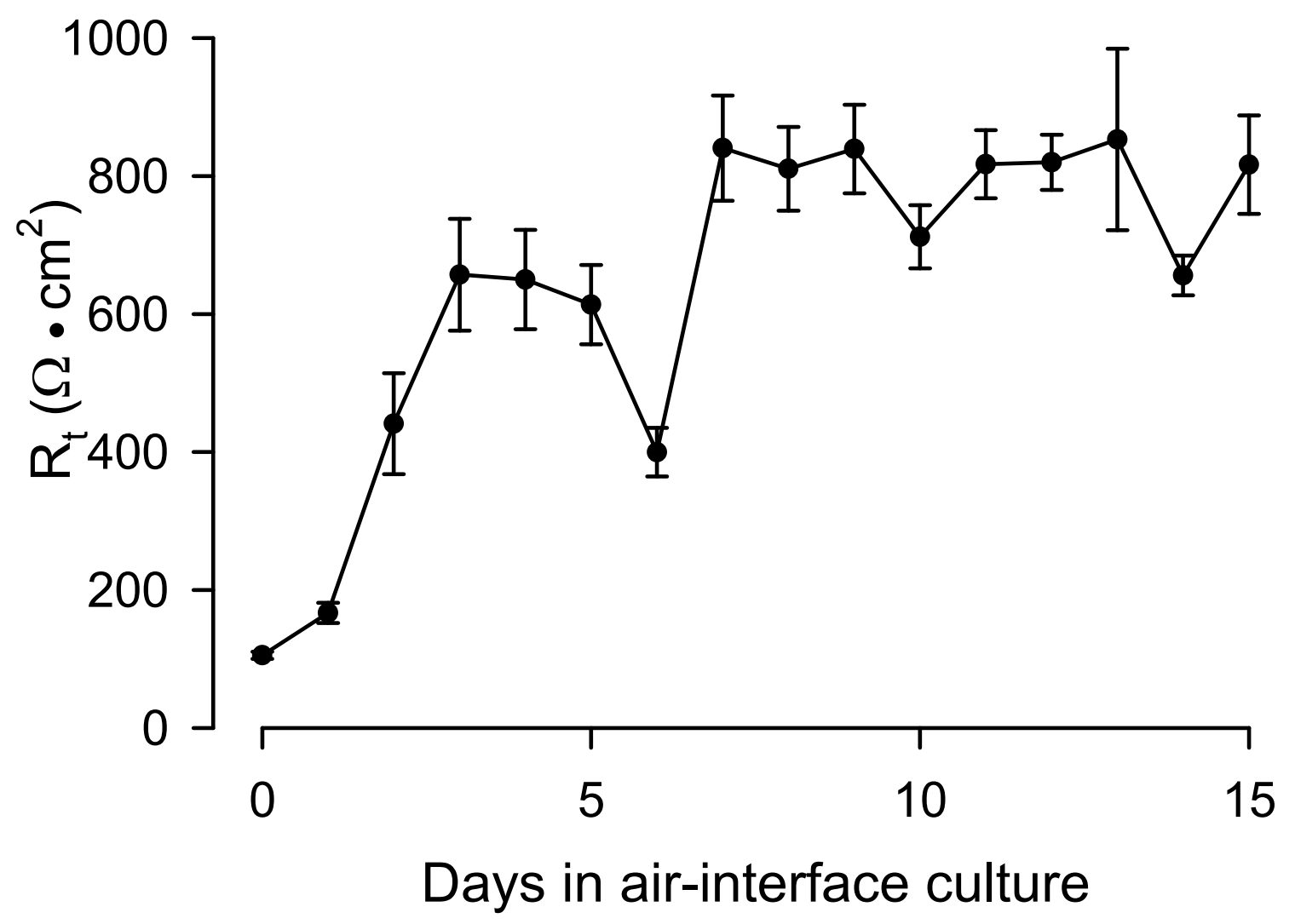

FIGURE 3. $R_{t}$ of NHBE in air-interface culture. $R_{t}$ values increased and stabilized over time. After raising the cultures in air interface, $R_{t}$ increased from $105 \pm 5 \Omega \cdot \mathrm{cm}^{2}$ from day 1 to $816 \pm 72 \Omega \cdot \mathrm{cm}^{2}$ on day 15 . The $R_{t}$ was relatively stable after 1 week thereafter. 


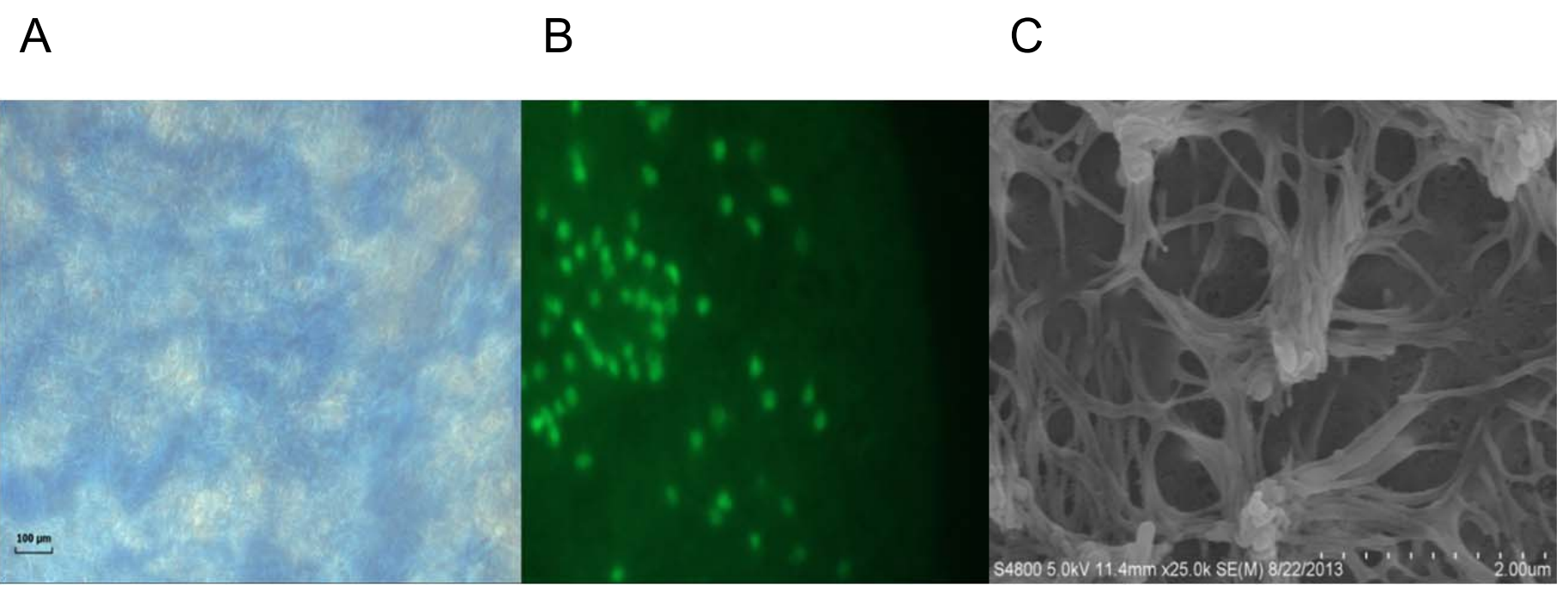

FIGURE 4. Characteristics of cultured NHBEs. (A) Mucus production was confirmed using alcian blue staining for mucus (objective magnification $=10 \mathrm{x}$ ) Bar $=100 \mu \mathrm{m}$. (B) The presence of cilia was confirmed using immunostaining for $\beta$-tubulin (objective magnification $=20 x$ ) and $(C)$ SEM imaging. 


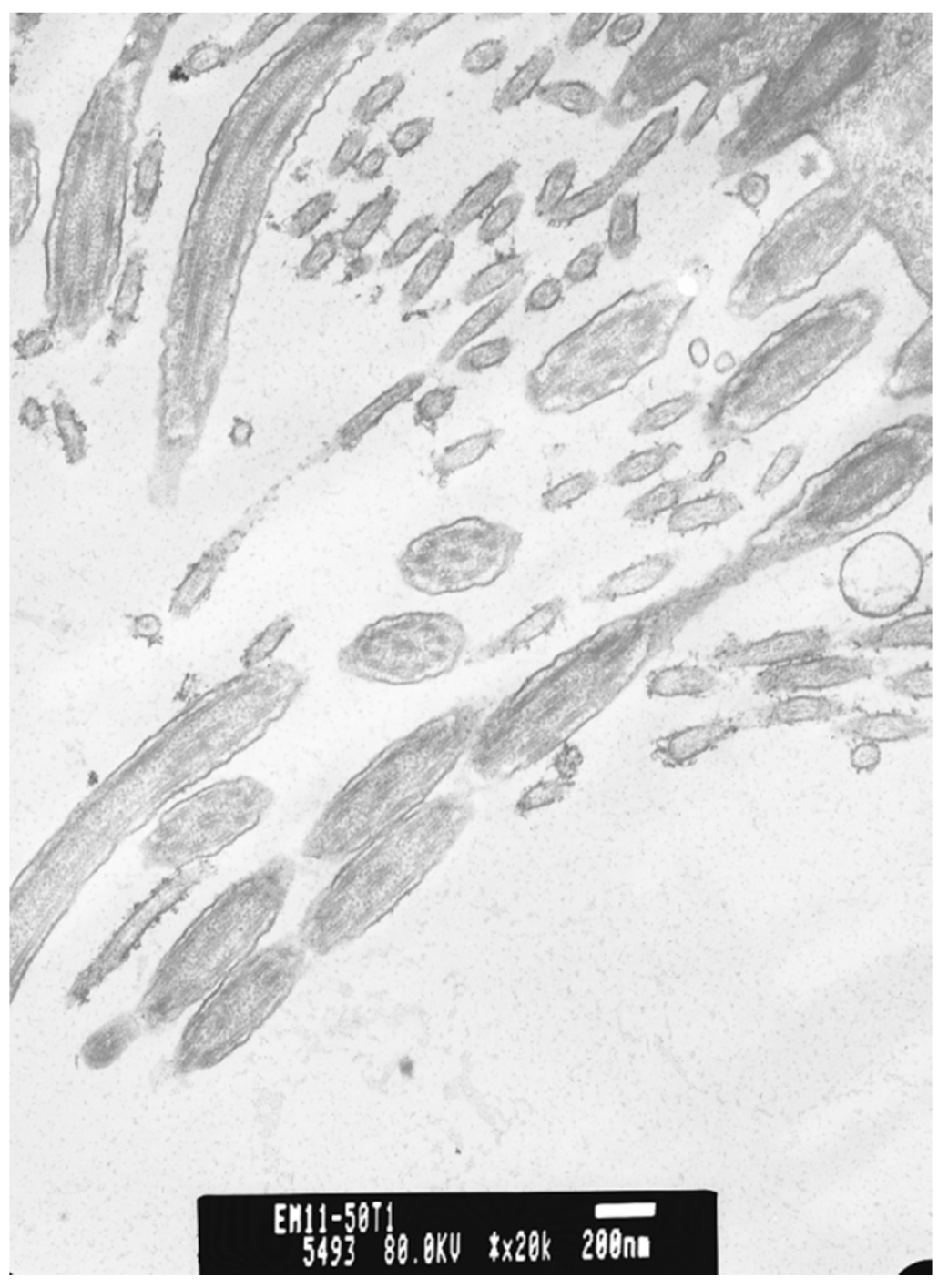

FIGURE 5. TEM imaging demonstrating the presence of cilia on NHBEs. The image shows the presence of the $9+2$ doublet arrangement of microtubules, confirming the presence of cilia. 


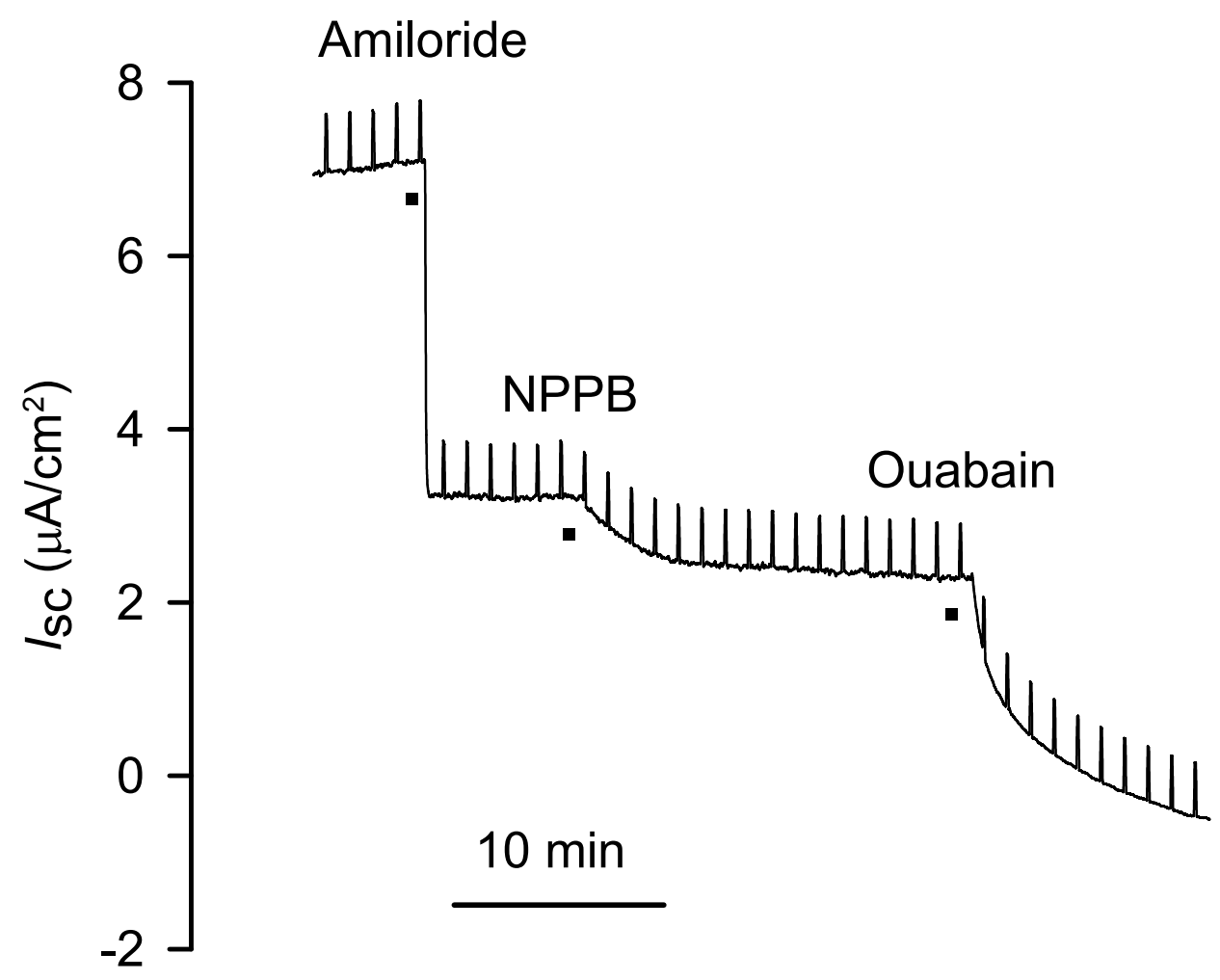

FIGURE 6. Representative bioelectric responses to ion transport blockers amiloride $\left(3.5 \times 10^{-5} \mathrm{M}\right)$, NPPB $\left(10^{-4} \mathrm{M}\right)$, and ouabain $\left(10^{-4} \mathrm{M}\right)$. 

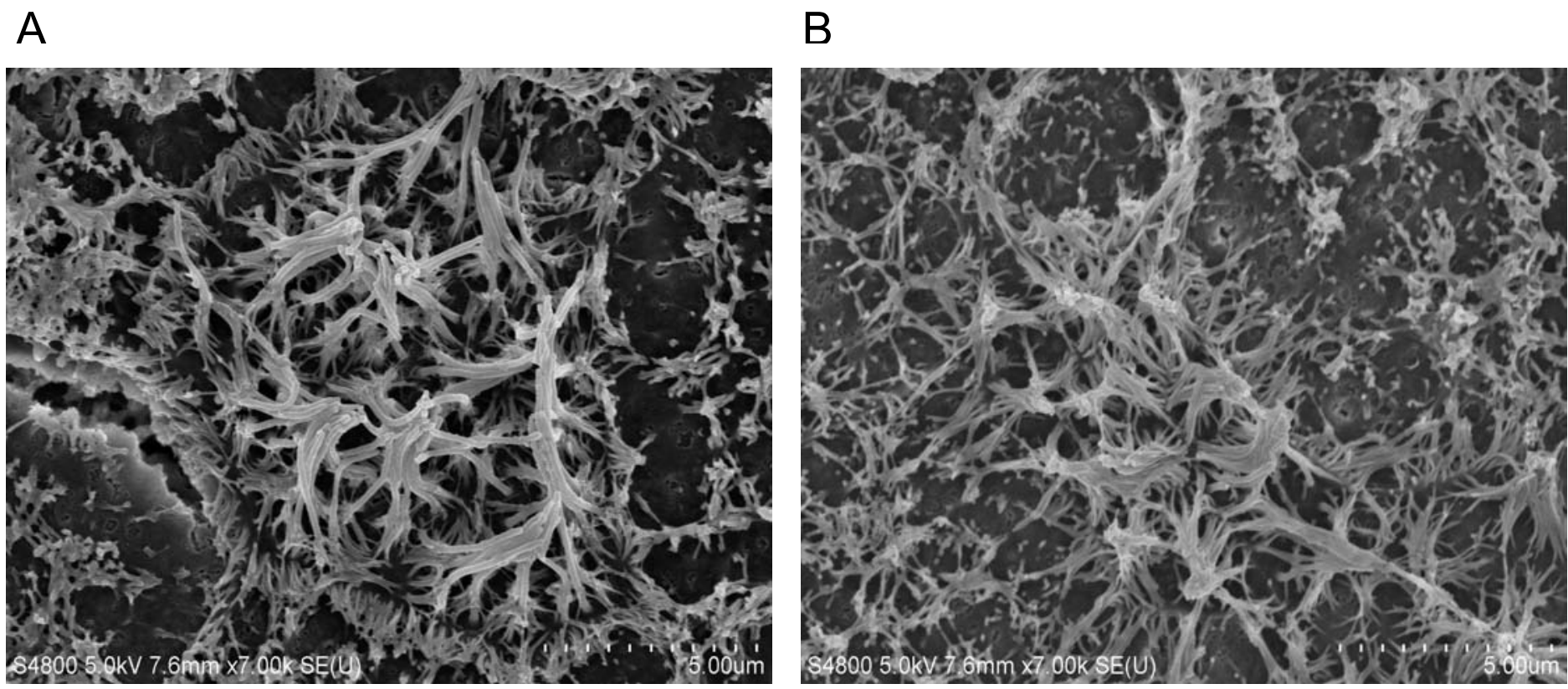

FIGURE 7. SEM micrographs of the apical surface of cultured NHBEs. There were no differences in the morphology of the control cells, which were not placed in the exposure chamber (A), compared to exposure chamber control (ECC) cells (B), which were placed in the chamber for $6 \mathrm{~h}$ and exposed to air only. 
A

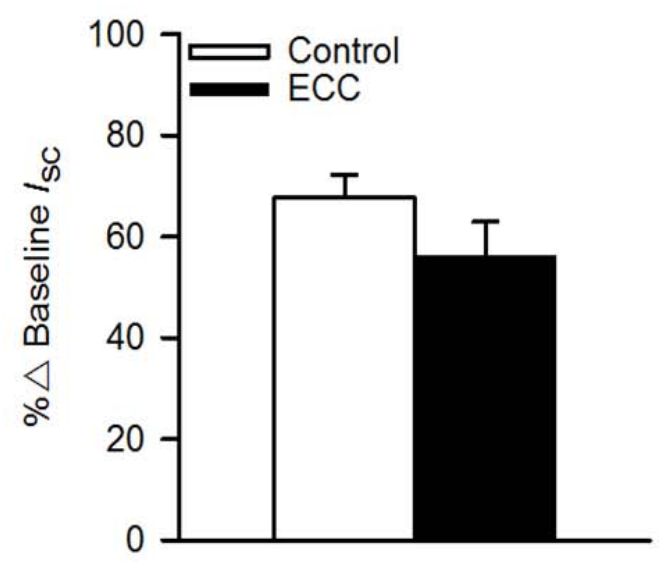

B

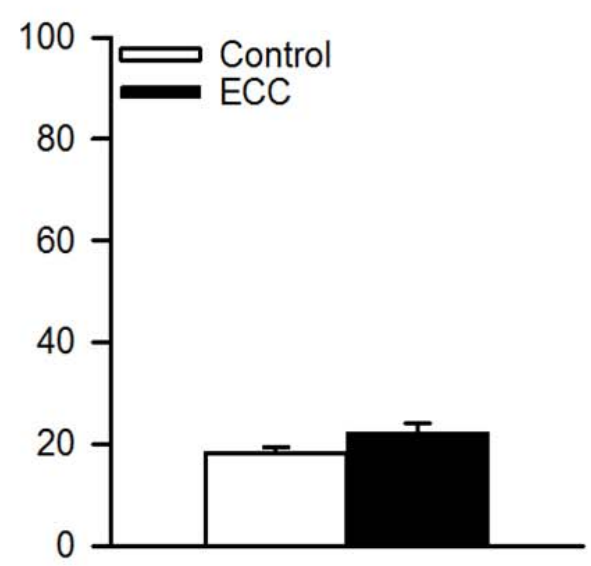

C

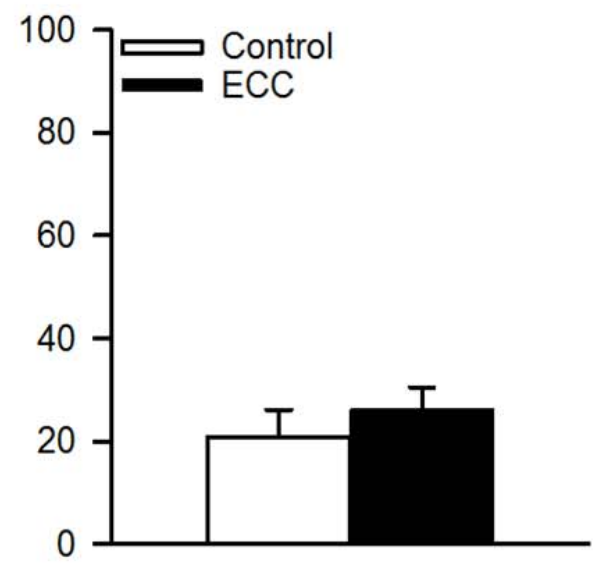

FIGURE 8. Comparison of bioelectric responses of NHBEs to (A) apically-applied amiloride $\left(3.5 \times 10^{-5} \mathrm{M}\right)$, (B) apically-applied NPPB $\left(10^{-4} \mathrm{M}\right)$ and $(\mathrm{C})$ basolaterally-applied ouabain $\left(10^{-4} \mathrm{M}\right)$ between control cells and ECCs. 


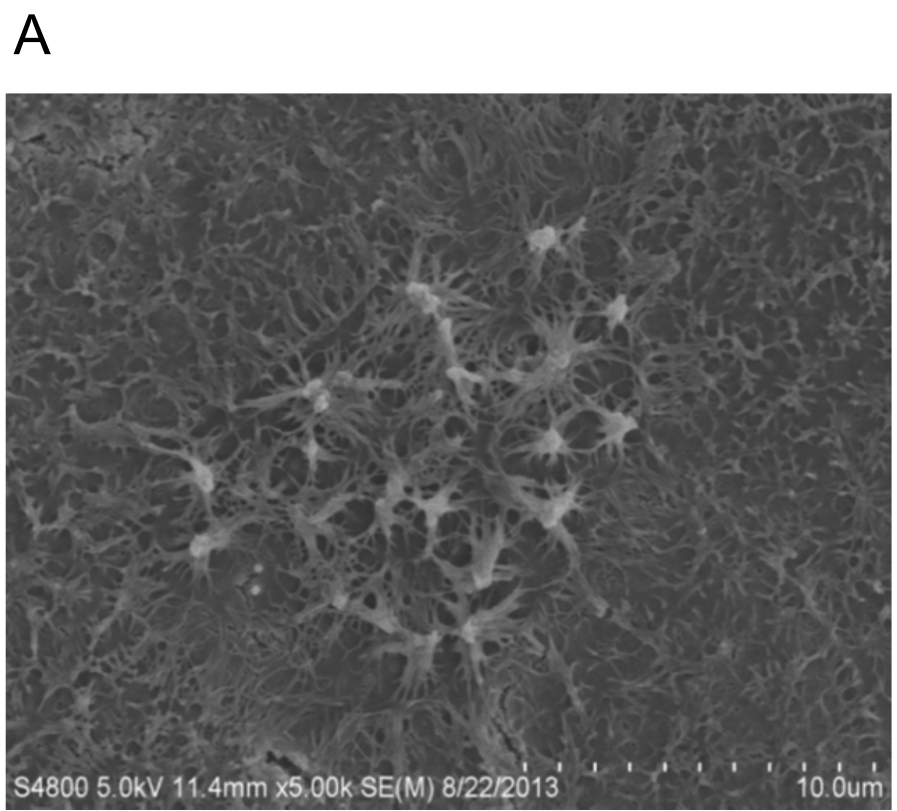

B

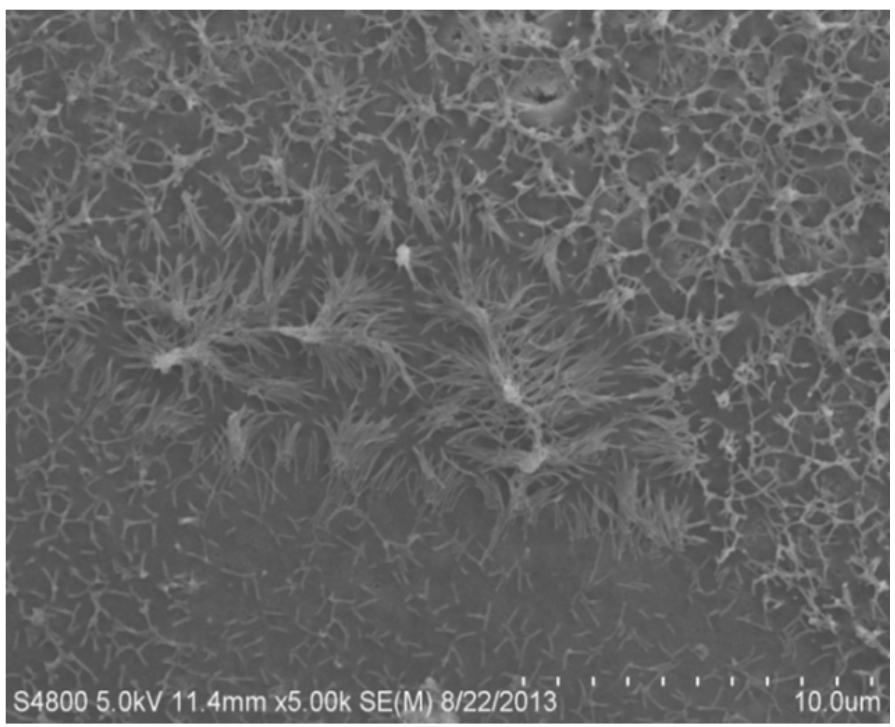

FIGURE 9. SEM image of the apical surface of differentiated NHBEs and cells exposed to 25 ppm diacetyl.

(A) SEM images of control cells and (B) 25 ppm diacetyl-exposed cells. 


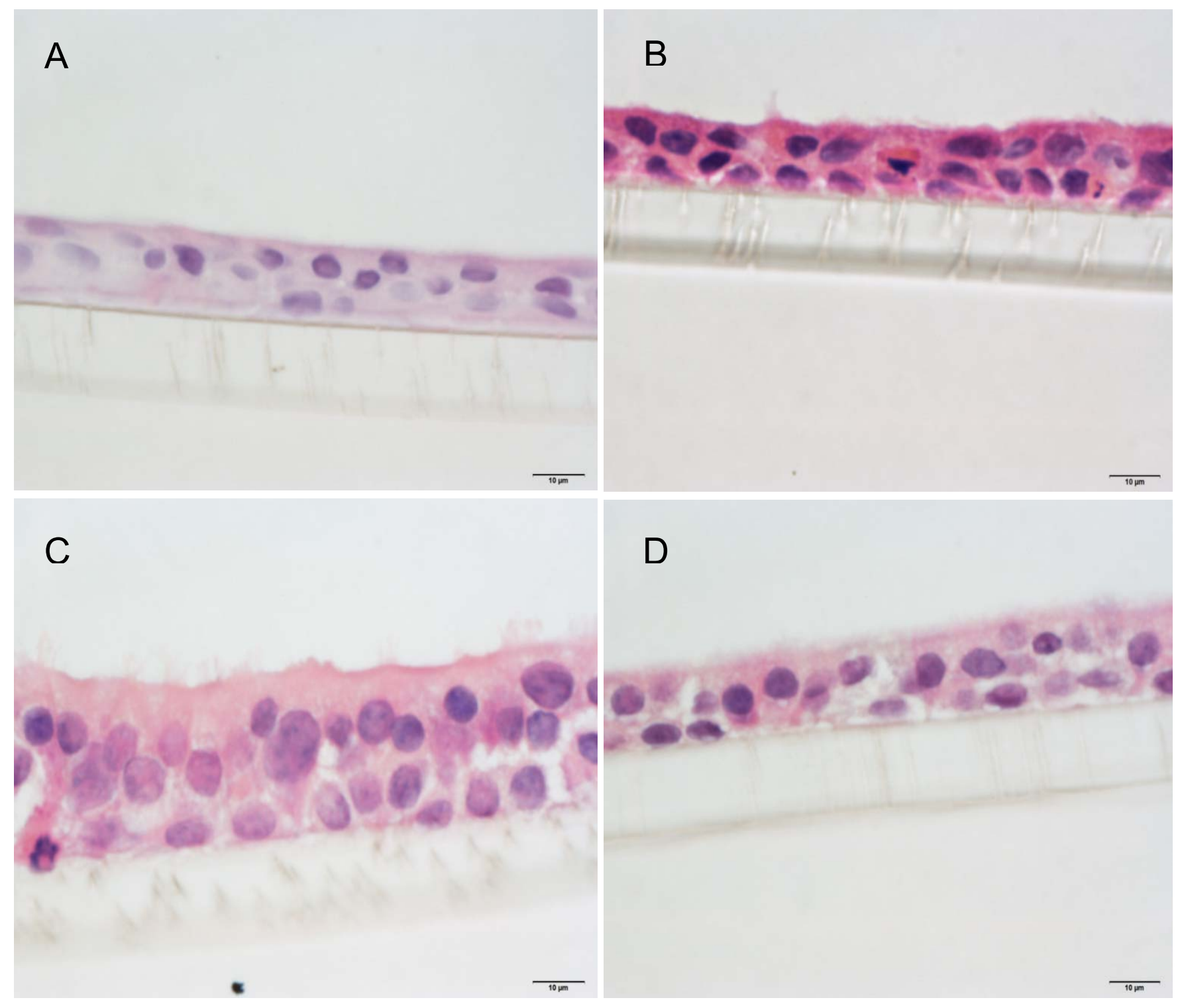

FIGURE 10. H\&E staining (objective magnification = 100x) illustrating similar morphology between control NHBEs and cells viewed after a 6-h diacetyl or a 2,3-pentanedione (25 ppm) exposure. (A) Unexposed, control NHBEs, (B) ECC NHBEs, (C) cells exposed to diacetyl and (D) cells exposed to 2,3-pentanedione. Bar $=10 \mu \mathrm{m}$. 


\section{Controls}
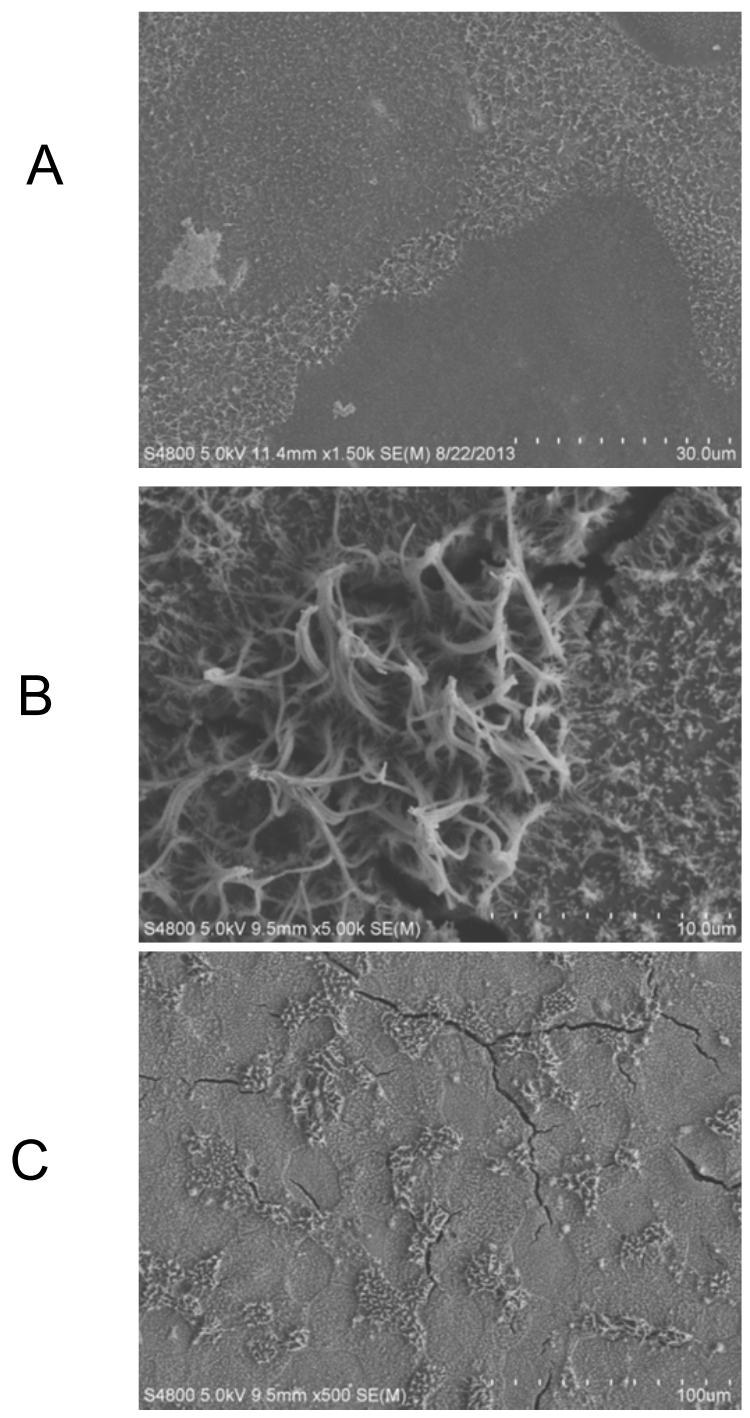

\section{Flavoring exposed cells}
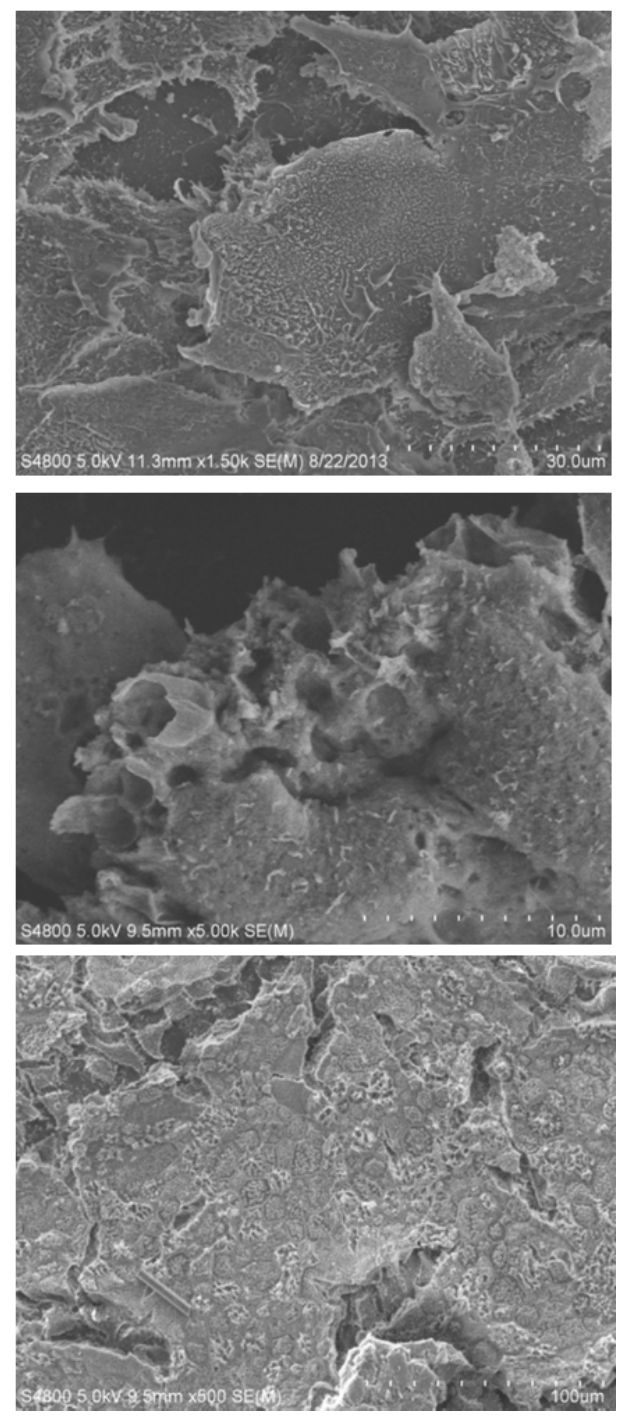

FIGURE 11. SEM image of the apical surface of NHBE control cells and cells exposed to diacetyl $(60,100$, and 360 ppm). (A) SEM images of control cells (left panel) compared to $60 \mathrm{ppm}$ diacetyl exposed cells (right panel). (B) Control cells (left panel) compared to 100 ppm diacetyl exposed cells (right panel). (C) Control cells (left panel) compared to $360 \mathrm{ppm}$ diacetyl exposed cells (right panel). 

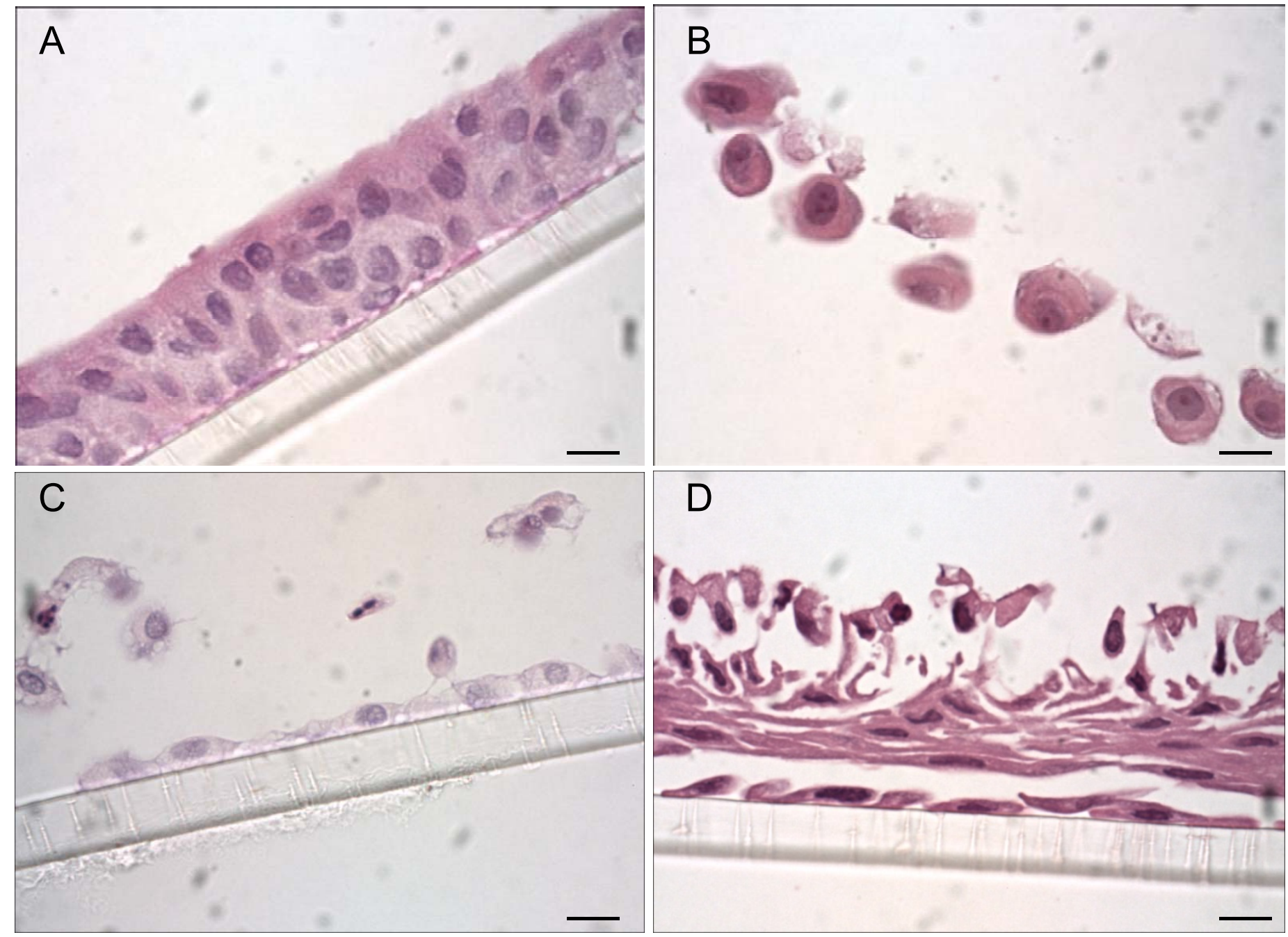

FIGURE 12. H\&E images (objective magnification = 100x) illustrating diacetyl $(100,200,300$ ppm)-induced cell death. (A) Unexposed, control epithelial cells demonstrating the presence of a confluent, pseudostratified epithelial cell culture. (B) Cells exposed to diacetyl at 100 ppm, (C) 200 ppm and (D) 300 ppm. $\operatorname{Bar}=10 \mu \mathrm{M}$. 

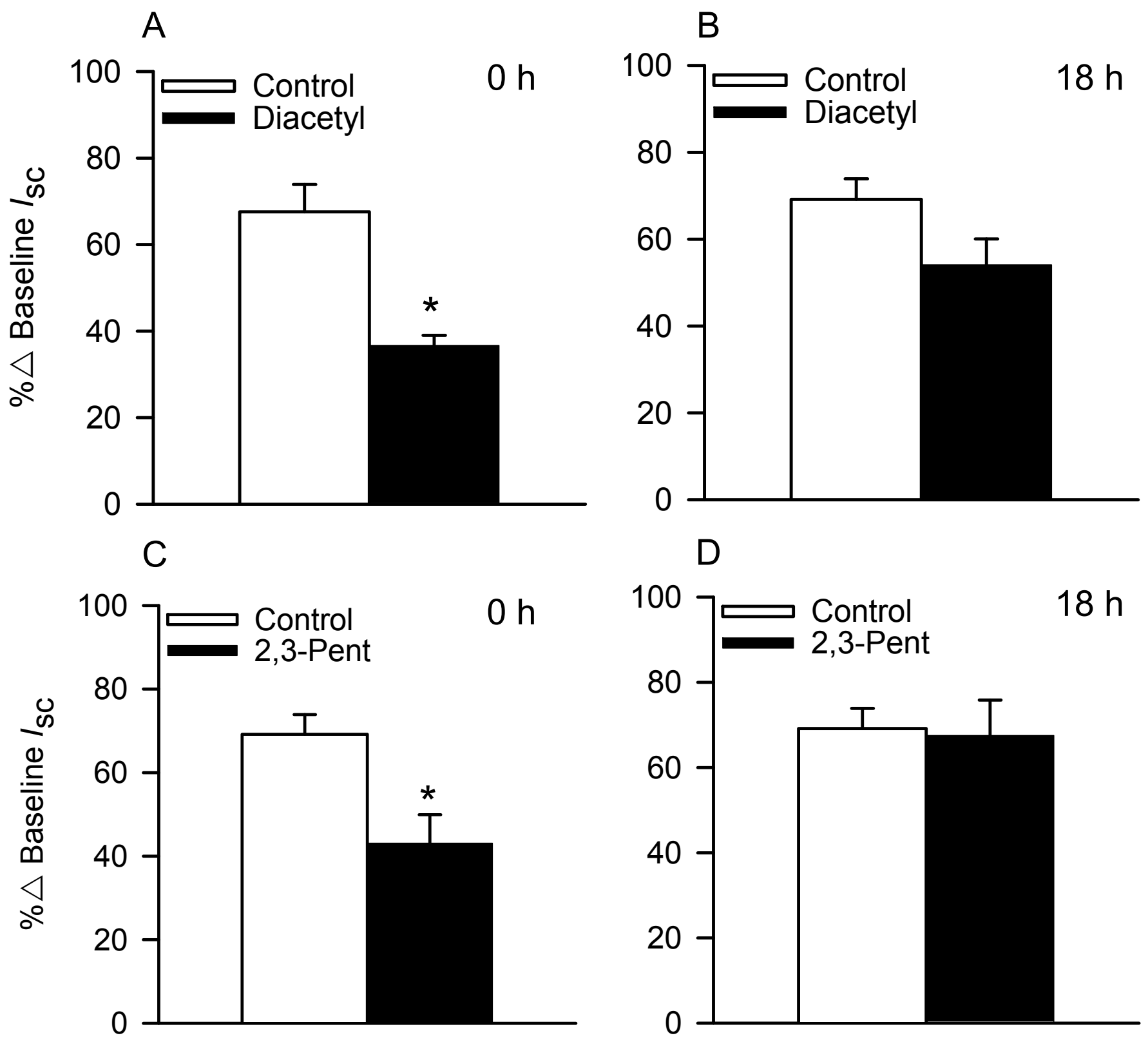

FIGURE 13. Effects of flavoring (25 ppm) on bioelectric responses of NHBEs to apically-applied amiloride $\left(3.5 \times 10^{-5} \mathrm{M}\right)$ at $0 \mathrm{~h}$ and $18 \mathrm{~h}$ post-exposure. (A) Responses to amiloride after air or diacetyl (25 ppm) exposure at the $0 \mathrm{~h}$ time point and (B) $18 \mathrm{~h}$ time point. (C) Response to amiloride after 2,3-pentanedione (2,3-pent; $25 \mathrm{ppm}$ ) exposure at the $0 \mathrm{~h}$ time point and (D) the $18 \mathrm{~h}$ time point. *Significantly different from control $(p<0.05)$. 

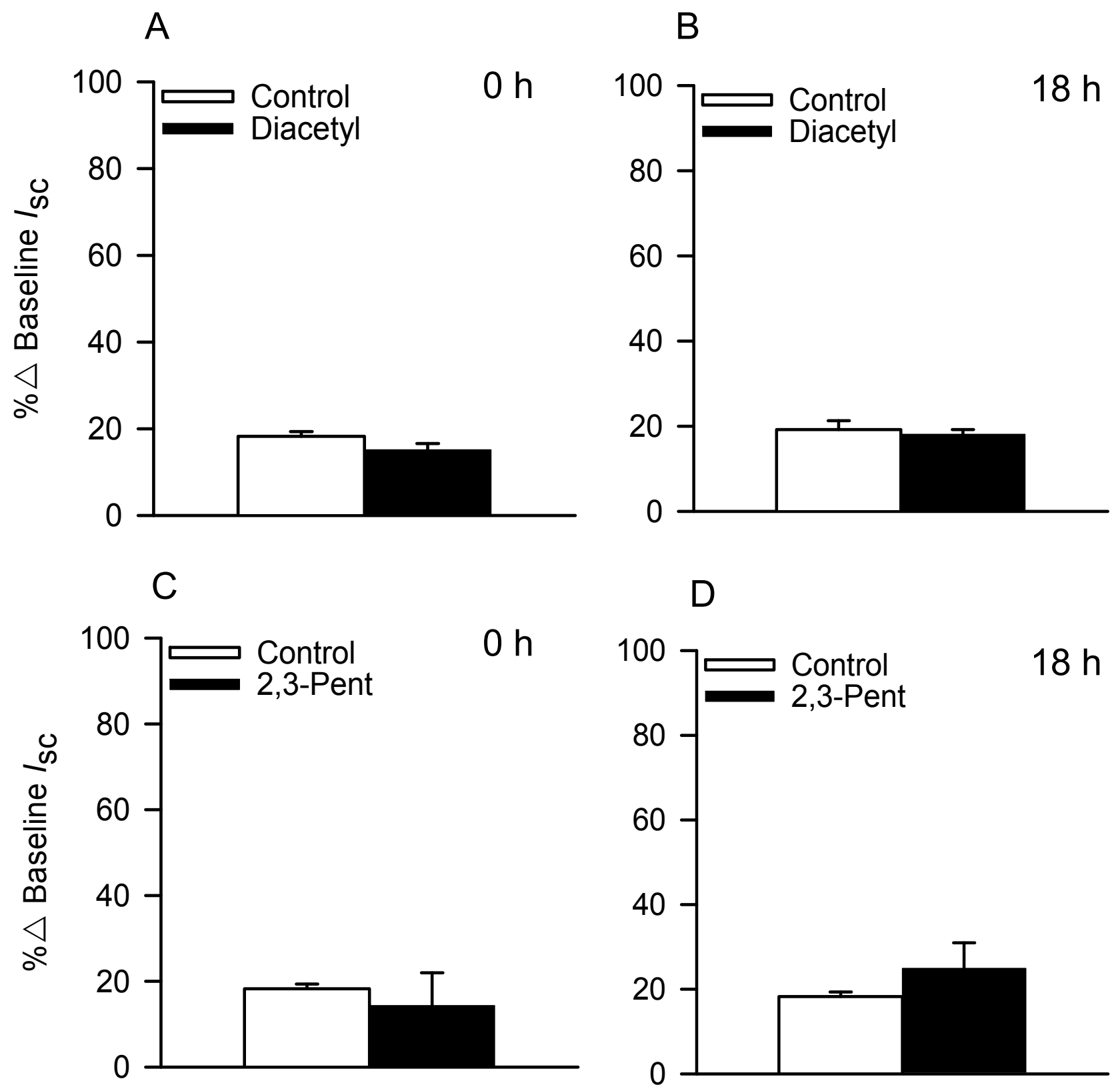

FIGURE 14. Effects of flavoring (25 ppm) on bioeletric responses of NHBEs to apically-applied NPPB $\left(10^{-4} \mathrm{M}\right)$. (A) Responses to NPPB after air or diacetyl (25 ppm) exposure at the $0 \mathrm{~h}$ time point and (B) the $18 \mathrm{~h}$ time point. (C) Response to NPPB at the $0 \mathrm{~h}$ and (D) the $18 \mathrm{~h}$ time point following 2,3-pentanedione (2,3-Pent; 25 ppm) exposure. 

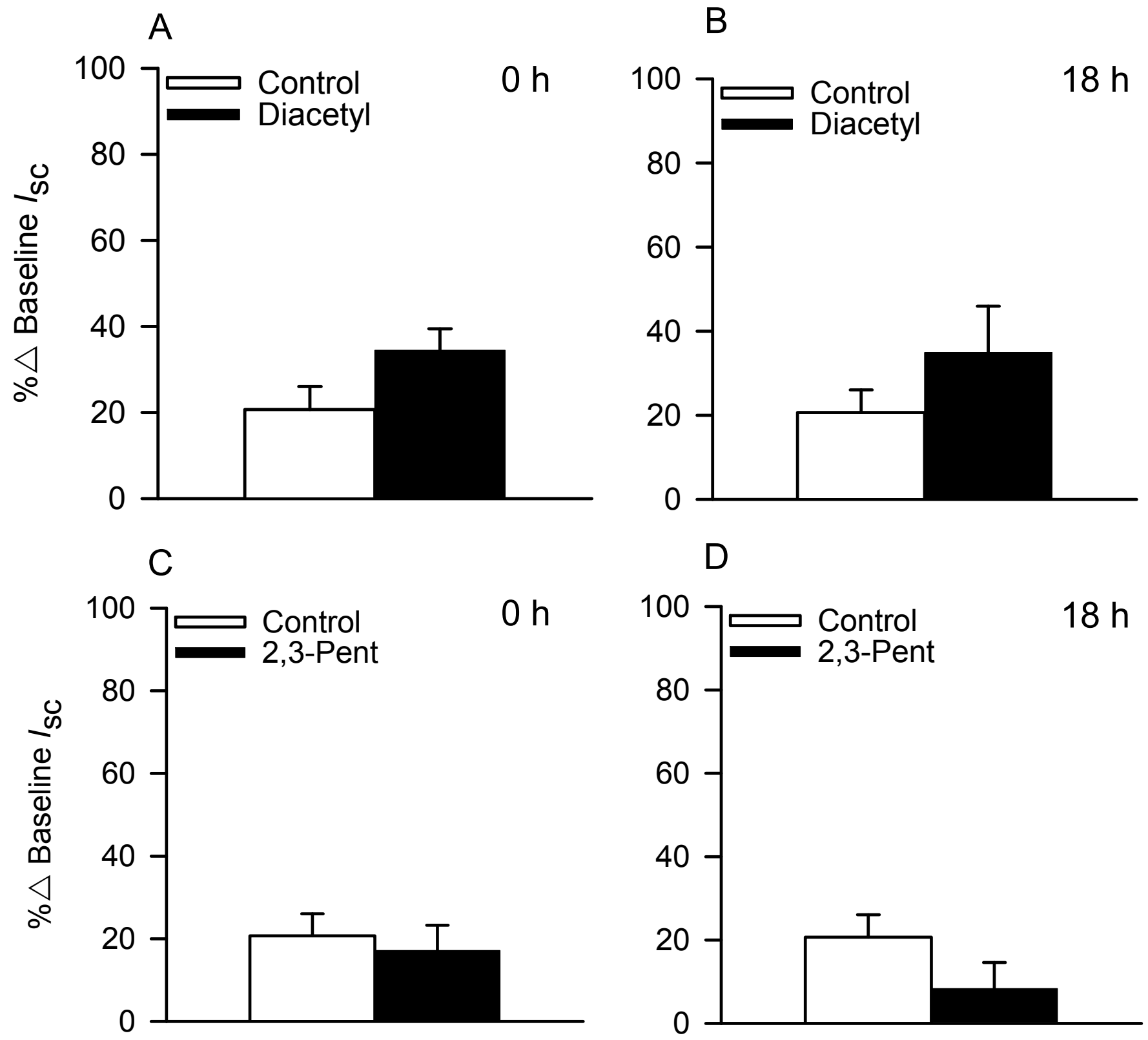

FIGURE 15. Effects of flavoring (25 ppm) on bioeletric responses of NHBEs to basolaterally-applied ouabain $\left(10^{-4} \mathrm{M}\right)$. (A) Responses to ouabain after air or diacetyl (25 ppm) exposure at the $0 \mathrm{~h}$ time point and (B) the $18 \mathrm{~h}$ time point. $(C)$ Response to ouabain at the $0 \mathrm{~h}$ and $(\mathrm{D})$ the $18 \mathrm{~h}$ time point after 2,3-pentanedione (2,3-Pent; 25 ppm) exposure. 


\subsection{Discussion}

Abnormal ion transport has been associated with dysfunction in mucociliary clearance (Danahay et al., 2002; Eisenhut, 2006; Houtmeyers et al., 1999). We investigated whether diacetyl and 2,3-pentanedione exposure affects ion transport in cultured NHBEs. These experiments demonstrated that cells exposed to flavoring concentrations as low as 25 ppm displayed changes in ion transport without disrupting tight junction integrity and resulting in cell death as demonstrated by microscopy. The exposure to butter flavorings significantly reduced responses to amiloride but did not alter responses to NPPB or ouabain. Thus, $\mathrm{Na}^{+}$transport but not $\mathrm{Cl}^{-}$or $\mathrm{Na}^{+}, \mathrm{K}^{+}$-ATPase were altered by flavoring exposure. Overall, our findings indicate that alterations in ion transport occur at lower diacetyl and 2,3-pentanedione concentrations than those that induce morphological damage. Thus, changes in ion transport may be among the earliest toxic effects of flavorings on the epithelium.

In inhalation studies using animal models, Hubbs et al. (2012) demonstrated that 2,3-pentanedione (318 ppm) inhalation did not result in severe epithelial damage immediately after exposure. Respiratory epithelial injury in the nasal cavity involved both apoptosis and necrosis, which progressed hours after exposure. Cell death was significantly greater at $18 \mathrm{~h}$, as opposed to immediately after exposure. Thus, we anticipated the $18 \mathrm{~h}$ time point to result in more prominent changes in $I_{\mathrm{sc}}$ or result in greater cytotoxicity. Contrary to these results, after the initial effects of flavorings on ion transport at a $0 \mathrm{~h}$ time point, the cells appear to recover $18 \mathrm{~h}$ after exposure to $25 \mathrm{ppm}$ of flavorings.

It is not known if these effects on ion transport are attributed to the release of cytokines by the epithelial cells or direct interaction of $\alpha$-diketones on the $\mathrm{Na}^{+}$channel. 
Sun et al. (2013) demonstrated that a 30 min exposure to diacetyl (10 mM) stimulates ROS-dependent epithelial production of neutrophil chemoattractant IL-8 in cultured human airway epithelial ( $\mathrm{NCl}-\mathrm{H} 292)$ cells. Cytokines such as IL-4 have been shown to reduce the expression of $\beta$ and $\mathrm{y}$ units of $\mathrm{ENaC}$ and is associated with inhibition of the amiloride-sensitive $\mathrm{Na}^{+}$channel (Eisenhut, 2006; Galietta et al., 2004). IL-1 $\beta$ has also been found to reduce $\mathrm{ENaC}$ function in human bronchial epithelial cells without reducing ENaC expression (Gray et al., 2004). Whether inflammatory mediators are associated with reduced airway $\mathrm{Na}^{+}$transport following flavoring exposure requires further study. Interaction of diacetyl reacting with arginine-containing peptides and proteins is well documented (Borders and Riordan, 1975; Epperly and Dekker, 1989; Mathews et al., 2010; Mueller et al., 1995). Thus, covalent binding of these $\alpha$-diketones with $\mathrm{Na}^{+}$ channels, such as $\mathrm{ENaC}$, may be a potential cause of the attenuated response to amiloride.

Acute flavoring affects in the airways can now be associated with imbalances of fluid secretion due to altered $\mathrm{Na}^{+}$transport. In a previous investigation, rats were exposed to either diacetyl or 2,3-pentanedione (100 - 360 ppm). The lower doses used in these animal inhalation exposures failed to result in increased reactivity to $\mathrm{MCh}$ in vivo (inhaled MCh aerosol) and in vitro (isolated, perfused trachea), indicative that there may be less toxic effect on the airway epithelium at lower concentrations (100 - 240 ppm). In contrast, all concentrations, including the lowest $(100 \mathrm{ppm})$ used in the animal inhalation studies, demonstrated cytotoxicity in cultured epithelial cells.

\subsection{Conclusion}

All concentrations of diacetyl and 2,3-pentanedione above $60 \mathrm{ppm}$ abolished $\mathrm{V}_{\mathrm{t}}$ and 
$\mathrm{R}_{\mathrm{t}}$ in cultured cells. Thus, cell death in culture occurs after similar exposure concentrations that do not result in hyperreactivity in vivo or in vitro. The electrophysiological changes immediately after the end of the $25 \mathrm{ppm}$ exposure, which did not result in cell death, help establish concentration-dependency in the toxic effects of flavorings on human airway epithelium. Immediately after 25 ppm flavoring exposure, amiloride-sensitive $\mathrm{Na}^{+}$transport was reduced, and $\mathrm{R}_{t}$ was unaffected. Apical $\mathrm{Na}^{+}$ transport was able to recover $18 \mathrm{~h}$ after $(25 \mathrm{ppm})$ exposures. The results are consistent with the proposed notion that these channels are initially affected by diacetyl and 2,3pentanedione vapor exposure. Thus, reductions in $\mathrm{Na}^{+}$transport following a-diketone exposure may be detected early in PWL disease. 


\subsection{References}

Akpinar-Elci, M., Travis, W. D., Lynch, D. A., and Kreiss, K. 2004. Bronchiolitis obliterans syndrome in popcorn production plant workers. Eur. Respir. J. 24: 298-302.

Balharry, D., Sexton, K., and Berube, K. A. 2008. An in vitro approach to assess the toxicity of inhaled tobacco smoke components: Nicotine, cadmium, formaldehyde and urethane. Toxicol. 244: 66-76.

Borders, C. L., Jr., and Riordan, J. F. 1975. An essential arginyl residue at the nucleotide binding site of creatine kinase. Biochemistry 14: 4699-4704.

Boylstein, R., Piacitelli, C., Grote, A., Kanwal, R., Kullman, G., and Kreiss, K. 2006. Diacetyl emissions and airborne dust from butter flavorings used in microwave popcorn production. J. Occup. Environ. Hyg. 3: 530-5.

Clarke, L. L. 2009. A guide to Ussing chamber studies of mouse intestine. Am. J. Physiol. Gastr. L. 296: G1151-66.

Danahay, H., Atherton, H., Jones, G., Bridges, R. J., and Poll, C. T. 2002. Interleukin-13 induces a hypersecretory ion transport phenotype in human bronchial epithelial cells. Am. J. Physiol. Lung-C. 282: L226-36.

Day, G., Lebouf, R., Grote, A., Pendergrass, S., Cummings, K., Kreiss, K., and Kullman, G. 2011. Identification and measurement of diacetyl substitutes in dry bakery mix production. J. Occup. Environ. Hyg. 8: 93-103.

Egli, M., Duplain, H., Lepori, M., Cook, S., Nicod, P., Hummler, E., Sartori, C., and Scherrer, U. 2004. Defective respiratory amiloride-sensitive sodium transport predisposes to pulmonary oedema and delays its resolution in mice. J. Physiol. 560: 857-865. 
Eisenhut, M. 2006. Changes in ion transport in inflammatory disease. J. Inflamm. (Lond) 3: 5.

Epperly, B. R., and Dekker, E. E. 1989. Inactivation of Escherichia coli L-threonine dehydrogenase by 2,3-butanedione. Evidence for a catalytically essential arginine residue. J. Biol. Chem. 264: 18296-18301.

Fedan, J. S., Dowdy, J. A., Fedan, K. B., and Hubbs, A. F. 2006. Popcorn worker's lung: In vitro exposure to diacetyl, an ingredient in microwave popcorn butter flavoring, increases reactivity to methacholine. Toxicol. Appl. Pharmacol. 215: 17-22.

Galietta, L. J. V., Folli, C., Caci, E., Pedemonte, N., Taddei, A., Ravazzolo, R., and Zegarra-Moran, O. 2004. Effect of inflammatory stimuli on airway ion transport. Proc. Am. Thorac. Soc. 1: 62-65.

Gray, T., Coakley, R., Hirsh, A., Thornton, D., Kirkham, S., Koo, J. S., Burch, L., Boucher, R., and Nettesheim, P. 2004. Regulation of MUC5AC mucin secretion and airway surface liquid metabolism by IL-1ß in human bronchial epithelia. Am. J. Physiol. Lung-C 286: 320-330.

Hamann, S., Herrera-Perez, J. J., Zeuthen, T., and Alvarez-Leefmans, F. J. 2010. Cotransport of water by the $\mathrm{Na}^{+}-\mathrm{K}^{+}-2 \mathrm{Cl}^{-}$cotransporter NKCC1 in mammalian epithelial cells. J. Physiol. 588: 4089-101.

Harris, A., 1996. Epithelial cell culture. Cambridge University Press, Cambridge England; New York, NY.

Hollenhorst, M. I., Richter, K., and Fronius, M. 2011. Ion transport by pulmonary epithelia. J. Biomed. Biotechnol. 2011: 174306.

Houtmeyers, E., Gosselink, R., Gayan-Ramirez, G., and Decramer, M. 1999. Regulation of mucociliary clearance in health and disease. Eur. Respir. J. 13: 1177-88. 
Hubbs, A. F., Battelli, L. A., Goldsmith, W. T., Porter, D. W., Frazer, D., Friend, S., Schwegler-Berry, D., Mercer, R. R., Reynolds, J. S., Grote, A., Castranova, V., Kullman, G., Fedan, J. S., Dowdy, J., and Jones, W. G. 2002. Necrosis of nasal and airway epithelium in rats inhaling vapors of artificial butter flavoring. Toxicol. Appl. Pharm. 185: 128-35.

Hubbs, A. F., Cumpston, A. M., Goldsmith, W. T., Battelli, L. A., Kashon, M. L., Jackson, M. C., Frazer, D. G., Fedan, J. S., Goravanahally, M. P., Castranova, V., Kreiss, K., Willard, P. A., Friend, S., Schwegler-Berry, D., Fluharty, K. L., and Sriram, K. 2012. Respiratory and olfactory cytotoxicity of inhaled 2,3-pentanedione in Sprague-Dawley rats. Am. J. Pathol. 181: 829-44.

Hubbs, A. F., Goldsmith, W. T., Kashon, M. L., Frazer, D., Mercer, R. R., Battelli, L. A., Kullman, G. J., Schwegler-Berry, D., Friend, S., and Castranova, V. 2008. Respiratory toxicologic pathology of inhaled diacetyl in Sprague-Dawley rats. Toxicol. Pathol. 36: 330-44.

Jeffery, P. K., and Reid, L. 1975. New observations of rat airway epithelium: A quantitative and electron microscopic study. J. Anat. 120 (Pt 2): 295-320.

Knowles, M. R., Olivier, K. N., Hohneker, K. W., Robinson, J., Bennett, W. D., and Boucher, R. C. 1995. Pharmacologic treatment of abnormal ion transport in the airway epithelium in cystic fibrosis. Chest 107 (2 Suppl): 71S-76S.

Kreiss, K., Gomaa, A., Kullman, G., Fedan, K., Simoes, E. J., and Enright, P. L., 2002. Clinical bronchiolitis obliterans in workers at a microwave-popcorn plant. New Engl. J. Med. 347: 330-8.

Lockey, J. E., Hilbert, T. J., Levin, L. P., Ryan, P. H., White, K. L., Borton, E. K., Rice, C. H., Mckay, R. T., and Lemasters, G. K. 2009. Airway obstruction related to 
diacetyl exposure at microwave popcorn production facilities. Eur. Respir. J. 34: 63-71.

Mathews, J. M., Watson, S. L., Snyder, R. W., Burgess, J. P., and Morgan, D. L. 2010. Reaction of the butter flavorant diacetyl (2,3-butanedione) with $\mathrm{N}$-a-acetylarginine: A model for epitope formation with pulmonary proteins in the etiology of obliterative bronchiolitis. J. Agric. Food Chem. 58: 12761-8.

Matsunaga, T., Kamiya, T., Sumi, D., Kumagai, Y., Kalyanaraman, B., and Hara, A. 2008. L-xylulose reductase is involved in 9,10-phenanthrenequinone-induced apoptosis in human T lymphoma cells. Free Radic. Biol. Med. 44: 1191-202.

Matthay, M. A., Folkesson, H. G., and Clerici, C. 2002. Lung epithelial fluid transport and the resolution of pulmonary edema. Physiol. Rev. 82: 569-600.

Morgan, D. L., Flake, G. P., Kirby, P. J., and Palmer, S. M. 2008. Respiratory toxicity of diacetyl in c57bl/6 mice. J. Toxicol. Sci. 103: 169-80.

Morgan, D. L., Jokinen, M. P., Price, H. C., Gwinn, W. M., Palmer, S. M., and Flake, G. P. 2012. Bronchial and bronchiolar fibrosis in rats exposed to 2,3-pentanedione vapors: Implications for bronchiolitis obliterans in humans. Toxicol. Pathol. 40: 448-65.

Morris, J. B. 2012. Biologically-based modeling insights in inhaled vapor absorption and dosimetry. Pharmacol. Therapeut. 136: 401-13.

Morris, J. B., and Hubbs, A. F. 2009. Inhalation dosimetry of diacetyl and butyric acid, two components of butter flavoring vapors. Toxicol. Sci. 108: 173-83.

Mueller, M. J., Samuelsson, B., and Haeggstrom, J. Z. 1995. Chemical modification of leukotriene A4 hydrolase. Indications for essential tyrosyl and arginyl residues at the active site. Biochemistry 34: 3536-3543. 
Palmer, S. M., Flake, G. P., Kelly, F. L., Zhang, H. L., Nugent, J. L., Kirby, P. J., Foley, J.F., Gwinn, W. M. and Morgan, D. L. 2011. Severe airway epithelial injury, aberrant repair and bronchiolitis obliterans develops after diacetyl instillation in rats. PLoS One. 6: e17644.

Nakagawa, J., Ishikura, S., Asami, J., Isaji, T., Usami, N., Hara, A., Sakurai, T., Tsuritani, K., Oda, K., Takahashi, M., Yoshimoto, M., Otsuka, N., and Kitamura, K. 2002. Molecular characterization of mammalian dicarbonyl//-xylulose reductase and its localization in kidney. J. Biol. Chem. 277: 17883-91.

Schachter, E. N., 2002. Popcorn worker's lung. New Engl. J. Med. 347 (5), 360-1.

Sun, J., Kelly, F. L., Morgan, D. L., Martinu, T., and Palmer, S. M. 2013. Oxidative stress in diacetyl-induced airway epithelial injury and bronchiolitis obliterans. Am. J. Respir. Crit. Care Med. 187: A3369.

van Rooy, F. G., Rooyackers, J. M., Prokop, M., Houba, R., Smit, L. A. and Heederik, D. J. 2007. Bronchiolitis obliterans syndrome in chemical workers producing diacetyl for food flavorings. Am. J. Resp. Crit. Care 176: 498-504.

van Rooy, F. G., Smit, L. A., Houba, R., Zaat, V. A., Rooyackers, J. M. and Heederik, D. J. 2009. A cross-sectional study of lung function and respiratory symptoms among chemical workers producing diacetyl for food flavourings. Occup. Environ. Med. 66: 105-110.

Wu, D. X., Johnston R. A., Rengasamy, A., Van Scott, M. R., and Fedan, J. S. 2004. Hyperosmolar solution effects in guinea pig airways. II. Epithelial bioelectric responses to relative changes in osmolarity. J. Pharmacol. Exp. Ther. 308: 19-29.

Zaccone, E. J., Thompson, J. A., Ponnoth, D. S., Cumpston, A. M., Goldsmith, W. T., Jackson, M. C., Frazer, D. G., Hubbs, A. F., Shimko, M. and Fedan, J. S. 2013. 
Popcorn flavoring effects on reactivity of rat airways in vivo and in vitro. J. Toxicol. Env. Heal. A. 76: 669-689. 


\section{Chapter 5}

\section{Dicarbonyl/L-xylulose reductase (DCXR) metabolizes diacetyl and 2,3-pentanedione in NHBEs}

\subsection{DCXR}

DCXR is an enzyme that is highly expressed in the kidney and liver of both human and rodent tissues (Nakagawa et al., 2002). In the urinate cycle, DCXR catalyzes the nicotinamide adenine dinucleotide phosphate (NADPH)-dependent reduction of Lxylulose to xylitol, accounting for $\sim 5 \%$ of the total glucose metabolized per day in humans (Nakagawa et al., 2002; Matsunaga et al., 2008). Expression of DCXR has also been detected in the mitochondria and cytosol in rat and human airway epithelial cells (Hubbs et al., 2012; Ishikura et al., 2001; Nakagawa et al., 2002). Through the production of xylitol (an osmolyte), the enzyme is responsible for water reabsorption and cellular osmoregulation in the proximal tubules and decreasing airway surface liquid $\mathrm{Na}^{+}$ concentration, as well as enhancing antimicrobial defense in the airways (Nakagawa et al., 2002; Zabner et al., 2000).

DCXR also plays an important role in the reduction of a-dicarbonyl compounds, in order to detoxify endogenous and xenobiotic carbonyls such as glyoxal, 3deoxyglucosone, and methylglyoxal, all of which may potentially be converted to toxic advanced glycation end products (AGEs)(Lee et al., 2013; Matsunaga et al., 2008; Odani et al., 2008). Covalent AGE modifications alter structure and function of proteins and are usually involved in the pathogenesis of kidney disease (Suzuki and Miyata, 1999; 
Thomas, 2011). Thus, DCXR performs critical roles in both carbohydrate metabolism as well as detoxification (Lee et al., 2013).

Although DCXR is typically referred to as a detoxifying enzyme, it has, in contrast, also been associated with diseases that involve carbonyl stress, such as diabetes and cataracts, as well as playing a role in cancer, such as prostate cancer and melanoma (Cho-Vega et al., 2007; Lee et al., 2013). The enzyme has been associated with generating reactive oxygen species (ROS). Matsunaga et al. (2008) investigated the mechanism of the 9,10-phenanthrenequinone (9,10-PQ)-induced apoptosis, and found that DCXR is a ROS-generating enzyme. In addition, the 9,10-PQ-induced apoptosis was decreased using DCXR-specific inhibitors (Matsunaga et al., 2008). Thus, in contrast to the protective role of DCXR, it also generates ROS and contributes to cytotoxicity in vitro.

a-Diketones, such as diacetyl have been demonstrated to be metabolized in nasal and tracheal tissues of rats by DCXR (Gloede et al., 2011; Morris, 2012; Hubbs and Morris, 2009). Research into the differences in flavoring effects between rodents and humans led to development of a PBPK model, which suggested diacetyl and 2,3pentanedione absorption in the airways is augmented by local DCXR-mediated metabolism (Morris, 2012; Hubbs and Morris, 2009). Although it is known that DCXR metabolizes diacetyl and 2,3-pentanedione, little is known about the role of DXCR in flavoring-induced cell death.

\subsection{Role of DCXR in flavoring-induced toxicity}

Diacetyl is metabolized to acetoin by DCXR (Otsuka et al., 1996; Matsunaga et al., 2008; Nakagawa et al., 2002). Similar a-dicarbonyl compounds are also metabolized 
by DCXR, such as 2,3-pentanedione, which is metabolized to give rise to 2-hydroxy-3pentanone (Calam et al., 2013; Ishikura et al., 2001; Nakagawa et al., 2002).

In rats, DCXR is expressed in the cytoplasm of the olfactory neuroepithelium (Hubbs et al., 2012). Activation of caspase 3 and upregulation of inflammatory mediators such as IL-6 have been demonstrated in rat olfactory nerve bundles following 2,3pentanedione inhalation exposure, contributing to apoptosis and necrosis (Hubbs et al., 2012). Toxicity in the neuroepithelium involved olfactory neurons that had reduced expression of DCXR, whereas the sustentacular cells that had greater DCXR expression, demonstrated little injury following 2,3-pentanedione exposure (Hubbs et al., 2012). This likely indicates a protective role of DCXR in flavoring-exposed rats.

As mentioned in Chapter 4, using a custom-made exposure chamber for exposing NHBEs to flavoring vapors, we wanted to characterize flavoring toxicity in the cells, both in terms of concentration-response relationships and mechanisms of toxicity. We hypothesized that epithelial ion transport may be among the first targets associated with flavoring toxicity.

NHBEs were exposed to diacetyl or 2,3-pentanedione (25 ppm) vapors for $6 \mathrm{~h}$. After exposure, cells were placed in an Ussing chamber either after a $0 \mathrm{~h}$ or $18 \mathrm{~h}$ postexposure. From this study, we had demonstrated that $6 \mathrm{~h}$ flavoring exposure significantly reduced amiloride-sensitive $\mathrm{Na}^{+}$transport at the $0 \mathrm{~h}$ time point. However, $\mathrm{Na}^{+}$transport was not affected $18 \mathrm{~h}$ post-exposure, suggesting that transport recovery had occurred.

We questioned whether metabolism of diacetyl and 2,3-pentanedione by DCXR occurs in NHBEs and determined whether NHBEs were capable of metabolizing diacetyl and 2,3-pentanedione during vapor exposure. Thus, the focus of this investigation to was determine if DCXR was present and active in the NHBEs and whether this enzyme metabolized diacetyl and 2,3-pentanedione. 


\subsection{Materials and methods}

NHBEs were maintained and submerged for 3 days in B-ALI growth medium (100 $\mu \mathrm{l}$ apical; $500 \mu \mathrm{l}$ basal chamber) before $500 \mu \mathrm{l}$ of B-ALI differentiation medium (Lonza, Walkersville, MA) was added to the basal chamber and medium was removed from the apical compartment to initiate the air-liquid interface culture conditions. Before flavoring vapor exposure, the B-ALI medium was replaced with MKHS $(500 \mu \mathrm{l})$ in the basal chamber of the transwell chambers. Cells were exposed for $6 \mathrm{~h}$ to vapors from diacetyl or 2,3-pentanedione (25 ppm). This was accomplished by delivering vapors into the custommade exposure chamber described in Chapter 4.

Immediately after flavoring exposure, MKHS was collected from the basal chamber and was analyzed using GC-mass spectrometry as described in Wells (2012). In order to identify possible oxygenated compounds (i.e., aldehydes, ketones, and dicarbonyls) present in the purchased diacetyl or 2,3-pentandione, $100 \mu$ l of $0-(2,3,4,5,6-$ pentafluoro-benzyl)hydroxylamine hydrochloride (PFBHA)(250 mM in deionized water) was added to the sample (approximately $2 \mathrm{ml}$ ). The sample was heated for approximately $1 \mathrm{~h}$ in a $70{ }^{\circ} \mathrm{C}$ water bath to accelerate the derivatization reaction. The sample was removed from the water bath and once cooled, extracted with $3 \mathrm{ml}$ of methyl tert-butyl ether (MTBE). The MTBE layer, containing the derivatized compounds (oximes) was removed (ca. $2.5 \mathrm{ml}$ ) and blown to dryness with clean air and reconstituted in $100 \mu \mathrm{l}$ methanol. It should be noted that diacetyl or 2,3-pentanedione are also derivatized by PFBHA resulting in diacetyl oxime peaks in the chromatogram. Samples were analyzed using a Varian (Palo Alto, CA) 3800/Saturn 2000 gas chromatograph/mass spectrometer (GC/MS) system operated in the electron impact (EI) mode. Compound separation was achieved by a Restek (Bellefonte, PA) Rtx-5MS (0.25 mm I.D., 30-m long, $1 \mu \mathrm{m}$ film thickness) column and the following GC oven parameters: $40{ }^{\circ} \mathrm{C}$ for $2 \mathrm{~min}$, then ramp 
temperature to $240^{\circ} \mathrm{C}$ at $25^{\circ} \mathrm{C} / \mathrm{min}$ hold for $10 \mathrm{~min}$ then ramp temperature to $280^{\circ} \mathrm{C}$ at 25 ${ }^{\circ} \mathrm{C} / \mathrm{min}$ and hold for $5 \mathrm{~min}$. The GC injector was initially held at $60{ }^{\circ} \mathrm{C}$ for $2 \mathrm{~min}$, then ramped at $200{ }^{\circ} \mathrm{C} \min -1300{ }^{\circ} \mathrm{C}$. Each sample $(1 \mu \mathrm{l})$ was injected in the splitless mode and the injector was returned to split mode $1 \mathrm{~min}$ following sample injection. The Saturn 2000 ion trap mass spectrometer was tuned using perfluorotributylamine (FC-43). Fullscan El spectra were collected from $\mathrm{m} / \mathrm{z}$ 40-650. Acetonitrile was the chemical ionization (Cl) reagent used for all $\mathrm{Cl}$ spectra.

\subsection{Results}

Following NHBE cell exposure to diacetyl (25 ppm), the presence of the diacetyl metabolite, acetoin (Figure 1), was detected in the basolateral MKHS. Following cell exposure to 2,3-pentanedione (25 ppm), the metabolite, 2-hydroxy-3-pentanone (Figure 2), which is similar in structure to acetoin, was also detected in the basolateral MKHS. The findings indicate that DCXR is present in cultured NHBEs, and that it metabolized the flavoring a-diketones during exposure. After flavoring exposure, acetoin or 2-hydroxy-3pentanone were absent in the MKHS from the basolateral chamber of blank inserts that

did not contain cells (data not shown). This data supports the conclusion that the production of metabolites was cell-dependent. 


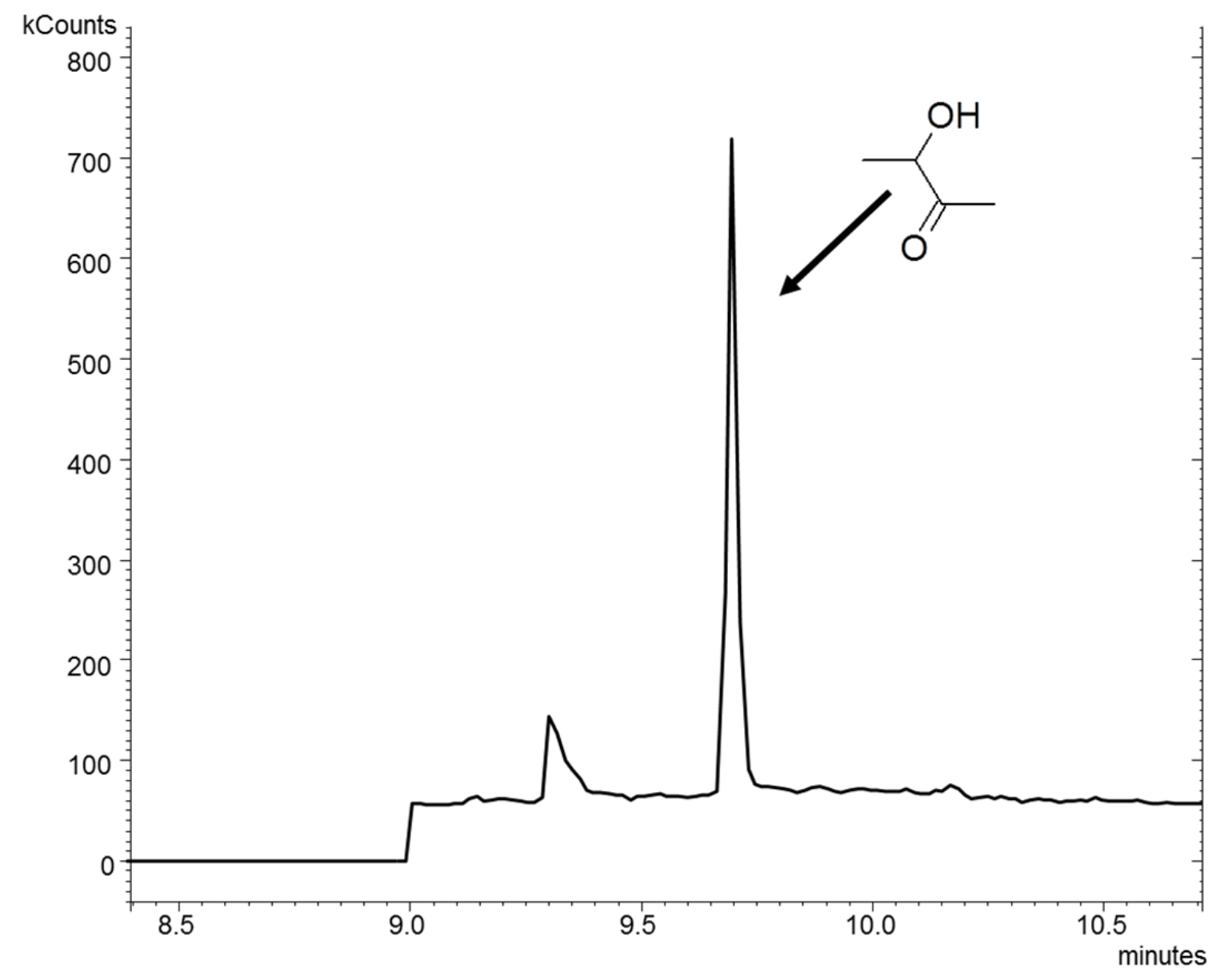

FIGURE 1. Identification of acetoin in basal chamber MKHS following incubation of NHBEs with diacetyl $(25 \mathrm{ppm})$ for $6 \mathrm{~h}$. The arrow indicates the peak identified as the diacetyl metabolite, acetoin. The diacetyl peak is not shown. 


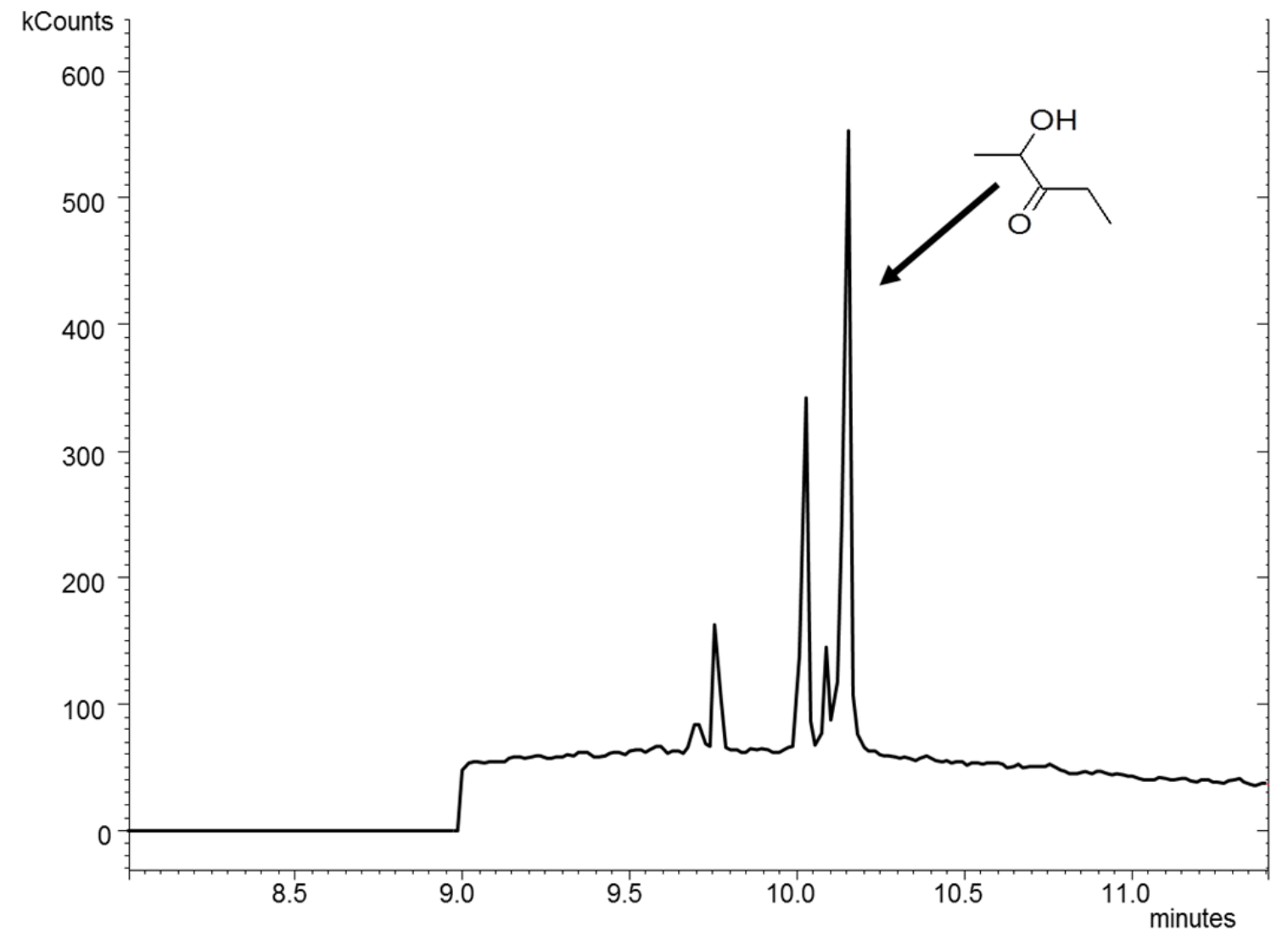

FIGURE 2. Identification of 2-hydroxy-3-pentanone in basal chamber MKHS following incubation of NHBEs with 2,3-pentanedione $(25 \mathrm{ppm})$ for $6 \mathrm{~h}$. The arrow indicates the peak identified as the 2,3-pentanedione metabolite, 2-hydroxy-3pentanone. The additional peaks are unidentified impurities. These peaks might also include other metabolites, but their identity has not been determined at this time. The 2,3-pentanedione peak is not shown. 


\subsection{Discussion}

Our results demonstrated that DCXR metabolizes diacetyl and 2,3-pentanedione in the cultured NHBEs, releasing the metabolite into the submucosal medium. This data also indicates it is possible to monitor the production of metabolites of $\alpha$-diketones by the epithelium with use of our novel exposure chamber. It is still to be determined whether DCXR metabolism may be a contributing factor of electrophysiological changes observed after the flavoring exposures.

Overall, this experiment demonstrates the presence of DCXR in the cultured NHBEs, which metabolizes diacetyl to acetoin and 2,3-pentanedione to 2-hydroxy-3pentanone. Whether DXCR is involved in protecting the epithelium requires further investigation (see Chapter 6). 


\subsection{References}

Calam, E., Porte, S., Fernandez, M. R., Farres, J., Pares, X., and Biosca, J. A. 2013. Biocatalytic production of a-hydroxy ketones and vicinal diols by yeast and human aldo-keto reductases. Chem. Biol. Interact. 202: 195-203.

Cho-Vega, J. H., Vega, F., Schwartz, M. R., and Prieto, V. G. 2007. Expression of dicarbonyl/L-xylulose reductase (DCXR) in human skin and melanocytic lesions: morphological studies supporting cell adhesion function of DCXR. J. Cutan. Pathol. 34: 535-542.

Gloede, E., Cichocki, J. A., Baldino, J. B., and Morris, J. B. 2011. A validated hybrid computational fluid dynamics-physiologically based pharmacokinetic model for respiratory tract vapor absorption in the human and rat and its application to inhalation dosimetry of diacetyl. Toxicol. Sci. 123: 231-246.

Hubbs, A.F., Cumpston, A.M., Goldsmith, W.T., Battelli, L.A., Kashon, M.L., Jackson, M.C., Frazer, D.G., Fedan, J.S., Goravanahally, M.P., Castranova, V., Kreiss, K., Willard, P. A., Friend, S., Schwegler-Berry, D., Fluharty, K.L., and Sriram K. 2012. Respiratory and olfactory cytotoxicity of inhaled 2,3-pentanedione in SpragueDawley rats. Am. J. Pathol. 181: 829-844.

Ishikura, S., Isaji, T., Usami, N., Kitahara, K., Nakagawa, J., and Hara, A. 2001. Molecular cloning, expression and tissue distribution of hamster diacetyl reductase. Identity with L-xylulose reductase. Chem. Biol. Interact. 130-132: 879-889.

Lee, S.-K., Son, L. T., Choi, H.-J., and Ahnn, J. 2013. Dicarbonyl/L-xylulose reductase (DCXR): the multifunctional pentosuria enzyme. Int. J. Biochem. Cell Biol. 45: 2563-2567. 
Matsunaga, T., Kamiya, T., Sumi, D., Kumagai, Y., Kalyanaraman, B., and Hara, A. 2008. L-xylulose reductase is involved in 9,10-phenanthrenequinoneinduced apoptosis in human T lymphoma cells. Free Radic. Biol. Med. 44: 1191-1202

Morris, J. B. 2012. Biologically-based modeling insights in inhaled vapor absorption and dosimetry. Pharmacol. Ther. 136: 401-413.

Morris, J. B., and Hubbs, A. F. 2009. Inhalation dosimetry of diacetyl and butyric acid, two components of butter flavoring vapors. Toxicol. Sci. 108: 173-83.

Nakagawa, J., Ishikura, S., Asami, J., Isaji, T., Usami, N., Hara, A., Sakurai, T., Tsuritani, K., Oda, K., Takahashi, M., Yoshimoto, M., Otsuka, N., and Kitamura, K. 2002. Molecular characterization of mammalian dicarbonyl/L-xylulose reductase and its localization in kidney. J. Biol. Chem. 277: 17883-17891.

Odani, H., Asami, J., Ishii, A., Oide, K., Sudo, T., Nakamura, A., Miyata, N., Otsuka, N., Maeda, K., and Nakagawa, J. 2008. Suppression of renal a-dicarbonyl compounds generated following ureteral obstruction by kidney-specific $\alpha$ dicarbonyl/L-xylulose reductase. Ann. N.Y. Acad. Sci. 1126, 320-324.

Suzuki, D., and Miyata, T. 1999. Carbonyl stress in the pathogenesis of diabetic nephropathy. Intern. Med. 38: 309-314.

Thomas, M. C. 2011. Advanced glycation end products. Contrib. Nephrol. 170: 66-74.

Wells, J. R. 2012. Use of denuder/filter apparatus to investigate terpene ozonolysis. J. Environ. Monit. 14: 1044-1054

Zabner, J., Seiler, M. P., Launspach, J. L., Karp, P. H., Kearney, W. R., Look, D. C., Smith, J. J., and Welsh, M. J. 2000. The osmolyte xylitol reduces the salt concentration of airway surface liquid and may enhance bacterial killing. Proc. Natl. Acad. Sci. USA, 97: 11614-11619. 


\section{Chapter 6}

\section{General Discussion}

\subsection{Specific Aim 1: Establish the concentration-response relationships for butter flavor vapor toxicity in vivo and in vitro}

"Popcorn workers' lung" is a life-threatening, fixed obstructive pulmonary disease caused by inhalation of artificial butter flavoring vapor. Histological evidence from animals exposed by inhalation to the butter flavorings diacetyl and 2,3-pentanedione demonstrated vapor-concentration-dependent damage to epithelial cells (Hubbs et al., 2002, 2008, 2012; Morris and Hubbs, 2009; Morgan et al., 2008, 2012a, 2012b; Palmer et al., 2011). Damage to the rat airway epithelium by inhalation of butter flavoring vapor was expected to increase reactivity to the bronchoconstrictor, $\mathrm{MCh}$. In addition, a recent finding suggested that diacetyl exposure increases SP production in injured regions of the rat tracheal epithelium (Goravanahally et al., 2013). SP released by airway sensory nerves is known to increase ozone and nerve growth factor-induced airway responsiveness in ferret trachea (Goravanahally et al., 2013; Wu and Dey, 2002; Wu et al., 2003; Wu and Dey, 2006). Thus, enhanced airway responsiveness after acute flavoring exposure was anticipated. It was also our intention to compare and contrast the effects of diacetyl and 2,3-pentanedione in the lung in vivo and in vitro, which would prove useful in understanding the progression of this disease.

In Specific Aim 1, our hypothesis was, diacetyl and 2,3-pentanedione damage airway epithelium resulting in hyperreactivity to MCh in vivo and in vitro. In the first series of experiments, animals were exposed by inhalation to diacetyl or 2,3-pentanedione in

order to investigate the flavoring effects on respiratory mechanics $\left(R_{L}\right.$ and $\left.C_{d y n}\right)$ and 
airway reactivity to $\mathrm{MCh}$. It was also of importance to identify the inhalation concentration range over which the flavorings could affect pulmonary function and airway reactivity to MCh. Although one may question whether these flavoring vapors reached the deep lung of rats, the finding that these agents decreased reactivity to MCh suggested they did exert toxic effects in lower airways. It is important to note that 2,3-pentanedione is $\sim 3.3$ fold less soluble in water than diacetyl (Occupational Safety and Health Administration, 2011; National Toxicology Program, 2011), suggesting that it may be less likely to absorb in the mucous layer of the nose and, therefore, may penetrate further into the lung. Deeper penetration of 2,3-pentanedione than diacetyl to the smaller airways would yield a greater toxic effect of this flavoring on the epithelium. Thus, using plethysmography, it was critical to assess and compare altered respiratory mechanics and reactivity to MCh in the lower airways after diacetyl and 2,3-pentanedione exposure.

Despite evidence of epithelial damage in upper airways of the rat observed in previous investigations (Goravanahally et al., 2013; Hubbs et al., 2002, 2008, 2012; Morgan et al., 2008, 2012), which led to the hypothesis that airway hyperreactivity would ensue, basal $R_{L}$ and $C_{d y n}$ were unaffected by inhalation of diacetyl or 2,3-pentanedione. In terms of MCh-induced responses, inhaled diacetyl reduced reactivity $\left(R_{L}\right)$ responses to MCh at one exposure concentration, and 2,3-pentanedione decreased responsiveness at three exposure concentrations (Zaccone et al., 2013). Thus, inhaled popcorn flavorings do not cause airway hyperreactivity in the face of substantial epithelial damage. As well, 2,3-pentanedione may be more toxic than diacetyl in this regard.

Increased $\mathrm{R}_{\mathrm{L}}$, which characterizes clinical bronchiolitis obliterans, was not present after acute exposure to diacetyl or 2,3-pentanedione but may appear after subchronic exposures (Morgan et al., 2012a; Palmer et al., 2011). Since MCh directly affects airway 
smooth muscle, our data suggested that smooth muscle reactivity of rat airways is reduced after high level acute exposures to either diacetyl or 2,3-pentanedione.

Most studies suggested that inhalation of flavorings leads to extensive absorption in the nasal cavity, thus, preventing flavoring penetration to the lower airways (Gloede et al., 2011; Morris and Hubbs, 2009; Morris, 2012; Hubbs et al., 2012). Epithelial necrosis in rat intrapulmonary airways involved the mainstem bronchus and larger bronchioles. These airways and trachea in the rat have dimensions similar to airways in the deep lung of humans (Yeh et al., 1976, 1979). In smaller airways the lumen volume to mucous surface area ratio is less than in large airways, increasing resistance and decreasing air flow (Frederick et al., 1998; Mauroy et al., 2004; Morris et al., 1997, 2012; Morris and Hubbs et al., 2009), resulting in greater mucosal deposition of vapors. This shifts the site of mucosal absorption of flavoring vapors in the upper respiratory tract of rats, compared to the respiratory tract of exposed workers.

With the knowledge that inhalation exposure of rats to diacetyl and 2,3pentanedione affected primarily the upper airways with minimal effects in the distal airways, we decided to investigate the functional consequences of flavoring-induced epithelial damage in the rat trachea. In the second series of experiments in Specific Aim 1, we examined the hypothesis that inhaled flavoring-induced airway epithelial damage increases airway reactivity to MCh in the upper airway (trachea) in vitro. We predicted that reactivity the response to MCh applied to the mucosal surface bath of the perfused trachea $18 \mathrm{~h}$ after a 6-h flavoring exposure would be significantly increased. Overall, diacetyl exposure did not alter airway reactivity to IL MCh in the IPT apparatus (Zaccone et al., 2013). In contrast to the plethysmography data, airway reactivity to MCh was increased at the two highest 2,3-pentanedione exposure concentrations in vivo. Therefore, 2,3-pentanedione was more toxic than diacetyl in terms of increasing airway 
reactivity to $\mathrm{MCh}$ in vitro (isolated, perfused trachea). Although both agents are absorbed by the nasal mucosa to yield equivalent epithelial damage, as judged morphologically (Hubbs et al., 2008, 2012; Morgan et al., 2012b), it is possible that the differing penetrations of diacetyl and 2,3-pentanedione into the trachea may explain some of the differences between the two agents.

We reasoned that the flavoring's effects on the airways would include more than one mechanism, i.e., damage to the epithelium and other toxicological effects in the airway wall, such as direct effects on airway smooth muscle. Due to our results demonstrating negligible change in basal $R_{L}$, basal $C_{d y n}$ and reactivity to $M C h$, and the notion that these a-diketones diffuses rapidly across the epithelium (Morris and Hubbs 2009; Morris 2012), it was postulated that the smooth muscle may be affected by the flavorings in addition to the epithelium.

In order to investigate this notion, the effects of diacetyl and 2,3-pentanedione in perfused rat trachea containing epithelium or lacking epithelium were investigated in the third series of experiments of Specific Aim 1. With use of the IPT, flavorings were administered to an IL or extraluminal (EL) bath to determine their effects on ASM. Our results suggest that diacetyl and 2,3-pentanedione have pharmacological effects on the ASM, eliciting relaxation both in the absence and presence of the epithelium, irrespective of the route of application, i.e., IL or EL (Zaccone et al., 2013). These results rule out relaxation responses as being attributed to the release of epithelial-derived relaxant mediators and indicate that both flavorings elicit similar relaxation effects directly on the ASM. These effects could have contributed to the unusual airway effects on airway reactivity demonstrated after rats inhaled flavoring vapor.

Because butter flavoring vapor consists of many different compounds, other flavorings could alter diacetyl's effects in the airways. One example of this is the reduction 
in diacetyl uptake in airways by a butter flavoring, butyric acid, which inhibits DCXR (Morris and Hubbs, 2009). Therefore, butyric acid can alter diacetyl inhalation dosimetry and toxicity (Morris and Hubbs, 2009). Employees in microwave popcorn factories were exposed to flavoring mixtures which included acetoin, diacetyl, and acetic acid (van Rooy, 2006, 2007, 2009; Hubbs et al., 2002). In addition, diacetyl is known to be metabolized to acetoin in the epithelial cells (Otsuka et al., 1996; Chapter 5). We questioned whether there was potentially enhanced toxicity in the intrapulmonary airways resulting from combined flavoring exposures (diacetyl + acetoin + acetic acid; $250+150+27$ ppm). Thus, in the fourth series of experiments, our goal was to characterize the toxic effects of flavoring compounds alone and potential interactions among flavoring combinations. We investigated whether alterations in $R_{L}$ and $C_{d y n}$, as well as reactivity to inhaled $M C h$, resulted after exposure to acetic acid and acetoin, alone and in combination with inhaled diacetyl as a mixed exposure in vivo. Acetoin $(150 \mathrm{ppm})$ did not alter pulmonary function and airway reactivity to $\mathrm{MCh}$. However, acetic acid (27 ppm) did increase reactivity to inhaled MCh. The most interesting finding from this experiment was the reductions in MCh reactivity when diacetyl was present in the mixed exposure (Zaccone et al., 2013). If diacetyl impeded an augmented response, this would certainly explain failure of acetic acid exposure to produce hyperreactivity to MCh in mixed exposures.

Collectively, all of these results demonstrate that it is necessary to consider the smooth muscle as a target for diacetyl or 2,3-pentanedione exposure, which elicits relaxation and inhibits the contraction induced by MCh. 


\subsection{Specific Aim 2: Investigate the possible involvement of the bitter taste receptor, TAS2R, in relaxant responses of airway smooth muscle (ASM) and bioelectric responses of tracheal epithelial cells in response to flavoring}

GPCR, ODR-10, is a transmembrane receptor responsible for diacetyl olfactory transduction in C. elegans. Because there is evidence of these butter flavorings binding to GPCRs, and that signaling through GPCRs mediates numerous ASM functions such as contraction, relaxation, growth, and secretion of cytokines (Billington and Penn, 2003), we questioned whether $\alpha$-diketone flavorings interact with GPCRs on the ASM, resulting in a failure of the diacetyl and 2,3-pentanedione to induce airway hyperreactivity in vivo, and to limit it in vitro.

The GPCRs, TAS2Rs, have been identified in the airways (Deshpande et al., 2010) and elicit relaxation of ASM. TAS2R-dependent $\mathrm{Ca}^{2+}$ signaling opens $\mathrm{BK}$ Ca channels that result in relaxation (Deshpande et al., 2010). To our knowledge, nothing is known about which receptors these flavorings activate, taste receptors or otherwise; or even if receptors are involved in mediating responses. In Specific Aim 2, the effects of flavorings on tracheal strips were investigated to determine whether $\alpha$-diketone flavorings interact with TAS2Rs, to induce ASM relaxation. In rat tracheal strips contracted with MCh, IbTx significantly reduced the relaxation response to denatonium, suggesting that the responses were mediated by TAS2R. Diacetyl- and 2,3-pentanedione-induced responses were not antagonized by $\mathrm{IbTx}$, suggesting that relaxation was not mediated by TAS2Rs.

Chemical irritation of airway mucosa elicits a variety of reflex responses such as coughing and apnea. Inhaled irritants can activate SCCs. The SCCs can be found in the 
nasal passages and larynx, as well as the bronchi (Tizzano et al., 2010, 2011). Recent studies indicate that SCCs are activated by a variety of chemical stimuli (Gulbransen et al., 2008; Lin et al., 2008; Tizzano et al., 2010, 2011), and trigger protective airway reflexes such as coughing (Finger et al., 2003; Tizzano et al., 2010, 2011). TAS2Rs are expressed in the SCCs of the nasal and tracheal epithelium and these SCCs respond to bitter compounds to evoke protective respiratory reflexes (Krasteva et al., 2010; Tizzano et al., 2011). In addition to SCCs, $\mathrm{BK}_{\mathrm{ca}}$ channels are also present on the airway epithelium. Apical $\mathrm{BK}_{\mathrm{ca}}$ channels in epithelial cells have been demonstrated to be critical for regulating airway surface liquid volume (Manzanares et al., 2011). It has been shown that knockdown of $\mathrm{BK}_{\mathrm{ca}}$ a-subunit expression leads to airway surface liquid dehydration as well as low ciliary beat frequency (Manzanares et al., 2011). Therefore, TAS2Rs as well as $\mathrm{BK}_{\mathrm{ca}}$ channels both play an important role to maintain the health of epithelial cells. In order to investigate whether flavorings could activate TAS2R located in the epithelium, rat tracheal segments containing the epithelium were mounted in Ussing chambers. Denatonium and the flavorings reduced $I_{\mathrm{sc}}$, which was not inhibited in the presence of $\mathrm{IbTx}$ and, therefore, was not mediated by TAS2R. Although bioelectric responses to denatonium and the flavorings were not mediated by TAS2R, it is of interest that these agents did reduce $I_{\mathrm{sc}}$ via an unknown mechanism that requires further investigation. The overall results from these experiments demonstrate that flavoringinduced relaxation and bioelectric responses are independent of TAS2R receptors. 


\subsection{Specific Aim 3: With the use of human cultured airway epithelial cells, to determine whether flavoring exposure affects ion transport and/or epithelial tight junctions}

Damage to the airway epithelium is believed to stimulate the development of PWL after chronic or high dose exposure to butter flavoring vapors (Hubbs et al., 2004, 2008, 2012; King, 1989; Morgan et al., 2008). Ion transport blockers were used to characterize the mechanisms involved in acute flavoring-induced toxicity. In Specific Aim 3, we investigated the effects of flavoring vapor exposure on ion transport in NHBEs using the Ussing chamber. Exposing NHBEs directly to diacetyl and 2,3-pentanedione avoids issues related to the role of inflammatory cells in the functional responses of animals to flavorings. This approach also circumvents differences in the sites of injury in exposed rats compared to humans. Thus, altered ion transport could be used for establishing the concentration-dependency in the toxic effects of flavorings on epithelium.

We investigated the electrophysiological changes following flavoring exposure in NHBEs. We anticipated that alterations in ion transport may be among the earliest toxic effects of flavorings on the epithelium, at concentrations that do not kill the cells or alter their morphology. Our results indicated that amiloride-sensitive $\mathrm{Na}^{+}$transport is reduced by $6 \mathrm{~h}$ exposure to diacetyl or 2,3-pentanedione $(25 \mathrm{ppm})$ at a $0 \mathrm{~h}$ time point, which recovered $18 \mathrm{~h}$ post-exposure. It is not known whether these effects on ion transport are attributable to a direct interaction of $\alpha$-diketones with $\mathrm{ENaC}$.

The respiratory epithelial injury caused by diacetyl in rats tends to be localized to the nose, not in the lower airways as occurs in humans, but PBPK models indicate that this results from species differences in the site of diacetyl absorption (Morris and Hubbs, 2009; Gloede et al., 2011). Our laboratory has evidence that supports the presence of 
DCXR in NHBEs, which metabolizes diacetyl and 2,3-pentanedione vapor during exposure (Chapter 5), as it does in rat nasal and tracheal tissues (Gloede et al., 2011; Goravanahally et al., 2013; Hubbs et al., 2012; Matsunaga et al., 2009; Morris, 2012; Morris and Hubbs, 2009). This enzyme reduces highly reactive a-dicarbonyl compounds, thus performing a role of detoxification (Lee et al., 2013). Because $\mathrm{Na}^{+}$conductance recovered $18 \mathrm{~h}$ after exposure, DCXR metabolizing diacetyl and 2,3-pentanedione may have potentially played a role in epithelial recovery. Flavoring metabolites as well as flavoring themselves may be contributing to cytotoxicity and altered ion transport.

\subsection{Future Studies}

\subsubsection{Flavoring vapor exposure via IPT}

In our previous experiments, the effects of diacetyl and 2,3-pentanedione inhalation exposure on pulmonary function and reactivity to inhaled MCh was examined. It was of interest to identify the concentration range over which diacetyl and 2,3pentanedione could affect pulmonary function and reactivity to inhaled MCh in vivo and in vitro, in the IPT. However, a clear concentration-dependency in the effects of diacetyl or 2,3-pentanedione on reactivity in the IPT has yet to be resolved. As an extension of Specific Aim 1, the effect of flavoring vapor exposures on reactivity to IL MCh could be further investigated. These experiments could involve exposing the air-filled lumen of rat tracheas in organ baths to flavoring vapors using our custom-made vapor generator with which we exposed NHBEs to flavorings. Concentration-response curves for IL MCh would be obtained before (control) and after delivery of vapor to the lumen. The results would be expressed as changes in the $\mathrm{MCh} \mathrm{EC}_{50}$ values. In addition to the vapor concentrations used in Specific Aim 1 (100 - 360 ppm), lower concentrations (25 ppm) would also be assessed. 
To our knowledge, there have been no experiments conducted to examine the direct effects of diacetyl or 2,3-pentanedione vapor after direct application to airways in vitro. Delivering diacetyl or 2,3-pentanedione vapor into the lumen of a rat trachea will circumvent nasal scrubbing of flavorings (which may have influenced results in Specific Aim 1). This novel exposure technique would also circumvent the differences in local tissue depositions in different regions of the lung, and allow for precise control of flavoring concentrations. Comparing changes in reactivity after in vitro exposures to those observed in IPT studies using tracheas from inhalation-exposed animals will help to clarify the direct (no inflammation in vitro) and indirect (inflammation induced in vivo) effects of the flavorings on the epithelium. In addition, this in vitro model could become a beneficial addition for characterizing the potential toxicity of flavorings that are hoped to be less toxic than diacetyl. The experimental approach to this future study would involve the IPT apparatus, which we used in Specific Aim 1 to examine epithelium function and smooth muscle mechanical responses. We would compare concentration-response curves for contraction induced by cumulative additions of IL-applied MCh before and after delivering diacetyl or 2,3-pentanedione vapors into the tracheal lumen. After obtaining the control curve, the lumen would be vacated of MKHS and flavoring vapor (one agent and concentration per trachea), in humidified air, would be pumped through the lumen for a period of $6 \mathrm{~h}$ (the duration of the animal exposures). After reperfusion of the lumen with MKHS, a second MCh concentration-response curve would be obtained. This would be repeated in tracheas that do not contain epithelium. To deliver warmed $\left(37^{\circ} \mathrm{C}\right)$ vapors to the trachea, custom-made, computer-controlled vapor-generator box and pump used in Specific Aim 3 would be used to deliver constant flavoring vapor levels. Because of our previous results, it is difficult to predict that, due to epithelial damage, diacetyl and 2,3pentanedione vapor will increase reactivity to $\mathrm{MCh}$ in a vapor-concentration-dependent 
manner and reduce the $\mathrm{MCh} \mathrm{EC}_{50 \text { s }}$ after exposure. If this were the case, this change would reflect damage to the airway epithelium, which regulates reactivity to IL MCh. Similar to the overall results demonstrated in Chapter 2, a decrease in the magnitude of responses to MCh also may occur, reflecting toxic interactions with ASM. Experiments also would be performed using tracheas which first have been denuded mechanically to remove epithelium. Changes in reactivity under these conditions would define the effect of flavorings on ASM. A reduction in smooth muscle contractility could help explain the absence of airway hyperreactivity to inhaled-MCh after inhalation of the flavorings. This study would provide information about effects of flavorings in the airway wall that do not involve an inflammatory component.

\subsubsection{Bioelectric effects of NHBEs exposed to flavoring vapor}

As an extension of a Specific Aim 3, future studies could include investigation as to whether flavoring exposure affects additional ion transporters other than those already studied. The experimental approach of this future study would be similar to that described in Chapter 4. Epithelial cells would be exposed for $6 \mathrm{~h}$ to vapors of diacetyl or 2,3pentanedione using our vapor-generator box containing NHBEs. Zero $\mathrm{h}, 18 \mathrm{~h}$, and 1 week time points would be assessed after the exposure, in which cells would be placed into the Ussing chamber in order to measure $I_{\mathrm{sc}}$ and $\mathrm{R}_{\mathrm{t}}$. To assess alterations in different ion transport systems due to flavoring exposure, additional ion transport blockers would be examined, such as serosally-applied bumetanide $\left(\mathrm{Na}^{+}, \mathrm{K}^{+}, 2 \mathrm{Cl}^{-}\right.$cotransport inhibitor; $\left.10^{-5} \mathrm{M}\right)$. Due to the use of MCh in the majority of our in vivo and in vitro experiments, serosally-applied $\mathrm{MCh}\left(10^{-5} \mathrm{M}\right)$ would be applied to the cells to assess flavoring-induced changes in responses. Another goal would be to investigate whether altered amiloridesensitive $\mathrm{Na}^{+}$transport occurs at concentrations lower than $25 \mathrm{ppm}$. Concentrations could 
be reduced progressively until no effect is observed. Other a-diketones that are used in the flavoring industry such as 2,3-hexanedione and 2,3-heptanedione (Hubbs et al., 2012) could also be investigated to determine whether close structural relatives of diacetyl and 2,3-pentanedione may have comparable effects on ion transport and to establish their potency in this regard.

The exact mechanism by which flavorings alter $\mathrm{Na}^{+}$transport remains unknown. Assessing whether ENaC mRNA expression is affected after $24 \mathrm{~h}$ and 1 week postexposure would be of interest. Prolonged exposure of alveolar epithelial cells to TNF- $\alpha$ by in vitro $(24 \mathrm{~h})$ has been shown to reduce ENaC mRNA expression without affecting $\mathrm{Na}^{+} / \mathrm{K}^{+}$ATPase expression (Dagenais et al., 2004; Eisenhut, 2006). TGF- $\beta 1$ has been shown to reduce alveolar epithelial $\mathrm{Na}^{+}$uptake in alveolar type II cells by reducing expression of the a subunit of ENaC (Eisenhut, 2006; Frank et al., 2003; Roux et al., 2005). Thus, the changes in $\mathrm{Na}^{+}$transport could be attributable to direct effects of flavorings on $\mathrm{ENaC}$ or on pathways that regulate $\mathrm{ENaC}$, as $\alpha$-diketones have been shown to modify proteins (Eisenhut, 2006; Epperly et al., 1989; Glomb and Monnier, 1995; Lo et al., 1994; Mathews et al., 2010; Riordan, 1973).

\subsubsection{Role of DCXR in ion transport}

In another addition to Specific Aim 3, one could investigate the role of DCXR on epithelial ion transport resulting from alterations in epitheilal tight junctions. Inhibiting the expression of DCXR through siRNA in our cultured cells could allow us to characterize the role of the enzyme in flavoring-induced epithelial damage. Application of siRNA to silence gene expression may not totally abolish expression of the gene. Therefore, any remaining reductase activity of $\mathrm{DCXR}$ could be inhibited by niacin $\left(\mathrm{IC}_{50}=100 \mu \mathrm{M}\right)$, a competitive inhibitor of DCXR (Carbone et al., 2005). Inhibiting the gene activity and the 
catalytic activity of DCXR could provide new information regarding the role of this enzyme in flavoring-induced epithelial disruption. Cells could be transfected with siRNA at $50 \%$ confluence. The effect of DCXR siRNA on epithelial $I_{\mathrm{sc}}$ could also be examined. Lastly, Western blot analysis could be conducted to confirm the presence of DCXR in epithelium and the effects of flavoring treatment and siRNA on its abundance. We predict that DCXR metabolizing these $\alpha$-diketones may contribute to changes in $\mathrm{Na}^{+}$transport, and inhibition of the enzyme could likely prevent these altered bioelectric effects.

\subsection{Conclusion}

Collectively, our findings indicate that the a-diketones have complex pharmacological characteristics. A concern evolving from this study is that despite epithelial damage, inhaled diacetyl and 2,3-pentanedione may not affect pulmonary function, at least in early stages of exposure in workers. Replacement of diacetyl with 2,3pentanedione may potentially heighten pulmonary function abnormalities in workers. Our results suggest that airway functional changes are not limited to the epithelium following flavoring exposure and that the exposure to either diacetyl or 2,3-pentanedione leads to reduced ASM reactivity and relaxation. We have ruled out TAS2Rs as potential mediators of flavoring-induced relaxation or bioelectric responses. More importantly, altered ion transport may be involved in early stages of PWL and may eventually result in ASL hydration. We were able to detect acetoin and 2-hydroxy-3-pentanone in basal media of flavor exposed cells, indicating that epithelial DXCR metabolizes these $\alpha$-diketones during exposure, and may potentially play a role in altered bioelectric effects. Prior to these studies, no experimental data had existed regarding the effects of flavorings on ASM or ion transport in airway epithelial cells. 


\subsection{References}

Billington, C. K., and R. B. Penn. 2003. Signaling and regulation of G protein-coupled receptors in airway smooth muscle. Respir. Res. 4: 2.

Carbone, V., Ishikura, S., Hara, A., and El-Kabbani, O. 2005. Structure-based discovery of human L-xylulose reductase inhibitors from database screening and molecular docking. Bioorg. Med. Chem. 13: 301-312

Dagenais, A., Frechette, R., Yamagata, Y., Yamagata, T., Carmel, J.F., Clermont, M. E., Brochiero, E., Masse, C., and Berthiaume, Y. 2004. Downregulation of ENaC activity and expression by TNF-a in alveolar epithelial cells. Am. J. Physiol. LungC. 286: 301-311.

Eisenhut, M., 2006. Changes in ion transport in inflammatory disease. J. Inflamm. (Lond.) 3: 5 .

Epperly, B. R, and Dekker, E. E. 1989. Inactivation of Escherichia coli L-threonine dehydrogenase by 2,3-butanedione: evidence for a catalytically essential arginine residue. J. Biol. Chem. 264: 18296-1830.

Finger, T. E., Bottger, B., Hansen, A., Anderson, K. T., Alimohammadi, H., and Silver, W. L. 2003. Solitary chemoreceptor cells in the nasal cavity serve as sentinels of respiration. Proc. Natl. Acad. Sci. 100: 8981-8986.

Frank, J., Roux, J., Kawakatsu, H., Su, G., Dagenais, A., Berthiaume, Y., Howard, M., Canessa, C. M., Fang, X., Sheppard, D., Matthay, M. A., and Pittet, J. F. 2003. Transforming growth factor- $\beta_{1}$ decreases expression of the epithelial sodium channel $\alpha \mathrm{ENaC}$ and alveolar epithelial vectorial sodium and fluid transport via an ERK1/2-dependent mechanism. J. Biol. Chem. 278: 43939-43950.

Frederick, C. B., Bush, M. L., Lomax, L. G., Black, K. A., Finch, L., Kimbell, J. S., Morgan, K. T., Subramaniam, R. P., Morris, J. B., and Ultman, J. S. 1998. Application of a 
hybrid computational fluid dynamics and physiologically based inhalation model for interspecies dosimetry extrapolation of acidic vapors in the upper airways. Toxicol. Appl. Pharmacol. 152: 211-231.

Gloede, E., Cichocki, J. A., Baldino, J. B., and Morris, J. B. 2011. A validated hybrid computational fluid dynamics-physiologically based pharmacokinetic model for respiratory tract vapor absorption in the human and rat and its application to inhalation dosimetry of diacetyl. Toxicol. Sci. 123: 231-246.

Glomb, M. A., and Monnier, V. M. 1995. Mechanism of protein modification by glyoxal and glycolaldehyde, reactive intermediates of the Maillard reaction. J. Biol. Chem. 270: $10017-10026$.

Goravanahally, M. P., Hubbs, A. F., Fedan, J. S., Kashon, M. L., Battelli, L. A., Mercer, R. R., Goldsmith, W. T., Jackson, M. C., Cumpston, A., Frazer, D. G., and Dey, R. D. 2013. Diacetyl increases sensory innervation and substance $P$ production in rat trachea. Toxicol. Pathol. Epub ahead of print.

Gulbransen, B. D., Clapp, T. R., Finger, T. E., and Kinnamon, S. C. 2008. Nasal solitary chemoreceptor cell responses to bitter and trigeminal stimulants in vitro. $\mathrm{J}$. Neurophysiol. 99: 2929-2937.

Hubbs, A. F., Battelli, L. A., Goldsmith, W. T., Porter, D. W., Frazer, D., Friend, S., Schwegler-Berry, D., Mercer, R. R., Reynolds, J. S., Grote, A., Castranova, V., Kullman, G., Fedan, J. S., Dowdy, J., and Jones, W. G. 2002. Necrosis of nasal and airway epithelium in rats inhaling vapors of artificial butter flavoring. Toxicol. Appl. Pharmacol. 185: 128-135.

Hubbs, A. F., Cumpston, A. M., Goldsmith, W. T., Battelli, L. A., Kashon, M. L., Jackson, M. C., Frazer, D. G., Fedan, J. S., Goravanahally, M. P., Castranova, V., Kreiss, K., Willard, P. A., Friend, S., Schwegler-Berry, D., Fluharty, K. L., and Sriram K. 
2012. Respiratory and olfactory cytotoxicity of inhaled 2,3-pentanedione in Sprague-Dawley rats. Am. J. Pathol. 181: 829-844.

Hubbs, A. F., Goldsmith, W. T., Kashon, M. L., Frazer, D., Mercer, R. R., Battelli, L. A., Kullman, G. J., Schwegler-Berry, D., Friend, S., and Castranova, V. 2008. Respiratory toxicologic pathology of inhaled diacetyl in Sprague-Dawley rats. Toxicol. Pathol. 36: 330-344.

King, T. E., Jr. 1989. Bronchiolitis obliterans. Lung 167: 69-93.

Krasteva, G., Canning, B. J., Veres, T., Papadakis, T., Hartmann, P., Mühlfeld, C., Schliecker, K., Hans, K., Tallini, Y. N., and Braun, A. 2010. Tracheal brush cells are neuronally connected cholinergic sensory cells (abstract). Society for Neuroscience. Online Program No 7737.

Lee, S. K., Son le, T., Choi, H. J., and Ahnn, J. 2013. Dicarbonyl/l-xylulose reductase (DCXR): The multifunctional pentosuria enzyme. Int. J. Biochem. 45: 2563-2567.

Lin, W., Ogura, T., Margolskee, R. F., Finger, T. E., and Restrepo, D. 2008. TRPM5expressing solitary chemosensory cells respond to odorous irritants. J. Neurophysiol. 99: 1451-1460.

Lo, T. W., Westwood, M. E., McLellan, A. C., Selwood, T., and Thornalley, P. J. 1994. Binding and modification of proteins by methylglyoxal under physiological conditions: a kinetic and mechanistic study with $\mathrm{N}$ a-acetylarginine, $\mathrm{N} \alpha-$ acetylcysteine, and $\mathrm{N}$ a-acetyllysine, and bovine serum albumin. J. Biol. Chem. 269: 32299-32305.

Manzanares, D., Gonzalez, C., Ivonnet, P., Chen, R. S., Valencia-Gattas, M., Conner, G. E., Larsson, H. P., and Salathe, M. 2011. Functional apical large conductance, $\mathrm{Ca}^{2+}$-activated, and voltage-dependent $\mathrm{K}^{+}$channels are required for maintenance of airway surface liquid volume. J. Biol. Chem. 286: 19830-19839. 
Mathews, J. M., Watson, S. L., Snyder, R. W., Burgess, J. P., and Morgan, D. L. 2010. Reaction of the butter flavorant diacetyl (2,3-butanedione) with N-a-acetylarginine: a model for epitope formation with pulmonary proteins in the etiology of obliterative bronchiolitis. J. Agric. Food Chem. 58: 12761-12768.

Matsunaga, T., Arakaki, M., Kamiya, T., Endo, S., El-Kabbani, O., and Hara A. 2009. Involvement of an aldo-keto reductase (AKR1C3) in redox cycling of 9,10phenanthrenequinone leading to apoptosis in human endothelial cells. Chem. Biol. Interact. 181: 52-60.

Mauroy, B., Filoche, M., Weibel, E. R., and Sapoval, B. 2004. An optimal bronchial tree may be dangerous. Nature 427: 633-636.

Morgan, D. L., Flake, G. P., Kirby, P. J., and Palmer, S. M. 2008. Respiratory toxicity of diacetyl in C57BL/6 mice. Toxicol. Sci. 103: 169-180.

Morgan, D. L., Jokinen, M. P., Johnson, C. L., Gwinn, W. M., Price, H. C., and Flake, G. P. 2012a. Bronchial fibrosis in rats exposed to 2,3-butanedione and 2,3pentanedione vapors. Toxicol. Sci. 126: 186.

Morgan, D. L., Jokinen, M. P., Price, H. C., Gwinn, W. M., Palmer, S. M., and Flake, G. P. 2012b. Bronchial and bronchiolar fibrosis in rats exposed to 2,3-pentanedione vapors: implications for bronchiolitis obliterans in humans. Toxicol. Pathol. 40: 448-465.

Morris, J. B. 1997. Uptake of acetaldehyde vapor and aldehyde dehydrogenase levels in the upper respiratory tracts of the mouse, rat, hamster, and guinea pig, Fund. Appl. Toxicol. 35: 91-100.

Morris, J. B. 2012. Biologically-based modeling insights in inhaled vapor absorption and dosimetry. Pharmacol. Ther. 136: 401-413. 
Morris, J. B. and Hubbs, A. F. 2009. Inhalation dosimetry of diacetyl and butyric acid, two components of butter flavoring vapors. Toxicol. Sci. 108: 173-183.

National Toxicology Program. Testing Status of Agents at NTP. CAS Registry Number: 431-03-8. Diacetyl. Accessed July 2011.

Occupational Safety and Health Administration. 2,3-Pentanedione. Accessed July 2011.

Otsuka, M., Mine, T., Ohuchi, K., and Ohmori, S. 1996. A detoxication route for acetaldehyde: metabolism of diacetyl, acetoin, and 2,3-butanediol in liver homogenate and perfused liver of rats. J. Biochem. (Tokyo) 119: 246-251.

Palmer, S. M., Flake, G. P., Kelly, F. L., Zhang, H. L., Nugent, J. L., Kirby, P. J., Foley, J. F., Gwinn, W. M., and Morgan, D. L. 2011. Severe airway epithelial injury, aberrant repair and bronchiolitis obliterans develops after diacetyl instillation in rats. PloS One 6, e17644.

Riordan, J. F. 1973. Functional arginyl residues in carboxypeptidase A: modification with butanedione. Biochemistry 12: 3915-3923.

Roux, J., Kawakatsu, H., Gartland, B., Pespeni, M., Sheppard, D., Matthay, M. A., Canessa, C. M., and Pittet, J. F. 2005. Interleukin-1 $\beta$ decreases expression of the epithelial sodium channel $\alpha$-subunit in alveolar epithelial cells via a p38 MAPKdependent signaling pathway. J. Biol. Chem. 280: 18579-18589.

Tizzano, M., Gulbransen, B. D., Vandenbeuch, A., Clapp, T. R., Herman, J. P., Sibhatu, H. M., Churchill, M. E., Silver, W. L., Kinnamon, S. C., and Finger, T. E. 2010. Nasal chemosensory cells use bitter taste signaling to detect irritants and bacterial signals. Proc. Natl. Acad. Sci. 107: 3210-3215.

Tizzano, M., Cristofoletti, M., Sbarbati, A., and Finger, T. E. 2011. Expression of taste receptors in solitary chemosensory cells of rodent airways. BMC Pulm. Med. 11: 3. 
van Rooy, F., Houba, R., Zaat, V., Smit, L., Rooyackers, J., and Heederik, D. 2006. A case series of bronchiolitis obliterans syndrome in workers at a diactyl production plant. Euro. Respir. J. 28: 462s.

van Rooy, F. G., Rooyackers, J. M., Prokop, M., Houba, R., Smit, L. A., and Heederik, D. J. 2007. Bronchiolitis obliterans syndrome in chemical workers producing diacetyl for food flavorings. Am. J. Respir. Crit. Care. Med. 176: 498-504.

van Rooy, F. G., Smit, L. A., Houba, R., Zaat, V. A., Rooyackers, J. M., and Heederik, D. J. 2009. A cross-sectional study of lung function and respiratory symptoms among chemical workers producing diacetyl for food flavourings. Occup. Environ. Med. 66: 105-110.

Wu, Z. X., Satterfield, B. E., and Dey, R. D. 2003. Substance P released from intrinsic airway neurons contributes to ozone-enhanced airway hyperresponsiveness in ferret trachea. J. Appl. Physiol. 95: 742-50.

Wu, Z. X., and Dey, R. D. 2006. Nerve growth factor-enhanced airway responsiveness involves substance $\mathrm{P}$ in ferret intrinsic airway neurons. Am. J. Physiol. Lung-C. 291, L111-18.

Yeh, H. C., Phalen, R. F., and Raabe, O. G. 1976. Factors influencing the deposition of inhaled particles. Environ. Health Perspect. 15: 147-156

Yeh, H. C., Schum, G. M., and Duggan, M. T. 1979. Anatomic models of the tracheobronchial and pulmonary regions of the rat. Anat. Rec. 195:483-492.

Zaccone, E. J., Thompson, J. A., Ponnoth, D. S., Cumpston, A. M., Goldsmith, W. T., Jackson, M. C., Kashon, M. L., Frazer, D. G., Hubbs, A. F., Shimko, M. J., and Fedan, J. S. 2013. Popcorn flavoring effects on reactivity of rat airways in vivo and in vitro. J. Toxicol. Env. Heal. A. 76: 669-689. 


\section{CURRICULUM VITAE}

Name:

Eric Joseph Zaccone

$\begin{array}{ll}\text { Residence: } & \text { 411 Broadway Avenue, Unit 2, } \\ & \text { Morgantown, WV 26505 } \\ \text { Telephone: } & \text { 732-977-3497 } \\ \text { E-mail: } & \text { IBZ5@cdc.gov }\end{array}$

Present Position: $\quad$ Ph.D. Researcher Center for Disease Control and Prevention (CDC)

National Institute for Occupational Safety and Health (NIOSH) 1095 Willowdale Road Morgantown, WV 26505

Telephone: $\quad$ 732-977-3497

Lab Phone: $\quad 304-285-6182$

E-mail: $\quad$ IBZ5@cdc.gov

Education:

2013

Ph.D. (Pharmaceutical and Pharmacological Sciences), West Virginia University, Morgantown, WV

2005 B.A. (Psychology), Rutgers University, New Jersey

Positions and Employment:

$\begin{array}{ll}2007-2013 & \text { Graduate Student, WVU/NIOSH, Morgantown, WV } \\ 2005-2007 & \text { Lab Technician, UMDNJ/VA Hospital, East Orange, NJ } \\ 2003-2006 & \text { Lab Technician, Rutgers University, Newark, NJ }\end{array}$

Honors and Awards:

2012 T32 training grant travel awards

2011-2012 Awarded WVU T32 training grant

2011 Selected to organize School of Pharmacy Research Day

2010-2011 Travel award - West Virginia University Department of Basic Pharmaceutical Sciences

2006 Phi Beta Kappa Honor Society 
Psi Chi Honor Society

2004

Golden Key Honor Society

2003-2005

Honors College - Rutgers University

2003-2004

National Dean's List

2001-2005

Dean's List - 7 semesters at Rutgers University

Memberships:

American Society for Pharmacology and Experimental Therapeutics (ASPET)

American Association of Pharmaceutical Scientists (AAPS)

American Physiological Society (APS)

American Heart Association (AHA)

American Thoracic Society (ATS)

Teaching Experience:

$2011-2013$

Applied Pharmacology (PCOL) 549 - "Respiratory Disease"

Seminars:

2008-2014 Biannual Graduate Student Pharmacology Seminar, WVU

2011-2013 Biannual T32 Progress Report Seminar

2012 Work In Progress, WVU

2013 Seminar at University of Pittsburgh

2013 Seminar at Washington University

2013 Seminar at Rutgers University

Publications:

Zaccone, E.J., Thompson, J.A., Ponnoth, D.S., Cumpston, A.M., Goldsmith, W.T., Jackson, M.C., Kashon, M.L., Frazer, D.G., Hubbs, A.F., Shimko, M.J., Fedan, J.S., 2013. Popcorn 
flavoring effects on reactivity of rat airways in vivo and in vitro. J. Toxicol. Environ. Heal. A 76: 669-89.

Zaccone, E.J., Shimko, M.J., Thompson, J.A., Fedan, J.S., 2014. Butter flavoring-elicited relaxation of airway smooth muscle and bioelectric responses of epithelium in rat airways are independent of TAS2R. In review: Eur. J. Pharmacol.

Roberts, J.R., Reynolds, J.S., Thompson, J.A., Zaccone, E.J., Shimko, M.J., Goldsmith, W.T., Jackson, M., McKinney, W., Frazer, D.G., Kenyon, A., Kashon,M.L., Piedimonte, G., Castranova, V. and Fedan, J.S., 2011. Pulmonary effects after acute inhalation of oil dispersant (COREXIT ${ }^{\circledR}$ EC9500A) in rats. J. Toxicol. Env. Heal. A 74: 1381-1396.

Abstracts and Poster Presentations:

Fedan, J.S., Thompson, J.A., Ponnoth, D.S., Zaccone, E.J., Mosely, A.M., Goldsmith, W. T., Jackson, M, C., Frazer, D.G., and Hubbs, A.F. (2010). Inhaled diacetyl vapors and in vivo airway reactivity to methacholine (MCh) in rats. Am. J. Respir. Crit. Care Med. 181: A1752 Presented at American Thoracic Society 2010 in New Orleans, LA.

Zaccone, E.J., Thompson, J.A., Mosely, A.M., Goldsmith, W.T., Jackson, M.C., Shimko, M.J., Frazer, D.G., Hubbs, A.F., and Fedan J.S. (2010). Effects of diacetyl and 2,3pentanedione vapor inhalation on airway reactivity to methacholine (MCh) in vivo and in vitro in rats. Am. J. Respir. Crit. Care Med; 181: A1753 Presented at American Thoracic Society 2010 in New Orleans, LA.

Zaccone, E.J., Thompson, J.A., Mosely, A.M., Goldsmith, W.T., Jackson, M, C., Shimko, M.J., Frazer, D.G., Hubbs, A.F., and Fedan, J.S. (2010). Effects of diacetyl and 2,3pentanedione vapor inhalation on airway reactivity to methacholine $(\mathrm{MCh})$ in vitro in rats. Poster presentation. E.J. Van Liere Research Convocation 2010, WVU.

Shimko, M.J., Zaccone, E.J., Thompson, J.A., Kashon, M.L., Piedimonte, G., and Fedan, J.S. (2011). Mechanical responses to COREXIT® EC9500A in rat trachea in vitro. FASEB J. 25: 1016.3 Presented at Experimental Biology 2011 in Washington, DC.

Roberts J.R., Reynolds, J.S., Thompson, J.A., Goldsmith, W.T., Jackson,M., McKinney,W., Frazer,D.G., Zaccone, E.J., Shimko, M.J., Kashon, M.L., Castranova, V. and Fedan, J.S. (2011). Pulmonary effects of inhaled oil dispersant (COREXIT® EC9500A) in rats. FASEB J. 25: 1016.6 Presented at Experimental Biology 2011 in Washington, DC.

Shimko, M.J., Zaccone, E.J., Thompson, J.A., Kashon, M.L., Piedimonte, G., and Fedan, J.S., (2011). Mechanical responses to COREXIT® EC9500A in rat trachea in vitro. NORA Symposium, NIOSH.

Zaccone, E.J., Thompson, J.A., Mosely, A.M., Goldsmith, W.T., Jackson, M, C., Shimko, M.J., Frazer, D.G., Hubbs, A.F., and Fedan, J.S. (2011). Effects of diacetyl and 2,3pentanedione using isolated, airway preparations. Poster presentation. E.J. Van Liere Research Convocation 2011, WVU. 
Zaccone, E.J., Thompson, J.A., Shimko, M.J. and Fedan, J.S. (2012). Effects of popcorn butter flavorings, diacetyl and 2,3-pentanedione using isolated, airway preparations. Poster presentation. Wagner Research Convocation 2012, WVU.

Zaccone, E.J., Thompson, J.A., Amy M., Goldsmith, W.T., Jackson, M, C., Shimko, M.J., Frazer, D.G., Hubbs, A.F., and Fedan, J.S. (2012). Effects of the popcorn flavorings, diacetyl and 2,3-pentanedione, in the airways. E.J. Van Liere Research Convocation 2012, WVU.

Zaccone, E.J., Shimko, M.J., Thompson, J.A., Goldsmith, W.T., and Fedan, J.S. (2012). Effects of diacetyl vapor exposure on human cultured airway epithelial cell ion transport. FASEB J. 26: 669.3 Presented at Experimental Biology 2012 in San Diego, CA.

Zaccone, E.J., Thompson, J.A., Shimko, M.J. and Fedan, J.S. (2013) Effects of popcorn butter flavorings, diacetyl and 2,3-pentanedione, on isolated airway preparations. FASEB J. 27: 1107.16 Presented at Experimental Biology 2013 in Boston, MA.

Zaccone, E.J., Thompson, J.A., Shimko, M.J. and Fedan, J.S. (2013). Effects of popcorn butter flavorings, diacetyl and 2,3-pentanedione using isolated, airway preparations. Poster presentation. E.J. Van Liere Research Convocation 2013, WVU.

Zaccone, E.J., Goldsmith,W.T., Shimko M.J., Wells, J.R., Thompson, J.A., Fedan, J.S. (2014). Effects of butter flavoring vapor exposure on cultured primary human tracheal/bronchial epithelial (HTBE) cell ion transport. Experimental Biology 2014 in San Diego, CA

Zaccone, E.J., Shimko, M.J., Thompson, J.A., Fedan, J.S., (2014). Butter flavoring-elicited relaxation of airway smooth muscle and bioelectric responses of epithelium in rat airways are independent of TAS2R. Experimental Biology 2014 in San Diego, CA.

Zaccone E.J., Goldsmith W.T., Shimko M.J., Wells R.J.,Schwegler-Berry D., Willard, P.A., Case, S.L., Thompson, J.A., and Fedan, J.S. (2014). Effects of butter flavoring vapor exposure on cultured normal human bronchial/tracheal epithelial cell (NHBE) ion transport. NIOSH Intramural Science Meeting 2014, Morgantown, WV.

\section{Other Abstracts:}

Shimko, M.J., Zaccone, E.J., Samsell L., Piedimonte G., Thompson, J.A., and Fedan, J.S. (2012). Effect of RSV on electrophysiological properties of human primary, air-interface cultured tracheal epithelial cells. Submitted to Experimental Biology 2012 in San Diego. Withdrawn.

Shimko, M.J., Zaccone, E.J., Samsell, L., Piedimonte, G. and Fedan, J.S. (2012). Effect of RSV infection on the neurogenic response of airway smooth muscle in vitro after vertical transmission of RSV in Fischer 344 rat pups. Am. J. Respir. Clin. Care Med. Submitted to the American Thoracic Society conference 2012. Withdrawn.

Shimko, M.J., Zaccone, E.J., Samsell, L., Piedimonte, G. and Fedan, J.S. (2012). Effect of RSV infection on terbutaline induced relaxation in vitro of airway smooth muscle from weanling Fischer 344 rats. Am. J. Respir. Clin. Care Med. Submitted to the American Thoracic Society conference 2012. Withdrawn. 
Sinha, S.P., Jiao, X., Zaccone, E.J., Agley, A., Fanselow, M.S., Beck, K.D., and Servatius, R.J. (2006). Slower acquisition and reduced reactivity in transgenic mice over expressing corticotropin releasing hormone. Pavlovian Society Conference in Philadelphia, PA.

Jiao, X., Zaccone, E.J., Ponzio, N.M., Beck, K.D., and Servatius, R.J. (2006). Cytokine administration to pregnant mouse dams: toward an animal model of autism. Pavlovian Society Conference 2006 in Philadelphia, PA.

Zaccone, E.J., Jiao, X., Sinha, S.P., Agley, A., Beck, K.D., and Servatius, R.J. (2006). Parametric study of eyeblink conditioning in mice: unconditional stimulus intensity and conditional stimulus characteristics. Pavlovian Society Conference 2006 in Philadelphia, PA.

Patterson, M.D., Eldreth, D.A., Zaccone, E., and Rypma, B. (2005). The role of automaticity in working memory performance. Proceedings of the Cognitive Neuroscience Society Meeting in New York, NY.

Eldreth, D.A., Porcelli, A.J., Patterson, M.D., Bukowski, E., Witham, J., Zaccone, E., and Rypma, B. (2004). Age related reduction of neural efficiency and cognitive performance: an eventrelated fMRI study. Proceedings of the 34th Annual Meeting of the Society for Neuroscience 2004 in San Diego, CA.

Eldreth D.A., Porcelli, A.J., Genova, H.M., Patterson, M.D, Hillary, F.G., Zaccone, E., Bukowski, E., Witham, J., and Rypma, B. (2004). Neural correlates of age-related reduction in processing speed: An event-related fMRI study. Proceedings of the Cognitive Neuroscience Meeting 2004 in San Francisco, CA. Supplement to the Journal of Cognitive Neuroscience.

Eldreth D.A., Porcelli, A.J., Genova, H.M., Patterson, M.D, Hillary, F.G., Zaccone, E., Bukowski, E., Witham, J., and Rypma, B. (2004). Neural correlates of age-related reduction in processing speed: an event-related fMRI study. Cognitive Aging Conference 2004 in Atlanta, GA.

\section{Ongoing Research Support:}

NIOSH 07/1/2013-present

Role: Graduate Student

\section{Completed Research Support}

NIH Cardiovascular and Pulmonary Disease Training Grant NHLBI-T32 07/1/11 - 7/1/2013

National Institute for Occupational Safety and Health

$06 / 1 / 09-07 / 1 / 11$

West Virginia University

07/14/07 - 06/1/09

Role: Graduate Student 